Mike Reich, Joachim Reitner, Vanessa Roden, Ben Thuy (Eds.)

Echinoderm Research 2010

7th European Conference on Echinoderms, Göttingen, October 2-9, 2010

Abstract Volume and Field Guide to Excursions
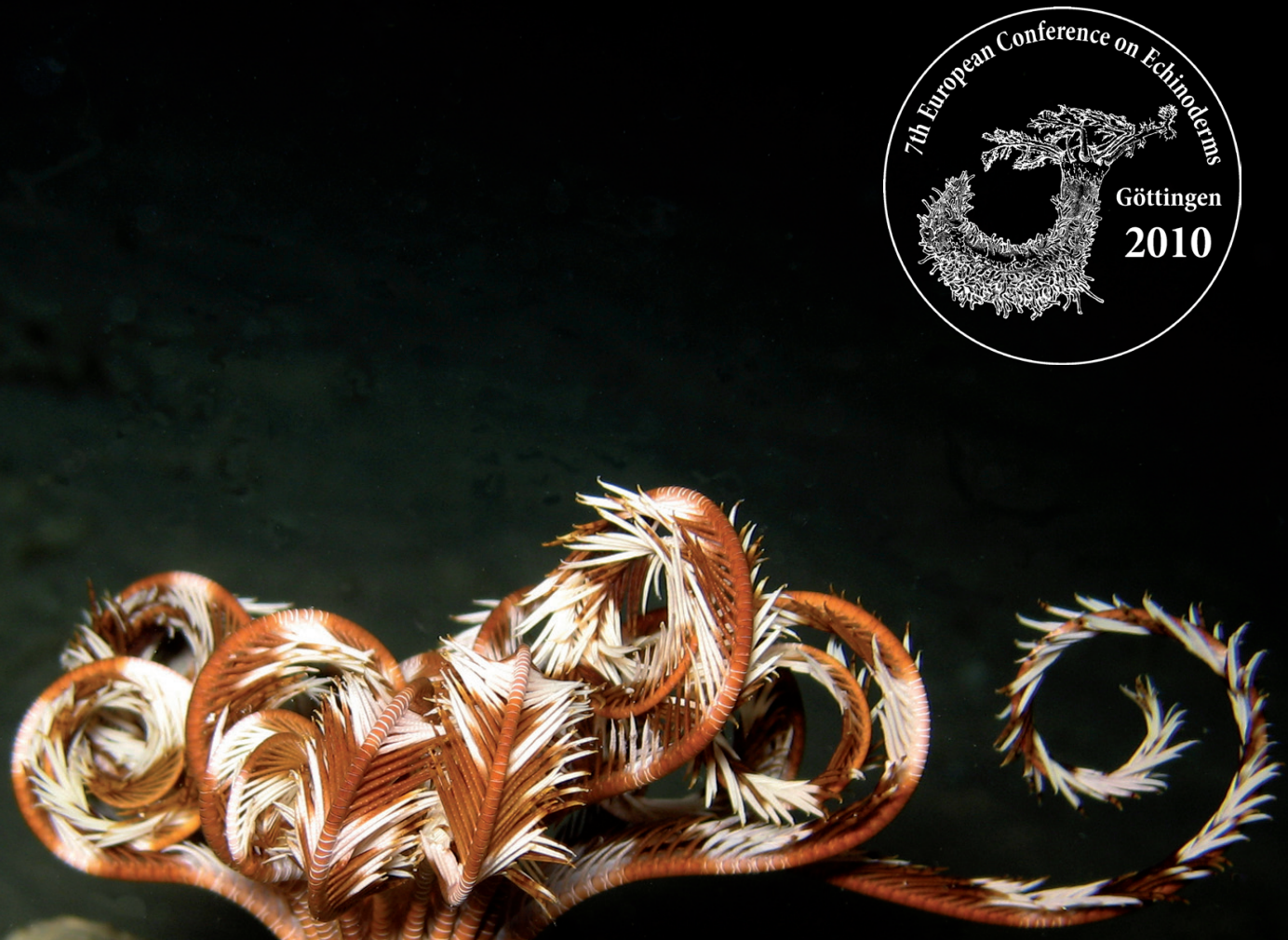

8

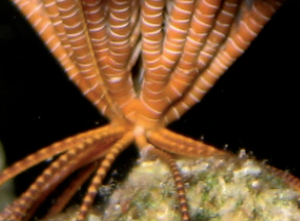

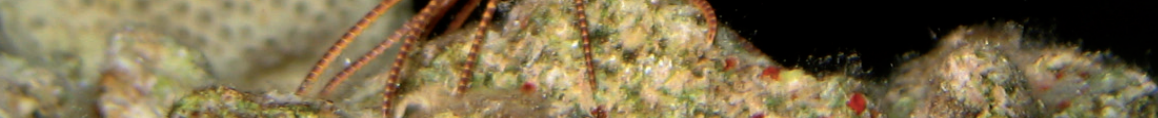

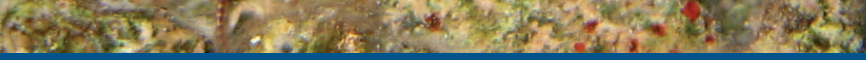

\&A Universitätsdrucke Göttingen

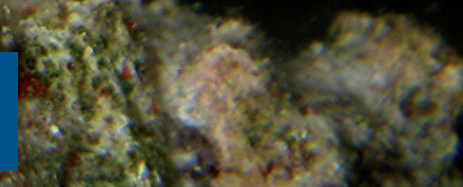


Mike Reich, Joachim Reitner, Vanessa Roden, Ben Thuy (Eds.)

Echinoderm Research 2010

This work is licensed under the

Creative Commons License 3.0 "by-nd", allowing you to download, distribute and print the document in a few copies for private or educational use, given that the document stays unchanged and the creator is mentioned.

You are not allowed to sell copies of the free version.

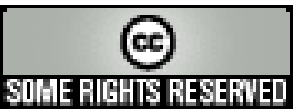


erschienen in der Reihe der Universitätsdrucke

im Universitätsverlag Göttingen 2010 
Mike Reich, Joachim Reitner,

Vanessa Roden, Ben Thuy (Eds.)

\section{Echinoderm Research 2010}

7th European Conference

on Echinoderms,

Göttingen, October 2-9, 2010

Abstract Volume and

Field Guide to Excursions

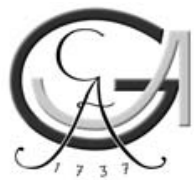

Universitätsverlag Göttingen

2010 


\section{Bibliographische Information der Deutschen Nationalbibliothek}

Die Deutsche Nationalbibliothek verzeichnet diese Publikation in der Deutschen Nationalbibliographie; detaillierte bibliographische Daten sind im Internet über $<$ http://dnb.ddb.de $>$ abrufbar.

\section{Editorial contact}

Dr. Mike Reich

Professor Dr. Joachim Reitner

Vanessa Julie Roden, B.Sc.

Dipl.-Geol. Ben Thuy

Geoscience Centre of the

Georg-August University of Göttingen

Goldschmidtstraße 1-5

37077 Göttingen, Germany

http://www.geomuseum.uni-goettingen.de

http://www.geobiologie.uni-goettingen.de

This work is protected by German Intellectual Property Right Law.

It is also available as an Open Access version through the publisher's homepage and the Online Catalogue of the State and University Library of Goettingen

(http://www.sub.uni-goettingen.de). Users of the free online version are invited to read, download and distribute it. Users may also print a small number for educational or private use. However they may not sell print versions of the online book.

Graphics and Layout: Mike Reich

Cover Design: Conny Kaubisch, Mike Reich

Cover Photos: Mike Reich, Tanja Stegemann, Ben Thuy, Gert Wörheide

(C) 2010 Universitätsverlag Göttingen

http:/ / univerlag.uni-goettingen.de

ISBN: 978-3-941875-68-5 


\section{Contents}

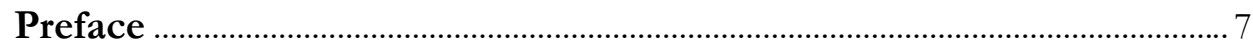

\section{Plenary Presentations}

Barker, M. F.; Dupont, S. T. \& Thorndyke, M. S.; Gale, A.; Kroh, A. \& Mooi,R.; Lawrence, J. M.; Lefebvre, B., David, B. \& Mooi, R.; Mallefet, J.;

Pawson, D. L. \& Pawson, D. J.; Scholz, J.; Seilacher, A.; Stöhr, S.;

Wolkenstein, $\mathrm{K}$ 9

\section{Abstracts of Oral \& Poster Presentations}

[in alphabetical order]

\section{Excursion Guides}

Lüter, C. \& Neumann, C.: The echinoderm collections of the Berlin Natural History Museum

Arp, G.: A Triassic echinoderm lagerstätte - Herberbausen quarry, near Göttingen

Schlüter, N. \& Wiese, F.: The late Cretaceous (Campanian) echinoderm faunas from the Hannover area 1 . Teil

Boos, K. \& Reich, M.: Echinoderms in the southern German Bight (southern North Sea) - a species overview 
The conference was funded in part by:
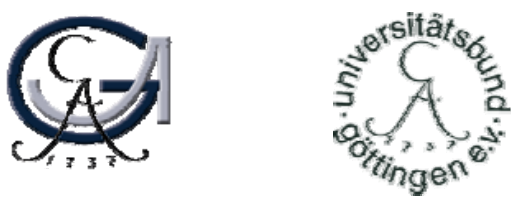

Deutsche

FOR $_{-736} 736$

Forschungsgemeinschaft

DFG

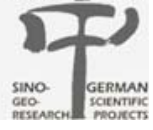

The session on ancient echinoderms was organised under the auspices of the DFGResearch Unit FOR 736 "The Precambrian-Cambrian Ecosphere (R)evolution": sub-project Re2599/4-1 "The Early Fossil Record and Evolution of Echinoderms and Octocorals: Evidence from the Yangtze Platform, China" [M. Reich] 


\section{Preface}

Since the first symposia and conferences on echinoderms four decades ago, more than 25 subsequent international meetings have been organised. The first International Echinoderm Conference (IEC) was held in Washington, D.C., in 1972, the first European Conference (ECE) in Brussels in 1979; these take place alternately since then.

The $7^{\text {th }}$ European Conference on Echinoderms was held on the northern campus of the Georg-August University in Göttingen, Germany, from October 2-9, 2010, this being the first time it has been held in Germany.

The Göttingen University has a long tradition in echinoderm research. A vast number of naturalists, zoologists, palaeontologists, and collectors, like (in chronological order) Samuel Christian Hollmann (1696-1787), Pehr Forsskål (1732-1769), Peter Simon Pallas (1741-1811), Johann Friedrich Gmelin (1748-1804), Johann Friedrich Blumenbach (1752-1840), Ernst Friedrich von Schlotheim (1764-1832), Johann Ludwig Christian Carl Gravenhorst (1777-1857), Lorenz Oken [Okenfuss] (1779-1851), Friedrich Tiedemann (1781-1861), Carl Heinrich Mertens (17961830), Karl Theodor Ernst von Siebold (1804-1885), Wilhelm Moritz Keferstein (1833-1870), Carl Claus (1835-1899), Adolf von Koenen (1837-1915), Christian Karl Hoffmann (1841-1903), Emil Selenka (1842-1901), Wilhelm Bölsche (18431893), Johann(es) Brock (1852-1889), Hubert Ludwig (1852-1913), Carl Friedrich Chun (1852-1914), Georg Böhm (1854-1913), Wilhelm ('Guillermo') Bodenbender (1857-1941), Theodor Ebert (1857-1899), Otto Hamann (1857-1925), Johannes Frenzel (1858-1897), Alexander Tornquist (1868-1944), Hermann Schmidt (18921978), Johannes Wolburg (1905-1976), and Arno Hermann Müller (1916-2004), were in direct connection with the University of Göttingen or studied and/or worked on echinoderms in Göttingen during the last 250 years. Not included above are several scientists who are currently working on or have recently contributed to echinoderm research.

The present volume contains the abstracts of lectures and posters presented during the $7^{\text {th }}$ European Conference on Echinoderms (ECE) as well as excursion guides by authors from 32 countries worldwide. More than 100 scientists from various fields, like marine biology, molecular biology, zoology, palaeontology, biochemistry, physiology, ecology, aquaculture and fisheries, from 25 countries worldwide joined the meeting and presented their most recent research on modern and fossil echinoderms and related topics.

Excursions included field trips to Heligoland, North Sea, and the echinoderm collections of the Berlin Museum of Natural History. Field trips to localities with fossil Mesozoic echinoderm faunas in Lower Saxony also took place. 
A concomitant event of the conference was the opening of a special bilingual exhibition on modern and fossil echinoderms in the Geoscientific Museum of the Georg-August University, entitled: Spiny and Colourful - Echinoderms from around the World through Time and History.

We wish all participants of the 7 th ECE a very successful meeting, resulting in intriguing new information and new ideas for research projects, and, last but not least, that new colleagues and friends for future cooperation and echinoderm research are found.
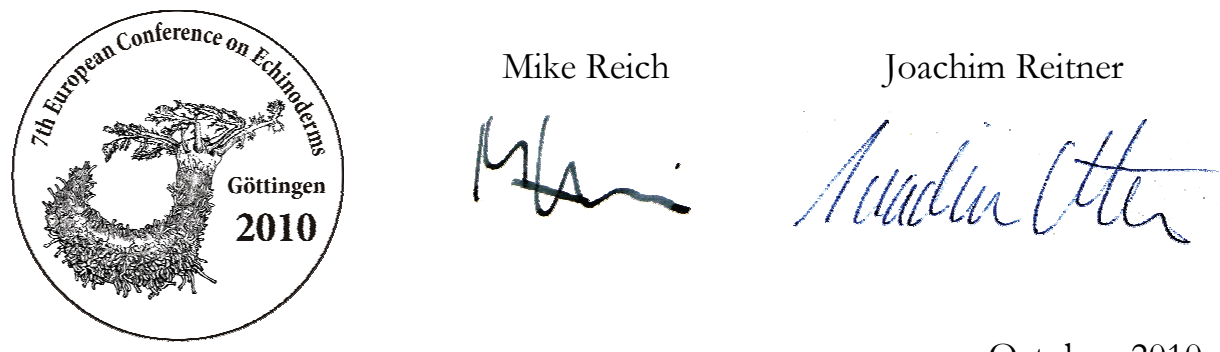

October, 2010

\section{Local Organising Committee:}

Mike Reich (Göttingen)

Stefanie Biermann (Göttingen)

Annina Böhme (Göttingen)

Marie-France Hesse (Göttingen)

Lea Numberger (Göttingen)

Ines Ringel (Göttingen)

Vanessa Julie Roden (Göttingen)

Gabriele Schmidt (Göttingen)

Tanja Stegemann (Göttingen)

Ben Thuy (Göttingen)
Scientific Committee:

concerning the conference, the special exhibition, and the excursions

Mike Reich (Göttingen)

Joachim Reitner (Göttingen)

Reimund Haude (Göttingen)

Tanja Stegemann (Göttingen)

Ben Thuy (Göttingen)

Karin Boos (Bremen)

Andreas Kroh (Vienna)

Gundolf Krüger (Göttingen)

Manfred Kutscher (Sassnitz)

Carsten Lüter (Berlin)

Christian Neumann (Berlin)

Martin Röper (Solnhofen)

Nils Schlüter (Berlin)

Anne-Katrin Sors (Göttingen)

Sabine Stöhr (Stockholm)

Hans-Volker Thiel (Bonn)

Gert Tröster (Göttingen)

Frank Wiese (Berlin / Göttingen)

Rainer Willmann (Göttingen)

Gert Wörheide (Munich) 


\title{
Plenary Presentations
}

\section{Divide and rule - the importance of asexual reproduction in the population biology of echinoderms [plenary presentation]}

\author{
Michael F. Barker \\ Department of Marine Science, University of Otago, P.O. Box 56 Dunedin, New Zealand; \\ E-mail:mike.barker@otago.ac.nz.
}

Key words: Echinodermata, Asteroidea, asexual reproduction, fission, environmental stress

Asexual reproduction in echinoderms occurs in a variety of different ways in embryonic, larval and adult stages in the life history. These include fission, budding, ameoitic parthenogenesis and polyembryony. While asexual reproduction is relatively common in asteroids, ophiuroids and holothurians, it is not known in echinoids or crinoids. The physiological and environmental factors that regulate asexual reproduction are generally poorly known, however it has been suggested that asexual reproduction is associated with small body size and that it may be modulated by seasonal changes. Environmental stability, population size, and stress associated with living in a harsh environment are also thought to be important. This talk will review how recent field and laboratory studies have increased our understanding of asexual reproduction in echinoderms, with an emphasis on recent research on asteroids.

\section{Impact of ocean acidification on echinoderms - from data to predictions [plenarypresentation]}

Sam T. Dupont ${ }^{1} \&$ Mike S. Thorndyke ${ }^{2}$

${ }^{1}$ Department of Marine Ecology, University of Gothenburg, Sweden; E-mail: sam.dupont@marecol.gu.se

${ }^{2}$ The Royal Swedish Academy of Sciences, Sweden; E-mail: mike.thorndyke@marecol.gu.se

Key words: Ocean acidification, evolution, plasticity, adaptability, environmental variability

Since the beginning of industrialization, mankind has released large amount of $\mathrm{CO}_{2}$ into the atmosphere. Half of these emissions have been absorbed by the oceans. In consequence, the world's oceans are becoming more acidic, a phenomenon known as ocean acidification (OA) that is believed to have a profound impact on marine species. Although such events have happened before, for example as a main driver 
of the Permian extinction, current rates of change are far beyond anything previously experienced by potentially vulnerable taxa. Calcification is one of the primary targets for studies of the impact of $\mathrm{CO}_{2}$-driven climate change in the oceans, and one of the key marine groups most likely to be impacted by predicted climate change events are the echinoderms. Rates of changes are increasingly fast and there is an urgent need to determine the rules that will decide what species will suffer ('losers') or benefit ('winners') from this stressor that can radically alter ecosystem structure(1,2). We will review the literature and summarize our data collected at the interface between genomics, physiology and ecology. These demonstrate that the impacts of OA can be dramatic but are also very species-, population- and even process- specific. Some species appear to be extremely sensitive to near-future $\mathrm{pH}$ conditions. For example, $100 \%$ mortality is observed in larvae of the brittlestar Ophiothrix fragilis when exposed to $\mathrm{pH}$ conditions expected for 2050(3). However, some unexpected developmental stability and buffering capacities are also observed, sometimes associated with genetic and physiological plasticity. Moreover, some species appear to be resistant or even to benefit under near-future ocean acidification conditions ${ }^{(4)}$. We will also stress the danger of overor under-estimating the real impact of OA on a given species and emphasize the importance of identifying bottlenecks in life cycles and in biological processes. This also includes assessment of ecological interactions and synergy between stressors. We will propose a new theoretical framework showing that by analyzing interactions between past, present and future environmental variability, life-history strategy and population plasticity along latitudinal gradients, we can explore both intra- and inter-specific adaptive potential and genetic variability and begin to make predictions on what echinoderms might be the winners and the losers in nearfuture oceans.

\section{References}

(1) Dupont, S.; Ortega-Martinez, O. \& Thorndyke, M. (2010): Impact of near-future ocean acidification on echinoderms. Ecotoxicology 19: 449-462.

(2) Dupont, S.; Dorey, N. \& Thorndyke, M. (2010): What meta-analysis can tell us about vulnerability of marine biodiversity to ocean acidification? Estuarine, Coastal and Shelf Science 89: 182-185.

(3) Dupont, S.; Havenhand, J.; Thorndyke, W.; Peck, L. \& Thorndyke, M. (2008): Nearfuture level of $\mathrm{CO}_{2}$-driven ocean acidification radically affects larval survival and development in the brittlestar Ophiothrix fragilis. Marine Ecology Progress Series 373: 285-294.

(4) Dupont, S.; Lundve, B. \& Thorndyke, M. (2010): Near future ocean acidification increases growth rate of the lecithotrophic larvae and juveniles of the sea star Crossaster papposus. Journal of Experimental Zoology (B: Molecular and Developmental Evolution) 314: 382389. 


\title{
Asteroidea - Quo Vadis? [plenary presentation]
}

\section{Andy Gale}

School of Earth and Environmental Sciences, University of Portsmouth, Burnaby Building,Burnaby Road, Portsmouth PO13QL UK; E-mail: andy.gale@port.ac.uk

Key words: Asteroidea, taxonomy, review, future direction

$20^{\text {th }} \mathrm{C}$ taxonomic work on asteroids was dominated by a few specialists who devoted most of their careers to monographic treatment of the group. The enduring legacy of these workers are numerous monographs illustrating and describing asteroid taxa, which provide a firm taxonomic basis for future work. However, the disappearance of dedicated taxonomists worldwide now presents a dilemma, because so few specialists exist who can interpret the monographs and update them. The internet should provide a solution, but worryingly, misinformation and misidentification of asteroids is prevalent on websites. This taxonomic crisis coincides with an exponential growth in molecular data, which is revealing the presence of numerous cryptic species, previously synonomysed by the taxonomic gurus; there clearly needs to be a continuing interplay between morphological and molecular studies. The lack of consideration of asteroid skeletons in taxonomy means that some groups, like the important deep sea family Pterasteridae, remain in taxonomic confusion. For fossil asteroids, the challenge is now to utilise the abundant material of dissociated ossicles for taxonomy and phylogeny.

\section{Global diversity of sea urchins (Echinodermata: Echinoidea) [plenary presentation]}

\author{
Andreas Kroh ${ }^{1} \&$ Rich Mooi $^{2}$ \\ ${ }^{1}$ Natural History Museum Vienna, Department of Geology \& Palaeontology, Burgring 7, 1010 Vienna, \\ Austria; E-mail: andreas.kroh@nhm-wien.ac.at \\ ${ }^{2}$ California Academy of Sciences, 55 Music Concourse Drive, San Francisco, CA 94118, USA; \\ E-mail:rmooi@calacademy.org
}

Key words: Echinoidea, biodiversity, species estimates

With about 1,070 valid extant echinoid species known from the world oceans, sea urchins constitute a relatively small group compared to asteroids (1,863 valid species$\left.^{(1)}\right)$, ophiuroids $(2,153$ valid species(2)$)$, and holothuroids. Only extant crinoids are less diverse than echinoids. However, in the fossil record things look different, with echinoids and crinoids dominating while asteroids, ophiuroids, and holothuroids are less diverse. This shift in diversity patterns is due to differing lifestyles, skeletal construction, and concomitant biostratinomic and taphonomic pathways. 
Echinoids inhabit a wide range of marine environments from the intertidal down to the bottoms of deep sea trenches. Accordingly, they come in a variety of different shapes representing adaptations to specific habitats and feeding strategies. The non-monophyletic 'regular' urchins can be extremely common, iconic forms along rocky shores worldwide. They are also ubiquitous members of the benthos even at the greatest ocean depths. Irregular urchins, denizens of sand and mud bottoms, form a monophyletic group. The Irregularia, although still exhibiting a basic pentaradiality, have secondarily acquired bilateral symmetry superimposed upon the radial symmetry when the anus evolved from the summit of the body towards what is now functionally defined as the posterior end of the animal. The spines of irregular echinoids are extremely miniaturized to form a dense felt which facilitates locomotion and burrowing, as well as feeding. Today two large groups of irregular sea urchins exist, the heart-shaped Spatangoida and the disc-shaped Clypeasteroida. Less well known are the Holasteroida, which have largely migrated to the deep sea during the Upper Cretaceous (about 70 million years ago) and which include the most bizarre of extant echinoids - the amphora- and vaseshaped pourtalesiids. Other minor groups of irregular urchins include the holectypoids and 'cassiduloids' (also not a natural group), which comprise a handful of species that essentially represent living fossil remnants of taxa once dominant in echinoid faunas of the Mesozoic.

In addition to this anatomical, behavioral, and paleontological diversity, the echinoids also display considerable nomenclatural multiplicity. For example, some 300 additional extant species had been described in the past which today are considered junior synonyms of other echinoid species. In the literature these taxa appeared in more than 2,800 combinations, owing to considerable progress in echinoid taxonomy and need to rectify generic attributions. Discovery rate of echinoids has dropped considerably in the past century, suggesting that our knowledge of echinoid diversity is fairly complete. Estimating the number of species yet to be discovered is fraught with difficulties. Based on discovery rates of the past 60 years we can extrapolate that there are at least 100 species of extant echinoids still to be discovered, $90 \%$ of which are expected to be described by the year 2250 . We warn, however, that the variance in discovery rate during the last 60 years is high for extant echinoids and these figures are only crude estimates. Because the numbers of echinoid species as well as taxonomists are small, any intense individual effort is bound to affect drastically future discovery rates. An excellent example of this phenomenon is Mortensen's Monograph of Echinoidea (1928-51), which hugely increased discovery rates and accounted for about $60 \%$ of all contemporaneously discovered species. Mortensen alone described about one fifth of all accepted extant echinoid species. Another problem is the possible impact of cryptic speciation and sibling species - phenomena yet to be fully explored among echinoids and which cannot be considered in the above estimates.

The diversity of fossil Echinoidea vastly surpasses present sea urchin biodiversity. More than 10,000 nominal species and 1,000 genera have been described. 
Although large numbers of these turn out to be junior synonyms, new species continue to be discovered at a rate of 15 to 25 species/year over the last 20 years. Statistics show that as in extant echinoids, the fossil species discovery curve is flattening, but there also remains a high number of fossil sea urchins still to be described.

\section{References}

(1) Mah, C. L. (2009): World Asteroidea database. Available online at http://www.marinespecies.org/asteroidea. Consulted on 2010-08-17.

(2) Stöhr, S. \& O’Hara, T. (2007): World Ophiuroidea database. Available online at http://www.marinespecies.org/ophiuroidea. Consulted on 2010-08-17.

\section{Form, function, food and feeding in stellate echinoderms [plenary presentation]}

\section{John M. Lawrence}

Department of Integrative Biology, University of South Florida, Tampa, Florida, USA; E-mail:lawn@usf.edu

Key words: Crinoidea, Asteroidea, Ophiuroidea, arms, feeding

The question is how the form of the body and arms of stellate echinoderms (crinoids, ophiuroids, asteroids) have adapted for increasing the efficiency of feeding. Crinoids are suspension feeders. An increase in number of arms by branching of the five rays arising from the calyx has been one evolutionary trend. This method of increasing the length of the ambulacra seems more effective than increasing the number of rays. A second trend has been production of pinnules. This increases the density of the tube feet and allows maintaining the same total length of the ambulacra while reducing the length of the arm. Rays have not branched in suspension-feeding ophiuroids except in the euryalids. This may be because the arms are involved in active locomotion or burrowing. Like crinoids, euryalids are epibenthic and slow moving. Like crinoids, increase in arm number is by branching and not by increasing the number of rays. Increase in efficiency of feeding is less than in crinoids because food capture by euryalid arms involves arm tips and spines, not the tube feet. In contrast to crinoids and ophiuroids, the arm of asteroids is supported by the body wall. No asteroid has branched arms, not even those that extend arms into the water column to capture macroprey. Is this because their basic anatomy constrains branching or because it would not increase their efficiency in feeding? Modifications of the arms occur in asteroids that change the body form. One is development of interbrachial septa that provides structural support for the arms. A second is multiplication of arms. A third is an extension of the interradius. Although these modifications may have multiple functions, one consequence is an increase in the diameter of the disc. Digestion in 
asteroids involves close contact between the stomach epithelium and the food. Because the stomach is not extended beyond the disc by extraoral feeders, an increase in disc diameter increases the area of digestion.

\section{The early history of echinoderms: current views, major issues, and new perspectives [plenary presentation]}

\section{Bertrand Lefebvre ${ }^{1}$, Bruno David ${ }^{2} \&$ Rich Mooi $^{3}$}

${ }^{1}$ UMR CNRS 5125 Paléoenvironnement \& Paléobiosphère, Université Lyon 1, Villeurbanne, France; E-mail: bertrand.lefebure@univ-lyon1.fr

${ }^{2}$ UMR CNRS 5561 Biogéosciences, Université de Bourgogne, Dijon, France;

E-mail:bruno.david@u-bourgogne.fr

${ }^{3}$ Department of Invertebrate Zoology \& Geology, California Academy of Sciences, San Francisco, California, USA; E-mail:rmooi@calacademy.org

Key words: Echinodermata, deuterostomes, phylogeny, Cambrian, Ordovician

After more than 250 years of active scientific research and in spite of significant advances, the origin and early history of echinoderms remain largely unresolved and controversial fields of investigation. Until very recently, embryological and palaeontological data were the only available sources of information to resolve early echinoderm evolution and phylogenetic position among metazoans. Because of their pervasive radial symmetry, echinoderms were first considered close relatives of coelenterates within the 'Radiata'. In the 1880s, the development of embryological studies prompted reevaluation of echinoderms as deuterostomes, alongside hemichordates and chordates. One conundrum concerning the origins of the Echinodermata is that palaeontological data suggest that when they first appear in the fossil record in the Early Cambrian (about $540 \mathrm{my}$ ), echinoderms were already relatively diverse, exhibiting all of their characteristic features (calcite skeleton with stereomic microstructure, water vascular system, and radial symmetry). Another difficulty lies in the observation that the five extant major clades ('classes') of echinoderms appear relatively late in the fossil record (within the Early-Middle Ordovician time interval, about 485 to $460 \mathrm{my}$ ), with no obvious ancestors in Cambrian faunas. In recent years, phylogenies based on molecular data have strongly modified earlier views of deuterostome relationships, and in particular, they support the existence of a clade (Ambulacraria) uniting echinoderms with hemichordates. However, molecular phylogenies have so far failed to unequivocally resolve the relationships among the five extant 'classes' of echinoderms. As a consequence, the main current scientific issues concerning the early history of echinoderms are: (1) the origin of radial organization in a group of such highly derived deuterostomes that exhibit common ancestry with bilateral forms (hemichordates); (2) the origin and phylogenetic relationships of the five extant 
classes; and (3) the phylogenetic position of the 15 extinct 'classes'. These issues are currently addressed through two main, but largely contrasting interpretations. The first one dates back to the 1930s (Bather, Gislén), and focuses on the absence of radial symmetry in several classes of Early Palaeozoic echinoderms (the 'carpoids' or 'homalozoans'). In this scenario, carpoids would represent pre-radial, basal members of the echinoderms, closely related to hemichordates and/or other basal deuterostomes (e. g., vetulicolians). Usually, this interpretation also considers asteroids as closely related to edrioasteroids (as members of an 'eleutherozoan' group), and 'pelmatozoans' as a clade uniting all stemmed echinoderms (crinoids and 'cystoids'). An alternative view regards the homalozoans and related forms as specialized echinoderms exhibiting loss of rays (Ubaghs, Parsley, Sumrall). A special formulation of this point of view is a logical extension of the Extraxial Axial Theory (EAT) that emerged in the 1990s. The EAT is based on morphological, embryological, and now also genetic arguments, and proposes a modular interpretation in which echinoderms have a body wall consisting of two main regions (axial and extraxial), each characterized by contrasting plating architectures as well as distinct embryologic origins and different coelomic affiliations. In this scenario, the asymmetry of homalozoans is interpreted as derived, possibly resulting from adaptations to a flatfish mode of life on soft substrates. The reduction in ray number would have occurred in several different lineages, and each of the major homalozoan groups can be allocated within recognized clades throughout the phylum depending on the formulation of ambulacral and other structures. The EAT also implies that metamorphosis was less pronounced (or entirely absent) in the earliest echinoderms. In part, this is evidenced by the much smaller role that the axial region plays in anatomical construction of early echinoderms than it does in extant clades, all of which appeared later in the fossil record (Ordovician). Finally, the EAT supports the findings of workers such as Sprinkle that the 'pelmatozoans' do not constitute a monophyletic group, nor does it provide evidence for an exclusive relationship between asterozoans and edrioasteroids. Recent advances in genetics (Hox genes), the discovery of exceptionally preserved fossils in Cambro-Ordovician strata, and the development of new vizualization techniques (3D reconstructions with CT-scans) constitute fascinating new perspectives for future research programs on the early history of echinoderms. 


\section{Bioluminescence in echinoderms [plenary presentation]}

Jérôme Mallefet

Marine biology laboratory, Catholic University of Louvain, 3 Place Croix du Sud, B-1348 Louvain-laNeuve, Belgium; E-mail:Jerome.mallefe@@uclouvain.be

Key words: Crinoidea, Asteroidea, Ophiuroidea, Holothuroidea, luminescence

Luminescence occurs in four of the five Echinoderm classes: Crinoidea, Holothuroidea, Asteroidea and Ophiuroidea. Until recently, in many cases the information was solely descriptive and limited to morphological, ecological and some features of bioluminescence. One major reason of this poorly documented phenomenon in echinoderms is restricted accessibility that limits the number of species studied. For the last ten years, a series of field trips and participation to one deep-sea cruise allowed to discover and describe the luminous capabilities of numerous ophiuroids as well as some holothuroids and one crinoid species. A multidisciplinary approach allowed to obtain physiological, morphological, ecological, ethological and finally biochemical data for some ophiuroid species, mainly because luminous representatives of this class are present from the intertidal zone downwards. This presentation attempts to synthesize recent information mainly on ophiuroid luminescence but will also present literature data on luminescence observations in other echinoderm classes in order to illustrate the diversity of this amazing phenomenom. New field surveys must be performed to increase the number of echinoderm species tested to highlight a possible link between luminescence and phylogenetic distribution of this capability in order to understand why so many echinoderms glow in the dark.

\section{Northern Pacific sea cucumbers and other echinoderms collected by the Steamer Albatross: the legacy of Hubert Ludwig and colleagues [plenary presentation]}

\section{David L. Pawson \& Doris J. Pawson}

Department of Invertebrate Zoology, National Museum of Natural History, Smithsonian Institution, W ashington DC 20013, 7012, USA; E-mail:pawsond@si.edu

Key words: Holothuroidea, sea cucumbers, echinoderms, abyssal, Albatross

Hubert Ludwig, with his superb 1894 monograph of deep-sea holothurians collected by the steamer Albatross in the northeastern Pacific, laid the foundation of our knowledge of the fauna of that region. Studies in progress on sea cucumbers collected by Scripps Institution of Oceanography (SIO) and the Monterey Bay Aquarium Research Institute (MBARI), California, along with a survey of the published literature, reveal a deep-sea $(>500 \mathrm{~m})$ holothurian fauna in the north- 
eastern Pacific, east of $140^{\circ} \mathrm{W}$ and from the equator to $60^{\circ} \mathrm{N}$, of approximately 75 species, of which at least 10 are undescribed. All of the six orders of the Holothuroidea are represented. The typically deep-sea groups, Order Elasipodida and Family Synallactidae in Order Aspidochirotida, are diverse in the area; approximately $20 \%$ of the known elasipodid species occur there. About $30 \%$ of the species are burrowing forms, not visible in the seafloor images obtained by both SIO and MBARI. Study of the images, along with collected specimens, has revealed much new information about the ecology and taxonomy of these animals.

Pioneering investigations in the northern Pacific were made by the US Fish Commission Steamer Albatross (1882-1921). On a series of scientific cruises, beginning in 1891, an enormous number of echinoderms were collected. Eminent European, Japanese, and American scientists, during this 'golden age' of ocean exploration, published comprehensive monographs on Albatross material that remain today as standard reference works. For holothurians, Hubert Ludwig (30 new species), Walter Fisher (19), Hiroshi Ohshima (46), and Hubert Clark (13) were the leading lights, and scientists studying other groups include Rene Koehler (430 new ophiuroids), Austin Clark (170 crinoids), Walter Fisher (188 asteroids), Hubert Ludwig (56 asteroids), Theodore Mortensen (28 echinoids, and with Lütken, 53 ophiuroids), Alexander Agassiz (20 echinoids, and with Hubert Clark, 33 echinoids), and Hubert Clark (16 echinoids, 6 ophiuroids).

In all, approximately 1682 new species of echinoderms have been described from Albatross collections. These comprise almost $25 \%$ of the echinoderm species known today.

\section{A Döderlein Iliad: The German Zoologist Ludwig Döderlein, his destiny and legacy in collections [plenary presentation]}

Joachim Scholz

Senckenberg Forschungsinstitut und Naturmuseum, Sektion Marine Evertebraten 3, Frankfurt am Main, Germany; E-mail:Joachim.Schol@@senckenberg.de

Key words: History of Science, Döderlein, Echinodermata, Japan, Sagami Bay, collections

The German zoologist Ludwig Döderlein (1855-1936) had lived a full and active professional life and seen three irrevocable changes in the workings of the world: the emergence of Japan during the Meiji Era, the First World War, and the birth and fall of the Republic of Weimar. He was one of the last of the great naturalists who were able to teach, and to write on the whole diversity of recent and fossil animals and plants: Döderlein published on evolution theory, on tapirs and elephants, he tackled Jurassic pterosaurs as well as new species of fish, corals, and sponges. The true passion of his life, however, were echinoderms, and he left us several voluminous monographies on asteroids, echinoids, and crinoids. 
His professional career as a collector of marine life and taxonomist started in Japan. He stayed for two years as an 'oyatoi (=employee) gaikokujin (=foreign)' professor of Natural History in the Medical Department of the newly founded Imperial University of Tokyo (1879-1881). After finding many rare marine animals sold in gift shops at Enoshima, a coastal town of Sagami Bay situated in the South of Tokyo, he recognized that this part of the world is exceptionally rich in marine fauna. He started collecting early in 1880, and discovered strange creatures such as the stalked crinoid Metacrinus rotundus Carpenter (Fujita 2007).

A 'Döderlein Renaissance' started when Shunsuke Mawatari (Hokkaido University, Sapporo) re-discovered the Döderlein collection of Japanese animals, kept at the Musée Zoologique in Strasbourg, on the grounds of an earlier recommendation of E. Voigt (University of Hamburg, Germany) to search there. (E. Voigt, a bryozoan researcher, was at that time the last surviving student of Döderlein).

A Japanese project team conducted from 1997 to 2005 surveys in Strasbourg and other museums and collections in Germany, Austria, and Switzerland. They revealed that the Döderlein collection consists of more than 3,550 specimens in total, including types for at least 372 species and/or genera. 654 specimens belong to the Echinodermata, including 49 types (Mawatari, in Scholz 2009). The numbers are still preliminary. For example, recently we discovered some more of the Döderlein echinoderms in a university collection transfered to the Senckenberg Research Institute in Frankfurt.

As time passes, it becomes slowly apparent that Döderlein's legacy is very much alive, especially in Japan. His collections in the Sagami Bay, and ethnological and biological research undertaken in Amami Oshima Island in Southwest Japan are considered to be one of the very keystones in natural history research in Japan. He also initiated a long lasting tradition of research on Sagami Bay, including the foundation of the Misaki Marine Biological station in 1886, field studies by Franz Doflein (1905), by the Showa Emperor (1928-1988) and today, by the National Museum of Nature and Science (Tokyo).

In the past 15 years, taxonomical studies on the collections have been accompanied by some biographical research. We need to know about sampling methods back in 1880, and sampling locations especially of the types, in order to understand how and why the collection may have come to various European museums. Fortunately, the Döderlein family kept most of the diaries, letters, and manuscripts of their great-grandfather. These documents and the family history (transmitted orally) also reveal a personal tragedy. When the success he had worked so hard to achieve came, Döderlein was plagued by tuberculosis, preventing his promotion to university professorship. After the first World War, the Alsace went back to France, and Döderlein, being director of the zoological museum in Strasbourg since 1893, was deported to Germany (1919). The structure of his earlier existence was shattered, and he spent the rest of his life in Munich at the Bavarian State Collection, often looking back and fighting an uphill battle to regain his collections 
he was forced to leave behind. A few years after he died, most of the Döderlein collection deposited in Munich was lost in the fire, caused by air raids of another war. The majority of the specimens however, surviving in Strasbourg and elsewhere, and the collections of the Döderlein successors serve to demonstrate the value of museum biological archives as a modern research infrastructure. Today, we are able to document 130 years of environmental changes that occured in the coastal seas off the Kanto plains in Honshū, Japan.

\section{References for further reading}

Döderlein, L. (1879-1881, unpublished): Japan-Tagebuch (diary). English translation by W. Falckenthal and S. Baier, Hamburg. [Privately circulated.]

Nishikawa, T. (ed., 1999): Preliminary taxonomic and historical studies on Prof. Ludwig Döderlein's collection of Japanese animals made in 1880-81 and deposited at several European Museums: Report on the activities in 1997-8 supported by Grant-in-Aid for International Scientific Research (field research), No. 09041155. Nagoya, Japan.

Scholz, J. (ed., 2009): Seesterne aus Enoshima - Ludwig Döderleins Forschung in Japan: 100 pp., Frankfurt (Khorshid Verlag).

\section{Life Styles of Early Echinoderms: Carpoids and Helicoplacoids [plenary presentation]}

\section{Adolf Seilacher}

Engelfriedshalde 25,D-72076 Tübingen,Germany; E-mail: sabine.stobr@nrm.se

Key words: Helicoplacoidea, Carpoidea, life style

The origin of echinoderms is a riddle. The Ediacaran Arkarua does show a 5-rayed symmetry; but otherwise it is more similar to a group of presumed sand sponges (Trilobozoa), which were attached to the tough biomats of those times. In contrast, the earliest undoubted echinoderms (with calcitic stereom and rows of tube feet) deviate enormously from the expected archetype. This could be related to life styles that are no more represented among modern echinoderms.

In carpoids, infaunality is indicated by terrace lines that correspond to the burrowing ribs of other phyla in all details (ratcheting; allometric densing). Their flexible tail, however, was unsuited for continuous locomotion within the sediment. Possibly, it was only used to implant the body in a vertical attitude, like in lingulid brachiopods.

The construction of the earliest echinoderms, helicoplacoids, fits a mobile life style better than a pelmatozoan one. In analogy to the mineralized scales of machaeridian annelids, their multi-element armor could have assisted peristaltic burrowing. 
The persistence of 5-rayed symmetries in extant eleutherozoan classes could mean that their mobility was secondarily acquired.

\section{Brittle star systematics - past, present and future [plenary presentation]}

\section{Sabine Stöhr}

Swedish Museum of Natural History, Department of Invertebrate Zoology, Box 50007, S-10405 Stockholm, Sweden; E-mail: sabine.stohr@nrm.se

Key words: Ophiuroidea, systematics, history, morphology

About 2170 Recent species of brittle star are currently known. The most active period of species discovery was between 1850 and 1950, with an average rate of about 17 new species per year, but even today, an average of 7 species per year are described. Counting all published names, the rates almost double. The most prolific authors were R. Koehler, H. L. Clark, T. Lyman, T. Mortensen and C. Lütken. Early classifications divided the Ophiuroidea into Euryalida and Ophiurida; Matsumoto suggested in 1917 further subdivision, accepted by some authors, rejected by others. His classification is still the most comprehensive work available. A first modern cladistic analysis was presented in 1995 by Smith et al., but despite its shortcomings, no further attempts at reconstructing the phylogeny of the whole class have been made. It is becoming increasingly clear that Ophiuroidea have undergone rapid evolution after the great extinction event at the $\mathrm{P} / \mathrm{T}$ boundary, complicating phylogenetic analysis both with morphological and molecular data. Palaeozoologists still debate which ophiuroid group(s) survived the extinction. It has been suggested that the modern families Ophiuridae and Ophiolepididae may be traced back to the Palaeozoic, but the traditional view puts Ophiacanthidae at the root of the tree and Euryalida as ancient sister group to Ophiurida. Unusual species with aberrant traits abound, but are still poorly understood. New morphological approaches, such as the study of the internal skeleton, ontogeny and the role of paedomorphosis, as well as the extensive use of SEM for microstructure examinations, attempt to improve our understanding of the diversity and evolution of brittle stars. The importance of careful taxon selection for the outcome of reconstructions of higher taxon relationships is emphasized. 


\section{Pigments of modern and fossil echinoderms [plenary presentation]}

\section{Klaus Wolkenstein}

\section{Staatliches Museum für Naturkunde Stuttgart, Germany; E-mail: klaus.wolkenstein@smns-bw.de}

Key words: Echinodermata, organic pigments, quinones, caretenoids, molecular fossils

Modern echinoderms are well-known for their often beautiful and bright colours comprising almost every hue imaginable. These colours are caused by a high diversity of organic pigments with quinones and carotenoids (carotenoproteins) as the most important groups. Individual pigment groups and subgroups show considerable differences in their occurrence between the major echinoderm clades. Whereas carotenoproteins have been isolated from a wide spectrum of asteroids, naphthoquinones are widespread in echinoids and anthraquinones as well as hypericinoid pigments are predominant among the crinoids. Although the specific function of most echinoderm pigments is still unknown, some pigments likely play an important role in biological defence.

Surprisingly, several organic pigments or their diagenetic products can also be found in fossil echinoderms. Most prominent are fossil polycyclic quinones (hypericinoids) found in distinctly purple to violet coloured crinoids from the Jurassic of Switzerland. Recent research has shown that these pigments are much more widespread than previously known and are preserved in many Mesozoic crinoids with examples even from the Middle Triassic. Since similar pigments are known from living crinoids, the fossil compounds are believed to be almost unchanged biomolecules. Colour preservation has been only scarcely reported for other classes of fossil echinoderms; however, at least characteristic colour patterns have been described for echinoids and blastoids. 


\section{Oral \& Poster Presentations}

Growth and gonad development of the sea urchin Hemicentrotus pulcherrimus in an Eisenia kelp bed in the Oshika Peninsula, northern Japan [oral presentation]

Yukio Agatsuma, Nanako Toda, Makoto Ogasawara, Junji Kinoshita, Masayuki Watanabe, Toshiyuki Matsui \& Eri Inomata

Graduate School of Agricultural Science, Tohoku University, Sendai, Japan;

E-mail:agatsuma@bios.tohoku.ac.jp

Keywords: Echinoidea, Growth, Gonad development, Eisenia, Nutritive phagocyte

Temporal and spatial variations of the growth and gonad development of edible sea urchins are closely associated with difference in the algal vegetations. The present study monitored the annual gonad index (gonad wet weight x 100/body wet weight), gonad development from histological observation, and gut content index (gut content wet weight x 100/body wet weight) of Hemicentrotus pulcherrimus in an Eisenia bicyclis kelp bed in relation to the seasonal changes in the kelp densities in the Oshika Peninsula, northern Japan from March 2008 to September 2009.

The kelp densities decreased from November to March, when the high velocity of west wind, which causes high wave action, was frequently recorded. The relationship between age and size of $H$. pulcherrimus in the kelp bed was similar to that in Fucales bed (Agatsuma \& Nakata 2004). The gonad indices were around 10 during February to April, when the gonads were in the recovering I stage with relict gametes surrounded by nutritive phagocytes (NPs) in the lumen, increased from May to August at the recovering II stage with Nps filling the lumen, reached a peak of 18.8 at the mature stage in December. In January, the gonad shifted to the partly spawned or spent stages, but the indices did not fall to $<10$. Gut content indices were low at the recovering II and growing stages, increased from the mature stage and reached a peak at the recovering I stage. These results suggest that renewal of NPs after spawning (recovering I stage) is caused by high food availability of the kelp due to increase in the thalli fallen off in addition to increase in lateral blades shed in winter (Taniguchi et al. 1991). 


\title{
Distribution, size and diet of Diadema mexicanum A. Agassiz, 1863 along the Eastern Tropical Pacific [oral presentation]
}

\author{
Juan José Alvarado ${ }^{1,2}$, Hector Reyes-Bonilla ${ }^{3}$, Jorge Cortés ${ }^{1} \&$ Hector Guzmán ${ }^{4}$ \\ ${ }^{1}$ Centro de Investigación en Ciencias del Mar y Limnología (CIMAR), Universidad de Costa Rica, San \\ Pedro, 11501-2060San José,Costa Rica; E-mail:juanalva76@yahoo.com \& jorgecortes@ucr.ac.cr \\ ${ }^{2}$ Posgrado en Ciencias Marinas y Costeras, Universidad Autónoma de Baja California Sur, La Paz, \\ México \\ ${ }^{3}$ Departamento de Biología Marina, Universidad Autónoma de Baja California Sur, La Paz, México; \\ E-mail:breyes@uabcs.mx \\ ${ }^{4}$ Smithsonian Tropical Research Institute, PO Box 0843-03092, Balboa, Ancon, Panamá; E-mail: \\ guzmanb@si.edu
}

Keywords: Echinoidea, densities, unimodal distribution, gut evacuation, organic matter, carbonates

The sea urchin Diadema mexicanum is considered a keystone species on the coral reefs of the Eastern Tropical Pacific (ETP). Its bioerosion impact has been studied in Panama, Costa Rica and Mexico, and its influence in coral reefs recovery in the Galapagos Islands (Darwin and Wolf) has been suggested. Several studies analyzed the presence of this sea urchin in various reefs of the ETP; nevertheless their focus was local. In this work we analyzed, with a standard methodology, 11 reefs in four countries of the region (México, El Salvador, Costa Rica and Panamá), and we include information of the Galapagos (Ecuador) and Revillagigedo (México). In the 11 localities, between two and five sites with coral reefs were visited, and in each site three transects of $10 \mathrm{~m} \times 2 \mathrm{~m}$ were established, between 4 and $10 \mathrm{~m}$ depth, to count and to measure the test diameter of the sea urchins. From each locality, between 30 and 50 individuals were extracted to analyze the stomach content through evacuation after a $24 \mathrm{~h}$ period. The mean density of Diadema along the ETP was $0.50 \pm 0.57$ ind $\mathrm{m}^{-2}$ with significant differences among localities, being highest in Bahía Culebra (Costa Rica) with 0.50 \pm 0.57 ind $\mathrm{m}^{-2}$, and lowest in Los Cóbanos (El Salvador) with $0.02 \pm 0.02$ ind $\mathrm{m}^{-2}$. We measured 1298 sea urchins, with an average test size of $3.98 \pm 1.90 \mathrm{~cm}$, a mode of $2.40 \mathrm{~cm}$, a minimum of $0.32 \mathrm{~cm}$ and a maximum $12.30 \mathrm{~cm}$. The biggest sea urchins are located on the oceanic islands of the region. The majority of localities present a unimodal distribution of test sizes, mostly with one tail. The mean gut content was $1.2916 \pm 0.0720 \mathrm{~g}$, consisting of $13.9 \pm 7.6 \%$ organic matter, $23.1 \pm 21.5 \%$ noncarbonate fraction, and $63.0 \pm 22.9 \%$ carbonates, with significant differences between localities for the three components. A positive significative relationship was observed between the size of the sea urchins test and the amount of carbonates inside the evacuated gut contents. 


\section{A remarkable new echinoderm Lagerstätte from the Eifelian of the Rhenish Massif [poster presentation]}

Jan Bohatý

Institut für Geologie und Mineralogie der Universität ₹u Köln, Zülpicher Str. 49a, D-50674 Köln (Cologne),Germany; E-mail:jan.bohaty@mail.com

Keywords: Echinoderm Lagerstätte, Rhenish Massif, Crinoidea, Asteroidea, Ophiuroidea, Cyclocystoidea

The Middle Devonian crinoids of the Eifel Synclines constitute one of the most classic Devonian echinoderm faunas. Numerous species (especially Crinoidea), were described in the famous monographs of the early-late $19^{\text {th }}$ century.

Due to the increased carbonate shallow shelf-environments from the Lower Eifelian toward the Eifelian/Givetian boundary, echinoderm palaeodiversity increased toward the Givetian. Many taxa are dominated by robust skeletons and compact arms (e. g., cupressocrinitids, crinoid subclass Cladida), presumably a reaction to the turbulent environments.

In contrast to the well known Lower Givetian crinoid associations of the Gerolstein and Hillesheim synclines, the Lower Eifelian echinoderms of these synclines are poorly known. Morphologically, they resemble the gracile taxa of the Upper Siegenian (Upper Pragian) to end of Lower Emsian of the famous 'Hunsrückschiefer' or the 'crinoids of the sandy Lower Devonian up to the Cultrijugatus-Zone' (Emsian/Eifelian boundary).

A new Lagerstätte within the Lower Eifelian of the Gerolstein Syncline (Rhineland-Palatinate, Germany) provides an insight into these echinoderms. Taxa include the first articulated ophiuroids and asterozoans (new taxa) of the Eifel Synclines; articulated crinoids (e. g., storthingocrinids, haplocrinids, vasocrinitids and myelodactylids), including new genera and species; and cyclocystoids. This soft-bottom dwelling echinoderm community was abruptly covered by a bentonite that provided spectacularly in-situ preservation of this fauna and affords dating of this unique echinoderm Lagerstätte via the analysis of contained, idiomorphic zircon crystals.

\section{Ossicular anomalies in Lower Givetian blastoids from the Eifel (Rhenish Massif, Germany) [posterpresentation]}

Jan Bohatý ${ }^{1}$, Elise Nardin ${ }^{1} \&$ Uwe Hein $^{2}$

${ }^{1}$ Institut für Geologie und Mineralogie der Universität zu Köln, Zülpicher Str. 49a, D-50674 Köln

(Cologne),Germany; E-mail:jan.bohaty@mail.com \& elnardin@gmail.com

${ }^{2}$ Klingestr. 204A, D-42651 Solingen, Germany; E-mail: uwealexa@t-online.de

Keywords: Blastoidea, ossicular anomalies, Middle Devonian, Rhenish Massif, Germany 
The Middle Devonian strata of the Eifel Synclines (Rhenish Massif, North RhineWestphalia/Rhineland-Palatinate, Germany) are now well known as a hotspot in echinoderm diversity during the Middle Palaeozoic. Within echinoderms, blastoids can be considered as an exception in terms of stable morphology for the whole clade and of a clear under-representation in comparison to the other echinoderm groups (e. g., crinoids). Blastoids possess a tripartite endoskeleton, composed of a stem articulated to a globular to pyriform theca (enclosing viscera) with a five-fold symmetry and a developed food-gathering system of erect brachioles bourne by ambulacra lying on the theca.

Recent field work has revealed an extraordinary rich fauna of blastoids from the Lower Givetian strata (Middle Devonian, hemiansatus Conodont biozone) of the Rhenish Massif (Germany). This new fissiculate fauna contains about 140 specimens of Hyperoblastus gilbertsoni showing various ontogenetic stages, 30 specimens of $H$. acutangulus and a possibly new species. The low pyriform theca of the H. gilbertsoni is composed of a short basal circlet (3 zygous basals), five radials and four deltoids. These relatively regular skeletal features result in a uniform pentagonal outline of the theca. Our material solely includes isolated theca.

Within the $H$. gilbertsoni material, two specimens show different types of extraordinary abnormalities, both presumably occurring in the early growth stages. The two individuals, described herein, are the first abnormal blastoids known from the Rhenish Massif. The first specimen shows an aberrant hexagonal outline with sixfold symmetry. The thecal plating is modified with a small additional plate in each circlet (basals and radials). The exceptional feature of this specimen is visible in the A-ray of the specimen, showing a duplicated ambulacrum resulting in an overall number of seven ambulacra - a unique discovery among blastoids. The second specimen possesses a partially damaged theca with numerous atypical features, such as a shortened ambulacrum and a strong concave thecal deformation. The first type can be interpreted as a genetic anomaly. The second type obviously indicates a nonlethal injury resulting in a functional but imperfect 'wound healing' regeneration.

\section{Description and functional morphology of three different types of teeth in the common brittlestar Ophiothrix fragilis (Abildgaard, 1789)} [poster presentation]

\section{Karin Boos}

Biologische Anstalt Helgoland, Marine Station, Alfred Wegener Institute for Polar and Marine Research, P.O. Box 180, 27483 Heligoland, Germany

Keywords: Ophiuroidea, Ophiothrix, functional morphology, teeth

Ophiothrix fragilis is a rheophilic epibenthic brittlestar, which has been designated to feed predominantly as podial suspension feeder. Hereby, suspended material is 
collected into a bolus, which increases in size as it travels down the arm towards the mouth. But additional feeding modes have been reported as well, such as deposit-feeding, browsing, grazing, scavenging and predation. Referring to the latter, the use of armloops has been described in O. fragilis, which is considered a common mechanism for feeding on active prey and larger chunks of carrion.

According to its various feeding modes, O. fragilis possesses morphologically different types of teeth. In an earlier study, I described two types of teeth, i. e. grinding and carnassial teeth. The description depicted "rows of short and flat teeth located along the vertical jaw edges surrounded by numerous dental papillae, which are slightly longer than the teeth and have tapered tops". The two types of teeth were designated firstly as grinding teeth for processing smaller organisms or deposit material and secondly as carnassial instruments enabling the animal to process larger particles or prey organisms by crushing or cutting them.

Detailed follow-up dissections of the mouthparts and full profile views of individual jaw elements revealed a third morphological type of teeth. While the above described teeth elements (grinding and carnassial teeth) are confined only to the first half of the jaw edge, the second half is equipped with a single row of large long teeth, with their tips sharply edged to the shape of an arrowhead.

In the present study, detailed morphological descriptions of all three types of teeth and/or associated papillae on the individual jaw elements in $O$. fragilis are given and their functional morphology discussed in relation to the animals' feeding process.

\section{Zoogeography of holothurians (Echinodermata: Holothuroidea) of the Mexican Pacific Ocean [oral presentation]}

Andrea Alejandra Caballero-Ochoa \& Alfredo Laguarda-Figueras

Instituto de Ciencias del Mar y Limnología (ICMyL), Laboratorio de Sistemática y Ecología de Equinodermos (LSEE), Universidad Nacional Autónoma de México (UNAM);

E-mail:andrea_marman@yahoo.com.mx_olaguarda-figueras@cmarl.unam.mx

Keywords: Holothuroidea, zoogeography, Mexican Pacific Ocean, Parsimony Analysis of Endemism (PAE)

Biogeography is the discipline that studies the distribution of living beings in space and over time; the main objectives are to describe and understand the patterns of geographical distribution of species and supraspecific taxa. The Phylum Echinodermata includes approximately 7,000 living species and 13,000 fossil species. Mexico hosts a high diversity of echinoderms. So far, we have reported over 600 species that inhabit our territorial waters, about $9 \%$ of existing species on Earth. The holothurians constitute almost $20 \%$ of species; this class is represented by approximately 114 species in the waters of the territorial sea, the Pacific Ocean being the most diverse, with 68 species reported by Solis-Marín \& LaguardaFigueras in 1998. Studies based on biogeography of echinoderms are poorly repre- 
sented in Mexico; there are studies about distribution, but without biogeography. The geographic area considered for this study corresponds to the Pacific coast of Mexico, which extends from $32^{\circ} 27^{\prime} \mathrm{N}, 117^{\circ} 07^{\prime} \mathrm{W}$ and $14^{\circ} 32^{\prime} \mathrm{N}, 117^{\circ} 13^{\prime} \mathrm{W}$. Mexico has 23,642 million $\mathrm{km}^{2}$ of sea in the Pacific Ocean, also including the island Guadalupe and Revillagigedo Archipelago as part of the national territory. This study analyzes the zoogeography of shallow-water holothurians of the Mexican Pacific Ocean by a taxonomic review of the samples of these sea cucumbers in the Colección Nacional de Equinodermos, 'Dra. María Elena Caso' of the Instituto de Ciencias del Mar y Limnología, UNAM and the echinoderm collection at the Smithsonian Institution in Washington D.C. We apply a parsimony analysis of endemicity (PAE), which allows to classify areas or sites according to taxa shared by a cladogram. We used 7 provinces and 68 species. We obtained one cladogram of 128 steps, CI: 0.81 and RI: 0.65 . The biogeographic studies are important to assess the current situation, to document the distribution of species in different regions; with all these we design management strategies and achieve the objectives of protection and conservation, as well as ensuring the preservation of resources, biodiversity and maintaining natural ecosystems.

\section{When a repellent becomes an attractant: harmful saponins are kairo- mones that maintain the symbiosis between the Arlequin crab and their sea cucumber hosts [oral presentation]}

Guillaume Caulier ${ }^{1}$, Patrick Flammang ${ }^{1}$, Pascal Gerbaux ${ }^{2}$, Pricilla Rakotoarisoa $^{3}$ \& Igor Eeckhaut ${ }^{1}$

${ }^{1}$ University of Mons, Marine Biology Laboratory, 6 Avenue du Champs de Mars, B-7000 Mons, Belgium

${ }^{2}$ Institute of halieutic and marine sciences of Toliara (IHSM), route du port, Mahavatse, Tulear, Madagascar

${ }^{3}$ University of Mons, Organic Chemistry Laboratory, Mass Spectrometry Center, 19 Avenue Maistriau, B-7000 Mons, Belgium

Keywords: Holothurians, host selection, kairomones, saponins

Saponins are secondary metabolites produced by some plants and animals that use them as defensive repellents. They are well known in sea cucumbers in which they function as a chemical protection against predators. Sea cucumbers however house batches of obligate symbiotic organisms for which host selection is generally mediated by chemical signaling. This study is the first to highlight the precise chemical nature of the specific odor involved in the recognition of a sea cucumber by one of its symbionts. Host choice experiments performed using a Y-tube olfactometer demonstrate that saponins secreted by Bohadschia vitiensis are specifically recognized by and attract one of its most common symbionts, the Arlequin Crab 
Lissocarcinus orbicularis. Conversely, saponins emitted by a non-host species of sea cucumber, Pearsonothuria graeffei, are not attractive to the crab. The chemical structure of the different saponins was resolved by mass spectrometry analyses. These analyses show that host saponins lack the sulfate group which is characteristic of most non-host saponins. In addition to their traditional defensive role (allomones), saponins therefore also function as kairomones, maintaining the symbiosis between the Arlequin crab and its sea cucumber host.

Characterization of the symbiotic crab Lissocarcinus orbicularis (Dana, 1952) population in Toliara bay, Madagascar [posterpresentation]

Guillaume Caulier ${ }^{1}$, Gilles Lepoint ${ }^{2}$, Fleur Van Nedervelde ${ }^{3} \&$ Igor Eeckhaut $^{1}$

${ }^{1}$ University of Mons, Marine Biology Laboratory, 6 Avenue du Champs de Mars, B-7000 Mons, Belgium

${ }^{2}$ University of Liège, Oceanology, B6 Sart Tilman, B-4000 Liège, Belgium

${ }^{3}$ University of Bruxelles, Marine Biology, 50 Avenue F.D. Roosevelt, B-1050 Bruxelles, Belgium

Keywords: Malacostraca, Holothuroidea, symbiosis, Lissocarcinus orbicularis, population, Madagascar

Arlequin crabs (Lissocarcinus orbicularis) are symbionts found exclusively on the integument or in the buccal/cloacal cavity of several species of sea cucumbers. The population of these crabs was investigated on holothuroids of the barrier reef of Toliara (south-west of Madagascar) from December 2006 to December 2007. Eleven holothuroid species were observed and seven were infested. There is generally only one crab on infested sea cucumber but up to ten individuals were recorded on a Thelenota ananas; in that case, most crabs were juveniles. The length of the observed L. orbicularis was of 0.3 to $1.4 \mathrm{~cm}$ from the tip of the rostrum to the end of the cephalothorax, with a mean length of $0.85 \mathrm{~cm}$ for the population. L. orbicularis is characterized by a sexual dimorphism (females are bigger than males) and the presence of pereiopods morphologically adapted to fixation on the integument. They harbour different colour patterns depending on the colour and pattern of their host. Gravid females were observed at each period indicating that the crabs reproduce all year round. 


\title{
Predators of the sea urchin Strongylocentrotus purpuratus and the effects of refugee utilization on juvenile survival [oral presentation]
}

\author{
Sabrina Clemente ${ }^{1,2}$, José Carlos Hernández ${ }^{1,2}$, Gabriela Montaño- \\ Moctezuma $^{3}$, Michael P. Russell ${ }^{1} \&$ Thomas A. Ebert ${ }^{4}$ \\ ${ }^{1}$ Department of Biology, Villanova University, Pennsylvania, USA; \\ ${ }^{2}$ Current address: Dpto. Biología Animal (Ciencias Marinas), Universidad de La Laguna, Tenerife, \\ Canary Islands; E-mail: msclemen@ull.es \\ ${ }^{3}$ Instituto de Investigaciones Oceanológicas, Universidad Autónoma de Baja California, Ensenada, B.C. \\ México \\ ${ }^{4}$ Department of Zoology, Oregon State University, Oregon, USA
}

Keywords: Echinoidea, Strongylocentrotus purpuratus, Pachygrapsus crassipes, predation, escape size, substrate refuges

Predation is a strong biological process affecting community structure and ecosystem organisation and an important cause of early mortality for mobile species. Variability in predator-prey interactions may potentially influence sea urchin mortality, particularly at early stages, and hence determine the organization of populations. The objective of this study was to determine the effects of several potential predatory species common in the intertidal habitat (tidepool fish, crabs and starfish) on the survival of the sea urchin Strongylocentrotus purpuratus by means of laboratory experiments. We aimed to give insight into the interactive effects of sea urchins' and main predators' sizes in mediating predation rates. The structural complexity of the habitat, in the form of spatial refuges provided by pits in the substrate and by spine canopy of adult individuals, was manipulated in order to examine the effects of physical protection on the survival of the sizes of urchins most susceptible to predation $(<14 \mathrm{~mm})$. Experiments identified a total of three species of crabs, including Cancer antennarius, Cancer magister and Pachygrapsus crassipes, as sea urchin predators. P. crassipes was a particularly voracious predator that significantly increased mortality of $S$. purpuratus of sizes up to $\approx 30 \mathrm{~mm}$ in test diameter; these medium-sized individuals were occasionally still vulnerable to the largest male crabs. In fact, in addition to a positive effect of predator size on consumption of progressively larger urchins, an effect of crab sex was detected. For predatory crabs, there is probably a mechanical limitation on the ability to handle and consume large preys using their claws as offensive structures; the largest claws that males of a certain size have with respect to females clearly facilitates the handling of progressively larger preys. Substrate heterogeneity and the presence of refuges showed their effectiveness in reducing mortality on juvenile $S$. purpuratus in the presence of crab predators. In conclusion, these results indicate that predation by crabs has the potential to play an important role in organizing intertidal benthic communities. However, different prey escape mechanisms, such as size and the utilization of spatial refuges are important ecological strategies that seem to promote sea urchin survival. 


\title{
The evolution of pedicellariae in echinoids: an arms race against pests and parasites [oral presentation]
}

\author{
Simon E. Coppard ${ }^{1}$, Andreas Kroh ${ }^{2} \&$ Andrew B. Smith ${ }^{3}$ \\ ${ }^{1}$ Smithsonian Tropical Research Institute, Balboa, Ancon, Republic of Panama \\ ${ }^{2}$ Naturhistorisches Museum Wien, Geologie \& Paläontologie, Burgring 7, 1010 Wien, Austria; \\ E-mail: andreas.krob@nhm-wien.ac.at \\ ${ }^{3}$ Natural History Museum, Palaeontology Department, Cromwell Road, London SW7 5BD, UK; \\ E-mail:a.smith@nhm.ac.uk
}

Keywords: Echinoidea, pedicellariae, post-Palaeozoic, evolution, phylogeny

Sea urchins have evolved a diverse array of jawed appendages termed pedicellariae to deter pests and predators. Pedicellarial structure and function is reviewed and their distribution mapped in 75 extant genera. Using a phylogeny of echinoids at family level constructed from 353 skeletal characters scored across 162 extant and fossil taxa, the evolution of pedicellarial form and function is reconstructed. For much of the Palaeozoic echinoids possessed a very restricted pedicellarial armament, and the establishment of a diverse array of pedicellarial types by the early Mesozoic implies that the threat from predators and pests markedly increased at this time. Since the Triassic, echinoids have continued to improve their defensive capability by evolving more effective venom delivery in globiferous pedicellariae, developing spatulate-tips and curved blades for a more efficient grab in tridentate pedicellariae, and stouter, more robust valves with a stronger bite in ophicephalous pedicellariae to disable and remove ectoparasites. However, pedicellarial types are shown to be particularly prone to subsequent secondary loss, especially amongst infaunal echinoids, and thus have higher homoplasy levels than other phylogenetically useful skeletal structures.

\section{Disorder in the Hox cluster as a generator of modularity [oral presentation]}

\section{Bruno David ${ }^{1} \&$ Rich Mooi $^{2}$}

${ }^{1}$ Biogéosciences (UMR CNRS 5561), Université de Bourgogne, 6, bd. Gabriel, 21000 Dijon, France; E-mail: bruno.david@u-bourgogne.fr

${ }^{2}$ California Academy of Sciences (IZ\&G), 55 Music Concourse Drive, San Francisco, CA 94118, USA

Keywords: Evolution, development, hox genes, antero-posterior axis, radial symmetry

The concept of modularity is widely used when describing organizational patterning of metazoans in a macroevolutionary framework. In echinoderms, which are 
radial close relatives of bilateral deuterostomes, modularity becomes particularly relevant. Recent sequencing of an entire echinoid genome revealed that its Hox cluster is disordered. Genes of the anterior class, usually located at the $3^{\prime}$ end of the cluster, are translocated in reverse order to the 5' end. This pattern seems unique among metazoans. Hox data and developmental evidence can be merged into a cohesive macroevolutionary model, shedding new light on the question of the orientation of the anteriorposterior $(\mathrm{A} / \mathrm{P})$ axis of echinoderms, a question that has been raised repeatedly, and is still under debate. There are two main parts in developing echinoderms. One incorporates somatocoels and develops in the nonrudiment region of the larva; the other incorporates the hydrocoel (water vascular system) and is derived from a rudiment that develops laterally on the larva. How can Hox disorder be integrated into this pattern? The most parsimonious interpretation is that it represents anatomical modularity paralleling the $\mathrm{A} / \mathrm{P}$ axis. First, a posterior somatocoelar module is formed. This is distinct from an anterior hydrocoelar module, which is formed later. The apparent disorganization of the cluster is the way by which echinoderms allow the expression of the most anterior genes after the posterior ones, in turn permitting dominant expression of the hydrocoelar over the somatocoelar module. This ensues from the downstream translocation of the anterior Hox class, and of the prevalence of the 5' end of the cluster. The macroevolutionary result is an apomorphic, dominant expression of the water vascular system and consequently of adult pentaradiality with concomitant obfuscation of the $\mathrm{A} / \mathrm{P}$ axis, even though the latter is more fundamentally and plesiomorphically bilaterian.

\title{
Spatangoid manipulation by bacterial symbionts: is the intestinal caecum an extended phenotype? [posterpresentation]
}

\author{
Chantal De Ridder ${ }^{1}$, Serge Gomes da Silva ${ }^{1} \&$ Bruno David ${ }^{2}$ \\ ${ }^{1}$ Marine Biology Laboratory, Université Libre de Bruxelles, Belgium; E-mail: cridder@ulb.ac.be \\ ${ }^{2}$ Biogéosciences (UMR CNRS 5561), Université de Bourgogne, Dijon, France; \\ E-mail: bruno.david@u-bourgogne.fr
}

Keywords: Echinoidea, symbiosis, extended phenotype, intestinal caecum

Durable interactions between species can lead to coevolution resulting in the adaptive emergence of new morphologies or behaviors triggered by the interacting species. In that context, the concept of 'extended phenotype' corresponds to cases in which the genotype of one partner interferes with the phenotype of the other partner.

Among spatangoids, several species harbor symbiotic bacteria in their hindgut. These bacteria typically form biofilms shaping spherical structures (nodules) that can be harvested in a more or less conspicuous pouch. According to species, 
hindgut pouches display several morphologies following a gradient, from a welldeveloped deep pouch (the intestinal caecum) to a slight bulging of the digestive wall. The work investigates the influence of mechanical properties of the hindgut regions on the settlement of the bacterial symbionts and on the subsequent development of an intestinal caecum. Results indicate that the intestinal caecum is a symbiotic organ that is directly related to the local accumulation of bacterial nodules at the junction between the intestine and rectum. We hypothesize that the caecum differentiation could be triggered by the bacterial symbionts, and that it could correspond to an extended phenotype, a possibility discussed on the poster.

\title{
Fine structure of bioluminescent areas in the ophiuroid Amphiura filiformis [oralpresentation]
}

\author{
Jérôme Delroisse ${ }^{1}$, Patrick Flammang ${ }^{1} \&$ Jérôme Mallefet ${ }^{2}$ \\ ${ }^{1}$ Marine Biology Laboratory, University of Mons, Belgium; E-mail: jerome.delroisse@umons.ac.be \& \\ patrick.flammang@umons.ac.be \\ ${ }^{2}$ Marine Biology Laboratory, University of Louvain-La-Neuve, Belgium; \\ E-mail:jerome.mallefet@uclouvain.be
}

Keywords: Ophiuroidea, brittle-stars, bioluminescence, ultrastructure, photocytes

Bioluminescence is present in at least thirteen phyla and in more than seven hundred identified genera of living organisms. Its implications in the biology of marine organisms are multiple and it is considered as the main source of light in deep marine ecosystems. It seems that bioluminescence appeared, at least, forty times in the evolution of organisms. In echinoderms, luminescent species are gathered predominantly in the class Ophiuroidea, which comprises more than 65 species able to emit light. In these organisms, the luminescence is always intrinsic and comes from specialized cells, the photocytes, which may have various localizations in the arms or the disc of the animal. The brittle-star Amphiura filiformis emits a blue light at the level of the arms when it is mechanically stimulated. The structure and accurate localization of the luminous areas are currently unknown in this species. The goal of this work was therefore to localize the light-emitting structures of $A$. filiformis and to describe their ultrastructure. At first, tests of bioluminescence with the aid of digital videography with intensification of brilliance and macrophotography were realized. No bioluminescence was observed at the level of the disc of the brittle-star. Most visible luminous areas are present at the tip of the dorsal spines of the brittle-star. The ultrastructure of photocytes and surrounding tissues was also considered and compared to that of Amphiura chiajei, a sympatric sister-species of A. filiformis which is not bioluminescent. Photocyte ultrastructure is studied during different stages of bioluminescence, i. e. before, during and after the emission of light. The obtained results are 
compared with data concerning photocytes of other luminous brittle-star species present in literature (Ophiopsila californica, Amphipholis squamata).

\title{
Living on the edge. Effects of a predicted future high-pCO $\mathrm{CO}_{2}$ level on the whole life cycle of two Nordic populations of the sea urchin Strongylocentrotus droebachiensis [poster presentation]
}

\author{
Narimane Dorey ${ }^{1}$, Mike S. Thorndyke ${ }^{2} \&$ Sam T. Dupont ${ }^{1}$ \\ ${ }^{1}$ Department of Marine Ecology, University of Gothenburg, Sweden; \\ E-mail:narimane.dorey@marecol.gu.se \&sam.dupont@marecol.gu.se \\ ${ }^{2}$ The Royal Swedish Academy of Sciences, Sweden; E-mail: mike.thorndyke@marecol.gu.se
}

Keywords: Ocean acidification, sea urchin, eco-physiology, development

By the end of the century, anthropogenic carbon dioxide emissions are expected to increase atmospheric $\mathrm{CO}_{2}$ partial pressure $\left(\not \mathrm{CO}_{2}\right)$ from todays $\sim 380 \mathrm{ppm}$ to 500 $1000 \mathrm{ppm}$. This higher $p \mathrm{CO}_{2}$ will lead to significant changes in seawater chemistry and cause a $\mathrm{pH}$ decrease of 0.3 to 0.5 units in surface waters (ocean acidification). In the last $150 \mathrm{yrs}$, the acidity of the oceans has already increased by $25 \%$ $(\sim 0.1 \mathrm{pH}$ unit). These changes are expected to have dramatic consequences for marine biota and especially for calcifying species. My project aims to understand these effects on the ecologically relevant green sea urchin Strongylocentrotus droebacbiensis. We are assessing the impacts of decreases in ocean $\mathrm{pH}$ alone and in synergy with other stressors (global warming, pollution) on the whole life cycle. In order to evaluate the consequences of predicted global changes on marine biota, combining ecophysiology with genetics, we focus on assessing $S$. droebachiensis plasticity, adaptation and resistance capacities in the face of predicted future conditions and provide new insights to the following questions: Can this species adapt or acclimate to future conditions? Is it able to survive in predicted conditions? Can selection take place over a few generations? What are the costs of resistance capacities? We analyze the effects on various key biological processes over the whole life cycle - with special emphasis on reproduction and larval development, both of which are suggested bottlenecks - and compare responses between two contrasting Nordic populations experiencing different environmental conditions. 
Echinoderm ossicles as a tool in palaeoenvironmental reconstructions: a taphonomic analysis of shallow water carbonates at Fernandez Bay, San Salvador, Bahamas [oral presentation]

\author{
Janina Dynowski ${ }^{1,2}$ \\ 'Staatliches Museum für Naturkunde Stuttgart, Germany; E-mail: janina.dynowski@smns-bw.de \\ ${ }^{2}$ Institut für Geowissenschaften, Universität Tübingen, Germany
}

Keywords: Echinodermata, taphonomy, carbonates, Holocene, Bahamas

A taphonomic study of echinoderm remains in the sand size fraction of tropical shallow water carbonates was conducted in order to find possible correlations between depositional environments, preservation potential, and taphonomic signatures of echinoderm ossicles. A total of 15 sediment bulk samples representing five different environments were collected at Fernandez Bay, San Salvador, Bahamas. Analyzed environments include: (1) intertidal beach rock near the shore, (2) subtidal bedrock overgrown by an algal turf, (3) subtidal Sargassum meadow, (4) subtidal loose sand without vegetation, and (5) subtidal patch reef. The sediment samples were dry sieved, separated into $125-250 \mu \mathrm{m}, 250-500 \mu \mathrm{m}$ and 500-1000 $\mu \mathrm{m}$ fractions, and analyzed using light microscopy. 50 echinoderm elements/fragments were randomly sampled from each fraction. Each specimen was identified and classified into three grades of taphonomic alteration for fragmentation, encrustation, bioerosion, abrasion and color preservation. The distribution and taphonomic signature of echinoid, asteroid, ophiuroid, crinoid and holothuroid remains were analyzed using exploratory data analyses. The results show a significant difference in element distribution between the different environments, but no clear separation between the analyzed size fractions. In all environments echinoid spines are the most abundant elements, the second most common elements are ophiuroid ossicles. Asteroid, holothuroid and crinoid ossicles are rare in all environments, the latter occurring only in the patch reef samples. The biologically mediated taphonomic alteration (encrustation and bioerosion) is rare in the sand-sized fraction of echinoderm remains, whereas fragmentation and abrasion show significant variations between the environments. These two taphonomic traits separate the sampled environments, with the highest fragmentation and abrasion levels observed in the intertidal beach rock environment. Local carbonate subenvironments can be differentiated and characterized based on sand-sized echinoderm bioclasts. 


\section{Application of Particle Image Velocimetry and Computational Fluid Dynamics to investigate filter feeding mechanisms of crinoids pposter presentation]}

Janina Dynowski ${ }^{1,2}$, Adrian Klein ${ }^{3}$, James H. Nebelsick ${ }^{2}$ \& Anita RothNebelsick $^{1}$

'Staatliches Museum für Naturkunde Stuttgart, Germany; E-mail: janina.dynowski@smns-bw.de \& anita.rothnebelsick@smns-bw.de

${ }^{2}$ Institut für Geowissenschaften, Universität Tübingen, Germany; E-mail: nebelsick@uni-tuebingen.de

${ }^{3}$ Institut für Zoologie, Universität Bonn, Germany; E-mail: adrian@uni-bonn.de

Keywords: Crinoidea, passive suspension feeding, Computational Fluid Dynamics (CFD), Particle Image Velocimetry (PIV)

Crinoids are passive suspension feeding organisms creating a three dimensional filter with their arms to capture food particles out of the water. Recent stalked crinoids open their arms in a parabolic filtration fan with the oral surface orienting down current. The arms recurve into the current by up to $270^{\circ}$. Some fossil representatives were not as flexible as living forms and were probably not able to bend their arms to such a large extent. In the present project, different filtering morphologies from extinct and extant stalked crinoids are compared including in a first attempt Encrinus liliiformis from the middle Triassic Muschelkalk of Germany, and recent Hyocrinus sp. Flume experiments with synthetic models of the crinoids are performed using Particle Image Velocimetry (PIV) at the Institut für Zoologie, Universität Bonn, Abteilung für Vergleichende Sinnes- und Neurobiologie. In addition filter feeding mechanisms, efficiency and fluid mechanical attributes are determined using Computational Fluid Dynamics (CFD) with the program package ANSYS ${ }^{\circledR}$ Academic Research, Release 12.1. The studies include different setups of filter positions as well as different current velocities. The results can be used to reconstruct feeding positions of fossil crinoids and to make assumptions about palaeoenvironmental conditions including current regime and concentration of available plankton particles. Furthermore the analysis of filter feeding mechanisms allows conclusions to be drawn concerning the performance of different filter architecttures to find simple and effective designs that may be interesting for industrial uses. First results of the CFD simulations of the global circulation of Encrinus liliiformis with an initial current velocity of $14.0,16.5$ and $21.5 \mathrm{~cm} / \mathrm{s}$ under stationnary conditions assuming laminar flow support the results of flume experiments, where a back flow of water into the crown could be recognized. Future simulations include the modeling of current flow patterns around the smaller features of the crinoids' arms, the pinnules covered with triads of tube feet. 


\title{
From vicariance to sympatry: history and genetic structure of a species complex Echinocardium cordatum (Loveniidae, Spatangoida) [oral presentation]
}

\author{
Emilie Egea, Jean Pierre Féral \& Anne Chenuil \\ UMR6540-DIMAR, Centre d'Océanologie de Marseille, Université Aix-Marseille II, France; E-mail: \\ egea@univmed.fr
}

Keywords: Echinoidea, biodiversity, cryptic species, biogeography, population differentiation

Species with long living planktotrophic larvae are expected to display shallow genetic structure around their geographical range. Echinocardium cordatum (Loveniidae, Spatangoida) is a burrowing species, presenting an antitropical distribution, and is registered on most of the temperate coastlines except American ones. Its planktotrophic larvae remains in the water column about three weeks before undergoing metamorphosis, conferring the species a high dispersal potential. Sometimes reaching very high abundance and presenting a high burrowing activity, E. cordatum is a key benthic species studied since the $19^{\text {th }}$ century. Nevertheless its diversity seems to have been underestimated, and genetic analyses revealed that it is a complex of at least five cryptic species living in sympatry or allopatry around the world. Mitochondrial 16S and CO1 sequences strongly support that clade appearance seems to have been greatly driven by the paleontological history of the Mediterranean Sea. Analyses of the test morphology coupled with genetic studies highlighted statistical differences between the different cryptic species, but to date, no diagnostic character permits to distinguish one from another. Comparison of the cryptic species reproductive cycles confirmed global constancy even if slight differences could be suggested. Though displaying high dispersion potential, E. cordatum cryptic species present strong genetic structure at the population level, and fast evolving nuclear markers revealed high genetic diversity and differentiation of populations separated by only a few kilometers.

E. cordatum cryptic species complex raised important questions on the appearance and maintainability of such a genetic diversity contrasting with its very low morphological or ecological diversity. The presence of a complex of cryptic species and the genetic differentiation of close populations within the cryptic species contrast with the high dispersal potential of the larvae. Even though major geographical events may have played an important role in the establishment of the different cryptic species, reproductive isolation should be a very dynamic process in these taxa, permitting to maintain genetic isolation between syntopic populations. The study of the Bindin gene should help to disentangle the influence of purely demographic events from the evolutionary ones in the establishment and maintenance of the observed pattern. 


\title{
Exploring the proteome of an echinoderm nervous system: 2-DE of the sea star radial nerve cord and the synaptosomal membranes subproteome [oral presentation]
}

\author{
Catarina Ferraz Franco ${ }^{1}$, Romana Santos 2 \& Ana Varela Coelho ${ }^{3}$ \\ ${ }^{1}$ Instituto de Tecnologia Química e Biológica, Universidade Nova de Lisboa Oeiras, Portugal; E-mail: \\ cfranco@itqb.unl.pt \\ ${ }^{2}$ Instituto de Tecnologia Química e Biológica, Universidade Nova de Lisboa, Oeiras, Portugal; Unidade de \\ Investigação em Ciências Orais e Biomédicas, Faculdade de Medicina Dentária, Universidade de Lisboa, \\ Portugal; E-mail:rsantos@itqb.unl.pt \\ ${ }^{3}$ Instituto de Tecnologia Quimica e Biológica, Universidade Nova de Lisboa, Oeiras, Portugal; \\ E-mail:varela@itqb.unl.pt
}

Keywords: Asteroidea, Echinoidea, radial nerve cord, synaptosomal membrane, proteomics, 2-D electrophoresis, MALDI-TOF/TOF

Up to date studies on echinoderms nervous systems have focused mainly on the essential neuroanatomy of sea stars radial nerve cord using several methods such as histology, ultrastructure and immunohistochemistry with antibodies against specific neurotransmitters and regulatory peptides. However, there is still a lack of studies providing large-scale identification of proteins involved in the molecular neuroarchitecture of the sea star nervous system.

Here we describe the first proteomic characterization of the radial nerve cord of an echinoderm, the sea star Marthasterias glacialis. The combination of twodimensional polyacrylamide gel electrophoresis (2-DE) with mass spectrometry (MALDI-TOF/TOF) resulted in the identification of 247 proteins in the radial nerve cord.

Furthermore, a nerve subcellular fractionation was performed to obtain a synaptosomal enriched fraction in order to study low abundant proteins. This resulted in the identification of 100 additional proteins in the synaptosomal membranes enriched fraction after 1-DE separation.

Altogether the identified proteins constitute the first high throughput evidence that seem to indicate that echinoderms nervous transmission relies primarily on chemical synapses similarity to the synaptic activity in adult mammal's spinal cord since evidences of membrane potentials generated by $\mathrm{K}^{+}$; $\mathrm{Ca}^{2+}$ and $\mathrm{Na}^{+}$permeability were found. Additionally, several homologous proteins known to participate in the regeneration events of other organisms were also identified as well as several proteins involved in neurogenesis with functions of axonal guidance, dentrite morphogenesis and neuron growth. Finally, several proteins responsible for sensory perception were also found to be present in sea stars radial nerve cord.

These results are of extreme importance, validating several predicted genes of the sequenced purple sea urchin Strongylocentrotus purpuratus, confirming of the expression of the corresponding proteins. Moreover, they can be used as a starting point to future studies on neurology and organ regeneration and also to elucidate 
the role of this organism as a model animal, as the given results reveal a extensive homology between the echinoderm nervous system and the dorsal nerve cord of chordates.

\section{Differential proteomics reveal a $\mathrm{Ca}^{2+}$-dependent proteolytic system activation in the sea star wound healing events and early stages of arm regeneration [poster presentation]}

Catarina Ferraz Franco ${ }^{1}$, Romana Santos $^{2} \&$ Ana Varela Coelho ${ }^{3}$

${ }^{1}$ Instituto de Tecnologia Química e Biológica, Universidade Nova de Lisboa Oeiras, Portugal; E-mail: cfranco@itqb.unl.pt

${ }^{2}$ Instituto de Tecnologia Química e Biológica, Universidade Nova de Lisboa, Oeiras, Portugal; Unidade de Investigação em Ciências Orais e Biomédicas, Faculdade de Medicina Dentária, Universidade de Lisboa, Portugal; E-mail:rsantos@itqb.unl.pt

${ }^{3}$ Instituto de Tecnologia Química e Biológica, Universidade Nova de Lisboa, Oeiras, Portugal; E-mail:varela@itqb.unl.pt

Keywords: Asteroidea, radial nerve cord, differential proteomics, wound healing, protein degradation, calpain activation

Thanks to their spectacular regenerative capabilities, echinoderms were recently considered as important models to explore the basic mechanisms of the regeneration phenomenon and its molecular aspects. The common sea star species Marthasterias glacialis, a close relative of Asterias rubens, is also capable of survival and complete regeneration if up to one fifth of the central body remains attached to an arm and for this reason it was selected as a model echinoderm to study the regeneration events of the radial nerve cord. Sea stars were collected at low tide and subsequently divided in 4 experimental groups: 2 regenerating and 2 control groups. According to our previous experience and data presented in the literature, $48 \mathrm{~h}$ and 13 days post arm tip ablation were selected in order to study 2 different phases: wound healing and tissue re-growth.

In order to find protein candidates actively involved in these two events of sea star radial nerve cord regeneration, the experimental approach of 2-D Fluorescence Difference Gel Electrophoresis (2D-DIGE) was employed. Nerve cord proteins that showed a differential expression pattern between the control groups and the wounded groups were selected and identified.

Several calpain-preferred substracts (i. e. $\alpha$-spectrin) were identified as proteolytic products indicating that an activation of this calcium dependent protease is most likely to be occurring at the selected time point of arm regeneration. It has been described for several invertebrate/vertebrate models that protein degradation mediated by calpain activation is required for recreation of the axon growth cone and axon regeneration after injury. Therefore, to our knowledge this study presents 
the first evidence that this specific protein degradation has also a main role in the early events of echinoderm nerve cord regeneration.

\section{Taxonomy of Ophiambix, an aberrant genus of the subfamily Ophiurinae [posterpresentation]}

Toshihiko Fujita $^{1}$ Seiichi Irimura ${ }^{2} \&$ Katsunori Fujikura ${ }^{3}$

${ }^{1}$ National Museum of Nature and Science, Tokyo, Japan; E-mail:füjita@kabaku.go.jp

${ }^{2}$ Setagaya-ku, Tokyo, Japan

${ }^{3} J a p a n$ Agency for Marine-Earth Science and Tecbnology, Yokosuka, Japan

Keywords: Ophiuroidea, taxonomy, SEM, internal ossicles, second oral tentacle pore

The genus Opbiambix has very unique morphological characteristics puzzling ophiuroid taxonomists, and has been placed in three different families, Amphiuridae, Ophiacanthidae and Ophiuridae. Currently, Ophiambix belongs to the subfamily Ophiurinae of Ophiuridae. However, Ophiambix is different from the other genera of this subfamily in many morphological characteristics. Based on newly collected material from the waters around deep-sea hydrothermal vent/methane seep areas in southwestern Japan, detailed morphological observation of Ophiambix was carried out mainly by using scannning electron microscopy to clarify the taxonomic status of Ophiambix. Ophiambix has 4 nominal species currently, and the present specimens are probably an undescribed species. Position of the second oral tentacle pores, characteristics of the articulation between radial shields and genital plates, and the jaw structure, have been considered important for taxonomic decisions. The second oral tentalcle pores opened completely outside proximal to the adoral plates. The articulations between radial shields and genital plates were not a typical 'pit and two condyle' articulation found widely in Ophiurinae. The oral plates were similar to those of the other Ophiurinae species in shape. The dental plates were small and positioned at the oralmost part of proximal surface of the jaw. They were undivided and circular without socket. The teeth of Ophiambix were, however, lamella-like and completely different from the other ophiuroids. Moreover, the articulation of vertebrae was hourglass-shaped, and many small imbricated scales were present on the dorsal side of arms instead of single series of dorsal arm plates. Those suggest that Ophiambix does not fit to Ophiurinae. Systematic position of Ophiamibix should be considered again. 


\section{Phylogeny of the football stars - asteroids pretending to be echinoids [oral presentation]}

\section{Andy Gale}

School of Earth and Environmental Sciences, University of Portsmouth, Burnaby Building, Burnaby Road, Portsmouth, PO1 3QL, UK; E-mail: andy.gale@port.ac.uk.

Keywords: Asteroidea, Sphaerasterida, phylogeny

The Sphaerasterida are a highly derived clade of asteroids, which have a spherical to subspherical morphology, resembling an echinoid test, and a long and intimate association with siliceous sponges. They are best known from the living genus Podosphaeraster (which closely resembles a tiny football), of which the six known species have a worldwide distribution. The relatively few, large, abactinal-marginalactinal ossicles are undifferentiated and form a tesselation of thin plates, notched at the margins for papulae. It has been argued that the sphaerasterids comprise forms which have independantly evolved spherical to subspherical morphologies. However, the monophyly of the Sphaerasterida has been established from numerous skeletal characters, most notably those of the mouth frame, ambulacral groove and the primary abactinal ossicles. The sister taxon to the group is the Triassic-Paleocene family Stauranderasteridae, a relatively uncommon, dominantly Cretaceous clade. The Sphaerasterida diversified during the early Jurassic and seven genera are found in Pliensbachian to Kimmeridgian sediments, of which four are new. These include tiny, highly ornate forms, the size of a large pea $(<1 \mathrm{~cm})$, and large $(10 \mathrm{~cm}$ diameter), highly spinose hemispherical taxa which superficially resemble regular echinoids. Jurassic Sphaerasterida are exclusively found in association with sponge reefs, or material derived from them, and they evidently adapted to the habit of living amongst and inside sponges. Only a single genus, $V$ alettaster, survived through from the Jurassic, and is commonly found in Cretaceous and Paleocene Chalks. Valettaster is sister taxon to Podosphaeraster, and together they form the most derived clade (Podosphaerasteridae) within the Sphaerasterida. Very little is known about the biology of Podosphaeraster. The spherical body form serves to maximise internal volume, and presumably provides space for large gonads.

\section{Marsupites testudinarius (von Schlotheim, 1820) in the Aleg Formation around Gafsa, Central Tunisia [posterpresentation]}

Jaume Gallemí ${ }^{1}$ \& Hassen Abdallah ${ }^{2}$

${ }^{1}$ Musen de Geologia de Barcelona-MCNB, Institut de Cultura de Barcelona, Barcelona, Spain; E-mail: jaume.gallemi@uab.cat

${ }^{2}$ Laboratoire de Géoenérgie, Technopole de Borj Cédria, B. P. 95, Hamman-Lif, 2050 Tunis, Tunisia; E-mail: Hassen.Abdallah@inrst.mrt.tn 
Keywords: Crinoidea, Marsupites, Upper Cretaceous, central Tunisia, biostratigraphy

A single thin shallow-marine limestones level in the Middle Alternances Member of the Aleg Formation at Sidi Bou Helel section (Northern Range of the Chotts) has yielded several specimens of the benthic crinoid Marsupites testudinarius.

The occurrence of the species encouraged a still more accurate sampling across this part of the section but no other levels furnished new individuals or remains of M. testudinarius. This fact precludes that the presence of $M$. testudinarius at Sidi Bou Helel section represents an event-bed.

Equivalent levels of the Aleg Formation around Gafsa have been sampled in other sections as Jabal Morra (Northern Range of the Chotts) or Jabal Berda (SE of Gafsa), but no further remains of $M$. testudinarius have been found.

The range of Marsupites testudinarius has been classically taken as its homonymous biozone, allowing the recognition of the uppermost Santonian. In fact two successive species of genus Marsupites occur in this biozone: Marsupites laevigatus Forbes, 1850 (having folded calyx plates) at the base and M. testudinarius (with radially-ornamented calyx plates) occurring higher up in the biozone and reaching its top. The calyx plates of the Sidi Bou Helel section specimens bear a radial ornamentation pattern.

Significant ammonoids have not been recorded in this part of the Sidi Bou Helel section but $3.6 \mathrm{~m}$ below the level with $M$. testudinarius inoceramids representative of the Upper Santonian Cordiceramus muelleri Biozone have been identified. Inoceramids of the lower Middle Campanian Cataceramus subcompressus Biozone occur $39 \mathrm{~m}$ over the $M$. testudinarius level.

$M$. testudinarius had been previously identified in southern and northeastern England, France, Germany, Poland, Kazakhstan, Turkmenistan, India, Madagascar, Algeria, the Gulf Coast and Western Interior (USA, Canada) and Australia. This worldwide distribution, together with the stratigraphic position of its biozone led the 1995 Brussels meeting on Cretaceous Stage boundaries to provisionally recommend the last occurrence of $M$. testudinarius as the boundary-marker for the base of the Campanian.

The $M$. testudinarius specimens from Sidi Bou Helel section represent the first record of this benthic crinoid in Tunisia and the second in continental Africa after that from Tilatou, a village south of Batna (Algeria).

\section{Echinoid species distribution in the Upper Cretaceous of the Gafsa region, Central Tunisia [oralpresentation]}

Jaume Gallemí ${ }^{1}$ \& Hassen Abdallah ${ }^{2}$

\footnotetext{
${ }^{1}$ Musen de Geologia de Barcelona-MCNB, Institut de Cultura de Barcelona, Barcelona, Spain; E-mail: jaume.gallemi@uab.cat

${ }^{2}$ Laboratoire de Géoenérgie, Technopole de Borj Cédria, B. P. 95, Hamman-Lif, 2050 Tunis, Tunisia; E-mail: Hassen.Abdallab@inrst.mrt.tn
} 
Keywords: Echinoidea, Upper Cretaceous, Gafsa region, central Tunisia, biostratigraphy

The distribution of macrofossils in selected Upper Cretaceous stratigraphic sections near Gafsa (Sidi Bou Helel, Jabal Morra, Jabal Zitouna, Jabal El Askar, and Jabal Batoum, in the Northern Chain of the Chotts, Jabal Berda and Jabal Chemsi, SE of Gafsa, and Jabal Ben Younès, NW of Gafsa), comprising the upper alternances of the Zebbag sensu stricto Formation and the Bahloul, Gattar, Aleg and Berda formations, indicates a rich and diversified Cenomanian to Maastrichtian echinoid record.

(1) Zebbag ss Formation: Heterodiadema lybicum (Desor), Tetragramma variolare (Brongniart), Coenholectypus chauveneti (Péron et Gauthier), C. excisus (Desor), Claviaster cornutus (Agassiz), Nucleolites angustior (Gauthier), Heteraster mattaneri Devriès, H. tissoti Coquand, Mecaster batnensis (Coquand) and $M$. pseudofourneli (Péron \& Gauthier). (2)Bahloul Formation: Mecaster batnensis (Coquand) and M. pseudofourneli (Péron \& Gauthier). (3) Gattar Formation: no echinoids have been found. (4) Aleg Formation (Biréno Member): Phymosoma delamarrei (Deshayes), P. tamarinense (Péron \& Gauthier), P. maresi (Cotteau), Codiopsis (Codiopsis) elissae Thomas \& Gauthier, Goniopygus peroni Thomas \& Gauthier, G. royanus d'Archiac, Orthopsis miliaris (d'Archiac), Coenholectypus serialis (Deshayes), C. turonensis (Desor), Nucleolites pseudominimus (Péron \& Gauthier), Parapygus cassiduloides Thomas \& Gauthier, Petalobrissus (Petalobrissus) djelfensis (Gauthier), P. (P.) julieni (Coquand), P. (P.) rimula (Thomas \& Gauthier), Parapygus trigonopygus (Cotteau), Mecaster consobrinus (Péron \& Gauthier), M. fourneli (Deshayes) and Linthia durandi Péron \& Gauthier. Aleg Formation (Middle Alternances): Phymosoma maresi (Cotteau), Parapygus cassiduloides Thomas \& Gauthier, Petalobrissus (Petalobrissus) djelfensis (Gauthier) and Parapygus trigonopygus (Cotteau). Aleg Formation (Upper Clays Member): Hemipneustes africanus (Deshayes), Mecaster brossardi (Coquand), $M$. gr. fourneli (Deshayes) and $M$. superbissimus (Coquand). (5) Berda Formation: cidaroid remains, Salenia nutrix Péron \& Gauthier, Phymosoma sanctiarromani (Thomas \& Gauthier), Orthopsis miliaris (d'Archiac), Coenholectypus subcrassus (Péron \& Gauthier), Globator bleicheri (Gauthier), Nucleopygus meslei (Péron \& Gauthier), Parapygus cassiduloides Thomas \& Gauthier, Petalobrissus (P.) setifensis (Cotteau), P. (P.) subsitifensis (Péron \& Gauthier), Stigmatopygus linguiformis (Péron \& Gauthier), Gitolampas zuffardii Checchia-Rispoli, Hemipneustes africanus (Deshayes), $H$. delettrei Coquand, Hemiaster (Bolbaster) auberti Thomas \& Gauthier, Mecaster gr. fourneli (Deshayes), Linthia payeni (Coquand) and Heterolampas maresi Cotteau.

The chronostratigraphy of several of these echinoid species can be accurately related to the biozones defined by the ammonites and inoceramids with which they co-occur. 


\title{
Middle Jurassic (Bajocian) echinoids of the Bucegi Mountains (Eastern Carpathians, Romania) [poster presentation]
}

\author{
Jaume Gallemí ${ }^{1}$ \& Iuliana Lazăr ${ }^{2}$ \\ ${ }^{1}$ Musen de Geologia de Barcelona-MCNB, Institut de Cultura de Barcelona, Barcelona, Spain; E-mail: \\ jaume.gallemi@uab.cat \\ ${ }^{2}$ Department of Geology and Palaeontology, Faculty of Geology and Geophysics, University of Bucharest, \\ Bucharest, Romania; E-mail:iuliana.lazar@g.unibuc.ro
}

Keywords: Echinoidea, Middle Jurassic, Bajocian, Bucegi Mts., eastern Carpathians, Romania

The Middle Jurassic deposits along the western side of the Bucegi Mountains (located in southern extremity of the East Carpathians) are distinguished by the richness of their fauna. The most complete succession of Middle and Upper Jurassic deposits occur in the area Strunga Pass-Strungulița Pass-Obârşia Văii Tătarului, confined northwards by the Strunga Pass and southwards by the Tataru Valley. Many of the macrofaunal assemblages from this area, dominated by bivalves, also contain other groups such as corals, gastropods, nautiloids, belemnites, serpulids, arthropods, bryozoans, crinoids, echinoids and fish teeth; these groups both show a reduced diversity and are represented by few specimens.

After the extensive field work campaigns accomplished by Lazăr (1994-2000) in this area, only few well-preserved echinoid specimens have been recovered. The specimens were collected at a section in the area of Pasul Strungulița-Vârful Tătarul-Obârşia Văii Tătarului where a 6 meter level of grey calcareous sandstones alternating with biocalcarenites, separated by centimetric joints of pelites and siltites, provided a rich fauna of molluscs, rare colonial corals and brachiopods, and the echinoids. These levels, formerly known as 'upper lumachellic level' and reputed as representative of the parkinsoni Zone, are considered to represent the uppermost part of a Lower to Middle Bajocian succession, the Strungulița Member of the Strunga Formation.

The recorded echinoids have been identified as Stomechinus longuemari Cotteau, 1867 and Pygaster semisulcatus (Phillips, 1829). S. longuemari was erected for a single specimen coming from the surroundings of Poitiers (Vienne, France), attributed to Bajocian and including Cotteau's indication 'Very rare'. The holotype (former Longuemar collection) is probably kept in the Université de Poitiers (France) palaeontological collections. This species, never quoted anywhere else is mentioned in Romania for the first time.

P. semisulcatus syntypes come from the Coralline Oolite (Oxfordian, plicatilis Zone) of Malton and Scarborough in North Yorkshire and from unspecified locations in Wiltshire (United Kingdom). It is also known from the Bajocian, Upper Bathonian, Lower, Middle and Upper Callovian, Middle and Upper Oxfordian and Lower Kimmeridgian of several localities in France. This is the first record in the Carpathians. 
Patterns of echinoderm colonization on artificial collectors: the effect of substrate complexity across subtidal habitats on Gran Canaria, Canary Islands [posterpresentation]

Sara García-Sanz ${ }^{1}$, Fernando Tuya ${ }^{1}$, Carlos Angulo-Preckler ${ }^{2}$ \& Ricardo Haroun $^{1}$

${ }^{1}$ Centro de Biodiversidad y Gestión Ambiental (BIOGES), Universidad de Las Palmas de Gran Canaria (ULPGC), 35017 Las Palmas de Gran Canaria, Canary Islands, Spain; E-mail: sarags81@yahoo.es

${ }^{2}$ Barcelona, Spain

Keywords: Echinodermata, colonization, settlement, recruitment, artifical collectors, habitats, Canary Islands

Any benthic subtidal habitat can be colonized by organisms from the water column and those migrating from adjacent habitats. Artificial collectors provided quantitative samples of patterns of echinoderms colonization. We developed three types of collectors: Artificial Seagrass Unit (ASU) and Cushion-shaped Artificial Seagrass unit (CAS) with buoyant plastic artificial seagrass (green plastic raffia, $35 \mathrm{~cm}$ long by $10 \mathrm{~mm}$ wide strips) and Cushion-shaped Unit (CU) without it. In two localities, four collectors of each type were placed in each of the four habitats (urchin-grazed barrens, sandy patches, macroalgal canopies and seagrasses). After a moon cycle, each collector was removed by divers from 5-7 days after the new moon in a cloth bag ( $\leq 0.5 \mathrm{~mm}$ diameter holes). Greater abundances of postlarvae of Opbioderma and Paracentrotus were collected from the most complex collectors, CAS and ASU with not significant differences ( $\mathrm{p}$-value $=0.8289)$. Sandy patches showed greater abundance than urchin-grazed barrens, macroalgal canopies and seagrasses, with significant differences $(\mathrm{p}=0.01, \mathrm{p}=0.01$ and $\mathrm{p}=0.04$ respectively). CAS collector was used to evaluate six moon cycles in the four subtidal habitats simultaneously. We observe a colonization peak for Ophioderma and Paracentrotus during spring-early summer well defined in the four subtidal habitats. Arbacia lixula, Coscinasterias tenuispina and Holothuria arguinensis showed very low abundance, but the colonization of new settlers was generally higher in macroalgal canopies. Ophioderma longicaudum and Paracentrotus lividus showed a higher abundance in sandy patches.

\section{Micro/nanostructural and biogeochemical features of the stereom of extant and fossil stalked crinoids [oral presentation]}

Przemysław Gorzelak ${ }^{1}$, Jarosław Stolarski ${ }^{1}$, Maciej Mazur ${ }^{2}$, Anders Meibom ${ }^{3}$, Yves Marrocchi ${ }^{3}$ \& Emilie Chalmin ${ }^{4}$

${ }^{1}$ Institute of Paleobiology, Polish Academy of Sciences, Warsaw, Poland;

E-mail:pgorzelak@twarda.pan.pl\&stolacy@twarda.pan.pl 
${ }^{2}$ Department of Chemistry, Laboratory of Electrochemistry, University of W arsaw, $W$ arsaw, Poland; E-mail:mmazur@,chem.uw.edu.pl

${ }^{3}$ Muséum National d'Histoire Naturelle, Laboratoire d'Etude de la Matiere Extraterrestre, Paris, France; E-mail:meibom@mnhn.fr \& marrocchi@mnhn.fr

${ }^{4}$ EDYTEM, UMR 5204, Université de Savoie / CNRS, Le Bourget du Lac, France; E-mail: emilie.chalmin-aljanabi@univ-savoie.fr

Keywords: Crinoidea, stereom structure, biomineralization, vital effect

An echinoderm ossicle consists of a three-dimensional meshwork of mineral trabeculae (stereom) that forms within the syncytial membrane through precisely orchestrated biomineralization processes. Individual ossicle behaves as a single calcite crystal in X-ray diffraction and polarizing microscopy; however, its physicochemical properties differ significantly from the properties of geologic or synthetic calcite. In order to determine which factors (environmental or biological) control the stereom formation, here, we report results of micro/nanostructural and biogeochemical analyses of the skeleton of extant and fossil stalked crinoids. Microscopic (AFM, FESEM) observations show that the crinoid skeleton is composed of nanograins of about $20-100 \mathrm{~nm}$ in size separated from each other by organic layers of a few nanometers. Geochemical analyses (NanoSims, EDS, Finnigan MAT Delta plus mass-spectrometer) reveal that significant variations in $\mathrm{Mg}^{2+}$ and light stable isotopes $\left(\delta^{13} \mathrm{C}\right.$ and $\left.\delta^{18} \mathrm{O}\right)$ occur at different length scales: within a single stereom trabeculae, within a single ossicle, within a skeleton of a single animal, at higher taxonomic levels. Fine scale geochemical mappings of crinoid ossicle (NanoSims microprobe) combined with in situ synchrotron sulphur K-edge x-ray absorption near edge structure spectroscopy (XANES) show that the high $\mathrm{Mg}^{2+}$ concentration in the central region of stereom bars coincides with the distribution of sulphated polysaccharides. This correspondence suggests involvement of sulphated polysaccharides in the crinoid biomineralization process. These data suggest that physiological factors play an important role in the formation of the crinoid skeleton and that great care should be taken in the use of their skeletons as (paleo)environmental proxies.

\section{Mitrates (Echinodermata, Stylophora) from the Middle Devonian of the eastern Rheinisches Schiefergebirge (Rhenish Massif) - inferences on the stylophoran life mode [oral presentation]}

\section{Reimund Haude}

Georg-August-Universität Göttingen, Abt. Geobiologie, Goldschmidtstr. 3, D-37077 Göttingen, Germany; E-mail: rhaude@gwdg.de

Keywords: Stylophora, hydraulic interpretation, Middle Devonian, Germany 
Documentation of Late Emsian through Early Givetian mitrates (Stylophora) in the eastern Rheinisches Schiefergebirge fills large informational gaps within some of their clades. Stylophorans are non-pentamerous, primitively asymmetric echinoderms with a depressed theca and an articulated flexible appendage. The biological interpretation and phylogenetic position of stylophorans is highly controversial depending on the orientation of the theca (with inferred soft body anatomy).

The new mitrates represent 3 to 5 new species belonging to 3 genera ( 2 of them new) within the suborders Mitrocystitida and Peltocystida: 3 rather complete specimens of 2 species of the anomalocystitid Rhenocystis in Late Emsian and Middle Eifelian siltstones; many almost complete but tectonized specimens of a monospecific form similar to the kirkocystid 'Mitrocystites' styloideus in Late Emsian and Early Eifelian silty shales, as well as few specimens representing 1 or 2 new kirkocystid species in the Late Eifelian and Early Givetian.

Besides the morphological documentation of these fossils a general discussion on the biological organisation of stylophorans is included. The two more generally accepted interpretations have only in common the ventral/dorsal orientation and some subvective functions of the appendage. They differ completely, however, in explaining the appendage as a biologically anterior resp. posterior structure. This has significant anatomical consequences: (1) In an anterior position the appendage represents a feeding arm (aulacophore) containing a hydrocoelic canal; (2) in a posterior position it represents a stele with a metacoelic canal.

Since the early seventies, anagenetic evolutionary reconstructions based on hydraulic mechanics of the soft body explain echinoderms to have been phylogenetically derived from primitive chordates via hemichordates. This has quite recently been confirmed by molecular studies. Thus, the possible persistence of (chordate-derived) branchial structures can be expected in non-pentameric branches of early echinoderms. Serial openings in some stylophorans, therefore, are interpreted as gill slits of a branchial basket similar to that in chordate-derived tunicates. Hence, stylophorans have informally been called 'branchio echinoderms'.

Anagenetic interpretation of the appendage as an arm-like feeding device (aulacophore) is highly supported by the fundamental 'ocular plate rule' of ambulacral growth, i. e., it is related to the 'axial' (mesocoelic) part of the body. On the other hand, a metasomic origin of stylophoran appendage based on similarities with the (metasomic) stele of solutes (Homoiostelea) can easily be excluded on morphogenetic grounds.

\section{Ophiuroids in the Lower Devonian of the Argentine Precordillera [poster presentation]}

\section{Reimund Haude}

Georg-August-Universität Göttingen, Abt. Geobiologie, Goldschmidtstr. 3, D-37077 Göttingen, Germany; E-mail: rhaude@gwdg.de 
Keywords: Ophiuroidea, Lower Devonian, Precordillera, Argentina

Ophiuroids from the Lower Devonian Talacasto Formation of the Argentine Precordillera show high taxonomic diversity quite similar to that known from the palaeogeographically adjacent Karroo-system of South Africa. In 1894, a Ph.D student of geology from Göttingen, Wilhelm ('Guillermo') Bodenbender, first discovered specimens, which were described by Ruedemann as Argentinaster bodenbenderi and Encrinaster yachalensis. Later, Furcaster separatus and a protasterid were found associated with these species. More recent research in the Talacasto Formation revealed a variety of ophiuroid taxa. Hence, the Lower Devonian ophiuroid fauna of the Precordillera is represented by mostly monospecific families: an eophiuroid (new species from 3 localities), a cheiropterasterid (new species from 1 locality), an encrinasterid (few specimens from 2 localities), a protasterid (arm of a new species), a furcasterid (Furcaster separatus, from 1 locality), an eospondylid (new species from 3 localities), and three ophiurinids (Argentinaster bodenbenderi, from several localities; a new species from 3 localities; a piece of arm of a new genus). Most ophiuroids occur in obrution lagerstaetten indicating palaeoenvironments, which reach from more proximal positions above to more distal positions below average storm wave base within a siliciclastic shelf depositional system. They are generally associated with other echinoderms, mostly with crinoids such as Acanthocrinus, Apurocrinus, or Pterinocrinus. Argentinaster proves to be an appropriate generic name since it is highly typical for the region and represented by juvenile and adult individuals occurring in about 3 different sedimentary levels over more than $10 \mathrm{~km}$.

\section{Virtual excursion to the Liassic holothurian park of Göttingen [oral presentation] \\ Reimund Haude \\ Georg-August-Universität Göttingen, Abt. Geobiologie, Goldschmidtstr. 3, D-37077 Göttingen, Germany; E-mail: rhaude@gwdg.de}

Keywords: Holothuroidea, Jurassic, Göttingen, Germany

Jurassic formations typically occur in the Leinetalgraben (N-S tectonic depression along the river Leine) below the graben shoulders of Muschelkalk in the east and west. During commercial mining of Lower Jurassic silty clays in a pit within the city limits of Göttingen, surprisingly many specimens of almost complete wormlike holothurians have been found. However, this important exposure has been closed several years ago, leaving nothing but a natural private park off limits to the public but not to frogs and birds of passage. Therefore, instead of visiting this formerly interesting echinoderm locality, a short survey is presented to give an impression of the scientific significance of these Göttingen holothuroids. 
Thus far, no complete fossils were known except for some aggregates of buttonand dumbbell-like spicule morphotypes (Calclamna, Binoculites) in association with hook-like spicules (Achistrum) as possible relicts of original body wall deposits. The worm-like specimens, which consist of such morphotype associations have been extracted from a layer almost $2 \mathrm{~m}$ thick and several meters in lateral extent within a monotonous succession of $50 \mathrm{~m}$ of clay. A few 'worm holothurians' contained ten ossicles of the calcareous ring showing different 2 dorsal / 3 ventral radials as they are typical in certain synaptids. Two types of 'worm holothurians' can be distinguished: (1) larger specimens consisting to $70-95 \%$ of buttons (assignable to paraspecies Binoculites germanica) and 5-30\% of hooks (paraspecies Achistrum bartenstein); (2) some small specimens consisting of dumbbells (paraspecies Binoculites jurassica) and small hooks.

Besides the holothurians, some other echinoderms were found in these layers: parts of crinoid stems (Isocrinus sp.), arms of ophiuroids (Palaeocoma? sp.), and echinoid coronas (Hemipedina cf. minima).

Yet, some observations may cast doubt on the supposed nature as body fossils, e. g.: (1) apparently non-anatomical positions of ring elements; (2) thin 'worms' of densely crowded spicules obviously without a hypothetic space left for an original body cavity; (3) extremely narrow and irregular three-dimensional meanders of thin specimens which appear too extreme even if compared with recent synaptids in rigor mortis. Hence, similarities with the typical Solnhofen fossil Lumbricaria may not be excluded, which would suggest a coprolitic (fecal) origin of the 'worm holothurians'. In this case, however, biostratinomic observations suggest that the supposed holothurian predator fed only on one individual prior to defecation, thus only transforming the original arrangement of spicules by intestinal passage.

\title{
Goniodonts, the serial tooth elements of ophiocistioids (Echino- dermata: Echinozoa) in the Middle Devonian of the Rheinisches Schiefergebirge (Germany) [posterpresentation]
}

\author{
Reimund Haude ${ }^{1}$ \& Mike Reich ${ }^{1,2}$ \\ ${ }^{1}$ Georg-August-Universität Göttingen, Abt. Geobiologie, Goldschmidtstr. 3, D-37077 Göttingen, \\ Germany; E-mail:rbaude@gwdg.de \\ ${ }^{2}$ Georg-August-Universität Göttingen, Museum, Sammlungen \& Geopark, Goldschmidtstr. 1-5, \\ D-37077 Göttingen, Germany; E-mail:mreich@gwdg.de
}

Keywords: Ophiocistioidea, goniodonts, Middle Devonian, Rheinisches Schiefergebirge, Germany

Ophiocistioids are Palaeozoic echinozoans, i. e. related to echinoids and holothurians, with a vaulted body, the wall of which is either well skeletonized with irregular non-spine-bearing plates or contains only microscopic wheel-like sclerites. The ambulacra are confined mainly to the oral side and have only few but huge 
skeletonized podia. The masticatory apparatus is very similar to an echinoid lantern, but differs mainly by its serially arranged minute, angular and anteriorly serrate tooth elements (goniodonts, not conodonts!). For a long time ophiocistioids were known as a small group represented by a few Silurian and Devonian individuals, and - highly questionable - by some Ordovician skeletal fragments. However, with the discovery of their masticatory apparatus with the typical tooth elements, goniodonts became a specific tool for recognizing an almost worldwide occurrence of ophiocistioids in the Palaeozoic. According to the 5 teeth each consisting of a series of almost 20 goniodonts, with newly formed small elements at their base, each ophiocistioid individual must have delivered during its life many goniodonts into the sediment. Several ophiocistioid parataxa are meanwhile based on goniodonts from the Silurian through the Carboniferous; a probably primitive goniodont type may extend the stratigraphic occurrence of ophiocistioids also into the Middle Ordovician and the Upper Permian.

By faunal analyses in the Middle Devonian shelf region of the eastern Rheinisches Schiefergebirge, many isolated goniodonts have been documented in almost all Eifelian and Givetian formations. Hence they indicate rather large ophiocistioid populations, which is corroborated by an echinoderm lagerstätte containing layers crowded with specimens of the completely preserved ophiocistioid Rotasaccus.

The Middle Devonian goniodonts presented here are distinguished mainly by the number of denticles/mm (index I) of the serrate anterior cutting edge. According to this, most goniodonts in the Givetian shelf may represent species of Rotasaccus; those in the Eifelian shelf may belong to Rhenosquama, which is represented by fairly complete individuals belonging to 2 species. Significant variations of (I) may indicate ontogenetic stages, which however, are not yet corroborated by the fossil material.

\title{
Silici-organic objects in Lower Devonian echinoderm lagerstaetten of Argentina and Bolivia [posterpresentation]
}

\author{
Reimund Haude ${ }^{1}$, Rainer Brocke ${ }^{2}$, Till Heinrichs ${ }^{3} \&$ Walter Riegel $^{1}$ \\ ${ }^{1}$ Georg-August-Universität Göttingen, Abt. Geobiologie, Goldschmidtstr. 3, D-37077 Göttingen, \\ Germany; E-mail: rhaude@gwdg.de \\ ${ }^{2}$ Senckenberg Forschungsinstitut, Sektion Palynologie und Mikrovertebra des Paläozoikums, \\ Senckenberganlage 25, D-60325 Frankfurt/M., Germany \\ ${ }^{3}$ Georg-August-Universität Göttingen, Abt. Angewnadte Geologie, Goldschmidtstr. 3, D-37077 \\ Göttingen, Germany
}

Keywords: Problematica, silici-organic objects, Echinodermata, Devonian, Argentina 
In almost contemporaneous Lower Devonian successions of mudstones with intercalated siltstones in the Argentine Precordillera and the Bolivian Eastern Cordillera formerly unknown small Silici-Organic objects (SOs) have been found. Significantly often, these SOs are associated with completely preserved parautochthonic echinoderms in the probably rather distal tempestitic siltstone beds. Obviously, they do not occur in the highly bioturbated mudstones, which represent background sedimentation.

The SOs are either of irregular sheet-like but mostly of disc-like shape always orientated parallel to the bedding plane. They have a hard, bright wall completely enclosing dark contents. According to qualitative EDX analyses, the wall consists of silicon $\left(\mathrm{SiO}_{2}\right)$, and the dark contents are of organic (C) origin. In disc-like SOs (diameters of about $0.2-7 \mathrm{~mm}$ ), the thickness of the wall varies according to their diameters. The internal surface of the wall is either smooth, but some specimens show a pitted pattern, which corresponds to a pustulous surface of the dark contents. In some cases the pits are separated by faint fissure-like lines implicating a polygonal, originally cellular structure of the contents. Some SOs display deformations induced by contiguous obstacles (e. g. shells and echinoderm skeletons), and settling processes.

All observations suggest that the discs must have been rather spherical, and probably originated from multicellular growing organisms with a soft and certainly translucent, possibly gel-like cover of (?)hydro- $\mathrm{SiO}_{2}$, which was permeable for processes of ionic mineral transfer. The pitted inner surface of the wall in some SOs could be related to hydrostatic pressure of its eventually expanding (growing?) outer cells of the organic contents.

The association with echinoderms may indicate that the SOs represent reproductive (blastula?) stages of one of their taxa. More probably they are of algal origin, with the certainly translucent shell/envelope presumably indicating photoautotrophic processes for synthesis of organic molecules. Sharing a common biostratinomic process with the echinoderms, their absence in the bioturbated mudstones would then indicate consumption by other organisms.

The sheet-like SOs are interpreted to document relicts of originally spherical, but considerably larger specimens representing another type (or species?) than the disclike forms. Due to their larger size and relatively thinner wall the sheet-like SOs might have been already distorted during tempestitic turbulent processes.

\section{Echinoderms don't suck: Evidence against the involvement of suction in tube foot attachment [oralpresentation]}

\section{Elise Hennebert \& Patrick Flammang}

Marine Biology Laboratory, University of Mons, Mons, Belgium; E-mail: elise.hennebert@umons.ac.be \&Patrick.Flammang@umons.ac.be

Keywords: Asteroidea, Echinoidea, podia, morphology, biomechanics 
Suction has always been regarded as the primary mean of attachment in sea star and sea urchin tube feet and this idea, relayed by almost every zoology textbook, has become widespread in the public knowledge. Yet, a few studies have suggested that suction alone is not responsible for tube foot attachment, but that adhesive secretions are also involved and could have a prominent role. However, in none of these studies were the respective proportions of attachment due to suction and to adhesion quantified. We use morphological and biomechanical approaches to demonstrate that sea star and sea urchin tube feet are not working as suckers. Microscopic observations of tube feet rapidly fixed while they were attached to a smooth substratum show that their distal surface is totally flat and lack a suction cavity. From the biomechanical point of view, critical detachment force and tenacity of single tube foot appear to be independent on the angle of pull: i. e. the introduction of a shear component in the pulling force does not decrease attachment strength as would be expected for a sucker. Finally, critical detachment force and tenacity of tube feet attached to perforated surfaces precluding the formation of a suction cavity are not different from those measured on their smooth counterparts. All these results taken together clearly show that echinoderm tube feet rely on adhesive secretions and not on suction for their operation.

\section{Influence of rocky substratum type on bioerosion activity and morphology of sea urchins [oral presentation]}

José Carlos Hernández ${ }^{1,2}$, Sabrina Clemente $^{1,2}$, Michael P. Russell ${ }^{1}$, Don Barber $^{3}$ \& Thomas A. Ebert ${ }^{4}$

${ }^{1}$ Department of Biology, Villanova University, Pennsylvania, USA

${ }^{2}$ Current address: Dpto. Biología Animal (Ciencias Marinas), Universidad de La Laguna, Tenerife, Canary Islands; E-mail: jocarber@ull.es

${ }^{3}$ Department of Geology, Bryn Mawr College, Pennsylvania, USA

${ }^{4}$ Department of Zoology, Oregon State University, Corvallis, Oregon, USA

Keywords: Echinoidea, Strongylocentrotus, west coast of North America, rock hardness, bioerosion, test morphology

Intertidal rocky communities exist in a mosaic of substrate types that differ in a variety of ways - for example, hard granite versus softer sandstones. Surprisingly, the effect of rocky substrate variability on intertidal organisms remains poorly understood. A good example of this influence is the purple sea urchin, Strongylocentrotus purpuratus, which is commonly found in a variety of intertidal rocky substrate types of the Pacific coast of Central and North America, from Los Ojitos $\left(28^{\circ} 54^{\prime} 30.35^{\prime \prime} \mathrm{N} 114^{\circ} 27^{\prime} 16.82^{\prime \prime} \mathrm{W}\right)$, Mexico, to Torch Bay (58 $19^{\prime} 20.42^{\prime \prime} \mathrm{N}$ $\left.136^{\circ} 46^{\prime} 50.76^{\prime \prime W}\right)$, Alaska. In sites where the substratum is soft enough to be eroded, urchins are found living inside cavities or 'pits'. However, there are other 
sites where the rock is less friable and the urchins do not form pits and are instead found distributed over the rock surface. The work presented here aimed to give insight into this sea urchin boring activity, using the wide variety of rock types collected at 26 sites along the Central and North American west coast, from Punta Baja, Baja California del Norte (Mexico), to Palmerston, Vancouver Island (Canada). In order to do so we combined measures of the physical properties of the rocks, such as abrasion resistance (abrasion index - AI), and the study of the structures originated in the substrate by urchin bioerosion, recording the presence, type and morphology of pits. Results showed that the contours of pits perfectly fitted the individuals inhabiting them $\left(\mathrm{R}^{2}=0.87\right)$; spines were slightly longer and urchin diameter smaller than pit diameter. These findings suggest that bioerosion, resulting from sea urchin foraging activity and spine abrasion, creates these cavities, and that individuals do not usually leave their substrate refuge. Abrasion index measures varied from 0.149 (very hard) to 137.386 (very soft). Rock abrasion resistance limits the pits' profiles and no rocky pits were found under $1.963 \pm$ 0.312 of AI (mean \pm SD). However, below this threshold, small pits over coralline algae were observed. Rock abrasion resistance modifies height to diameter ratio (H/D ratio) and urchins living in softer rocks always had higher profiles than those living in hard rocks, where the H/D ratio showed the highest variability.

\section{Observations on Onychaster (Ophiuroidea: Onychasteridae) (Famennian-Visean age) [posterpresentation]}

Frederick H. C. Hotchkiss ${ }^{1} \&$ Alexander Glass $^{2}$

${ }^{1} M P R I$, Vineyard Haven, MA, 02568 USA; E-mail: hotchkiss@MPRInstitute.org

${ }^{2}$ Earth and Ocean Sciences, Duke University, Durbam, NC, 27708 US A;

E-mail:alex.glass@duke.edu

Keywords: Ophiuroidea, Onychaster, Carboniferous, vertebrae, evolution

In Onychaster the lateral/adambulacral plates are strictly on the undersurface of the arm where they form a double row and nearly touch midventrally; there are no mid-ventral underarm plates. The undersurface laterals bear a transverse row of spines that point proximally (in retro-direction); groove spines were not seen. The disk in large specimens bulges interradially such that the arms insert subambitally. The morphology of Onychaster vertebrae is documented anew in SEM stereopair images. Distinctive features include: a median dorsal cleft or circular pit on the upper surface; an auluroid canal; paired epanapophyses; a zygosphene dorsal to the auluroid canal; exceptionally spacious fossae for the ventral longitudinal muscles; and an undersurface plastron that is dimensioned like a waist belt. These features are transformationally close to eospondylid/furcasterid vertebrae and pro- 
gressively/increasingly distant from zygospondylous, transspondylous, and streptospondylous vertebrae. Classification of Onychaster as a euryalid is not supported.

\title{
Crinoid diversity from the Upper Cretaceous deeper water facies of Hokkaido, Japan - Implications for the Mesozoic marine revolution [oral presentation]
}

\author{
Aaron W. Hunter ${ }^{1,2}$ \\ ${ }^{1}$ Department of Geosciences \& Petroleum Engineering, Petronas University of Technology, Tronoh, Perak, \\ Malaysia; E-mail:aaron_hunter@petronas.com.my \\ ${ }^{2}$ Georg-August-Universität Göttingen, Museum, Sammlungen \& Geopark, Goldschmidtstr. 1-5, \\ D-37077 Göttingen, Germany
}

Keywords: Crinoidea, Upper Cretaceous, Yezo Group, Japan, Mesozoic marine revolution, palaeobiogeography

Recent studies have pointed to a marked decline in crinoid diversity in response to the Mesozoic marine revolution (MMR), widely thought to be due to increased predation pressure by echinoids from the Middle-Late Triassic onwards (Baumiller 2010). Throughout this period, both sessile and motile crinoids radiated to occupy a range of habitats reaching an apparent peak during the Early to Middle Jurassic, having a truly global distribution (Hunter \& Zonnerveld 2008, Hunter \& Underwood 2009). These mainly motile 'Jurassic type faunas' of Isocrinus, Balanocrinus and Chariocrinus persisted well into the Early Cretaceous (Hunter et. al., in press) before declining and being replaced by 'Late Cretaceous type faunas' of Isselicrinus, Nielsenicrinus, Austinocrinus, by the mid-Cretaceous Aptian/Albian (Hess \& Gale 2010). These 'Late Cretaceous type faunas' are typified by taxa adapted to living in the soft substrate chalk seas of northern Europe.

New data principally from 'local' encrinites in the Yezo Group of Hokkaido suggest that many relict 'Jurassic type faunas' persisted in the Late Cretaceous deep water $(>100 \mathrm{~m})$ muddy sandstone facies. For example Isocrinus and Balanocrinus are found in the outer shelf sandy mudstone facies of the Turonian Saku Formation and the Coniacian-Santonian Haborogawa Formation of Mikasa, central Hokkaido. Isocrinus is also found in the deepwater siltstones and sandy siltstones of the Nishichirashinai Formation, Nakagawa area, northern Hokkaido. In contrast, Isselicrinus, which belongs to more 'Late Cretaceous type faunas' is found in the uppermost Cretaceous Campanian-Maastrichtian outer shelf mudstone facies of the Upper Yezo group around Hobetsu (south-central Hokkaido).

Although the collections of crinoids preserved in the chalks of northern Europe are themselves largely free from sampling biases (Hunter \& Donovan 2005), Cretaceous crinoid diversity data has been heavily influenced by fossils preserved in the relatively homogenous chalk facies where the faunal difference between the deep water Danish and English chalks $(>250 \mathrm{~m})$ and the shallow water facies 
found around Maastricht, The Netherlands $(<50 \mathrm{~m})$, are slight. Our preliminary results from Hokkaido suggest that the change in crinoid diversity reported so far for the MMR could have been influenced by sampling and facies biases.

\section{'Caught in the act'; evidence for asteroid predation on plesiosaur (Elasmosaurus: Plesiosauroidea) carcasses from the Upper Cretaceous of Hokkaido, Japan [poster presentation]}

Aaron W. Hunter ${ }^{1,2}$ \& Kazuhiko Sakurai ${ }^{3}$

${ }^{1}$ Department of Geosciences \& Petroleum Engineering, Petronas University of Technology, Tronoh, Perak, Malaysia; E-mail: aaron_hunter@petronas.com.my

${ }^{2}$ Georg-August-Universität Göttingen, Museum, Sammlungen \& Geopark, Goldschmidtstr. 1-5, D-37077 Göttingen, Germany

${ }^{3}$ Hobetsu Museum, Hobetsu, Mukawa-cho, Yufutsu-gun, Hokkaido, Japan;

E-mail:cxx03707@nifty.com

Keywords: Asteroidea, Upper Cretaceous, Elasmosaurus, taphonomy, Hokkaido, Japan

We report the unusual occurrence of an asteroid preserved within the metapodial bones (flipper) of a plesiosaur. Not only is this specimen one of the few asteroids reported from the Late Cretaceous of Japan, but it appears to be very well preserved with many of the marginal plates found intact.

A number of long necked Elasmosaurus (Plesiosauroidea) have been found across the Upper Coniacian to Campanian of northern and central Hokkaido, Japan. At Hobetsu Museum, the majority of Elasmosaurus skeletons are found in soft clastic sediments as semi-disarticulated post-cranial skeletons preserving just one part of the animal. Many examples show preserved limbs, paraxial section and the vertebral column. However, our example only preserves the metapodials and phalanges (centre part of the flipper). These remains occur within lithofacies interpreted as inner-shelf, a relatively deepwater substrate. We suggest that, like many plesiosaur skeletons found in Hokkaido, either the limb became detached from the postcranial skeleton shortly after death or in early necrosis and sank to the seabed, or it became detached during the subsequent benthic activity. Nevertheless, after death the plesiosaur would have become a 'fall' community, similar to post-Cainozoic whale falls.

The preserved semi-articulated asteroid appears to resemble the Late Cretaceous genus Recurvaster (Goniasteridea) found in the White Chalks of England and Denmark. Recurvaster are rarely preserved articulated; this is normally a result of exceptional preservation within soft sediments such as chalks and is seldom seem in the more clastic sediments of Hobetsu, which preserve very few articulated multi-element taxa such as isocrinid crinoids. 
We suggest that this starfish was either feeding off the carcass or preying on neighbouring organisms within the nutrient rich benthic island community on the seabed. The asteroid itself was subsequently entombed, by rear influx soft sediment, with its marginal plates being held in place by the weakly disarticulated metapodials of the Elasmosaurus, thus exceptionally preserving both organisms together within the same concretion.

\section{Behavior of extant ophiuroids in hypoxic water and its application to the mode of occurrence of fossil ophiuroids [oral presentation]}

Yoshiaki Ishida ${ }^{1}$, Hideshi Suzuki ${ }^{2}$, Toshiro Sakae ${ }^{3}$, Gengo Tanaka ${ }^{4}$, Masato Kiyomoto \& Toshihiko Fujita ${ }^{6}$

${ }^{1}$ Suginami-ku, Tokyo, Japan; E-mail:y-ishida@msi.biglobe.ne.jp

${ }^{2}$ Tadeshina Senior High School, Nagano, Japan

${ }^{3}$ School of Dentistry at Matsudo, Nihon University, Chiba, Japan; E-mail: sakae.toshiro@nihon-u.ac.jp

${ }^{4}$ Gunma Museum of Natural History, Gunma, Japan; E-mail: tanaka@gmnh.pref.gunma.jp

${ }^{5}$ Ochanomizu University, Tokyo, Japan; E-mail: kiyomoto.masato@ocha.ac.jp

${ }^{6}$ National Museum of Nature and Science, Tokyo, Japan; E-mail: fujita@kahaku.go.jp

Keywords: Ophiuroidea, hypoxic, behavior, extant, Miocene, Japan

Extant ophiuroids (138 individuals, 16 species, 4 families) were put in an aquarium filled with each gas of hydrogen sulfide, carbon dioxide, methane, nitrogen and then buried in fine sand or mud of $2-4 \mathrm{~cm}$ thick. In hydrogen sulfide and carbon dioxide, the ophiuroids stopped moving their arms in 30 minutes without autotomizing them. After buried in the sediments, they assumed various postures coiling or extending their arms. In methane and nitrogen, some individuals escaped from the accumulating sediments. When buried slowly in mud $(1 \mathrm{~cm} / 30 \mathrm{~min}$.), all the individuals escaped tilting discs with extending arms symmetrically.

A total of 40 fossil specimens of Ophiacanthidae were discovered from the Middle Miocene Iseyama and Bessho Formations in Nagano Prefecture, central Japan. The Iseyama Formation was mainly composed of well laminated shale and massive mudstone. Ophiuroid fossils occurred in three horizons in well laminated shale. Their arms were not disarticulated and remained intact from the base to the tip with many arm spines attached. The discs and arms of ophiuroid fossils were almost parallel to the lamina plane. The arms were extending straight, bending slightly, or coiling. SEM observations showed that these ophiuroids were filled with framboidal pyrite. In the massive mudstone, small pyrites and fossils were found. In the Bessho Formation, ophiuroids occurred in one horizon. The postures of ophiuroids and lithofacies of the formation were similar to those of the Iseyama Formation. 
Extant ophiuroids are usually disarticulated rapidly within several days after the death in natural environment, but remained articulated in several months after the death in sea water with hydrogen sulfide. The present fossil ophiuroids were articulated, and their postures were similar to those of the extant ophiuroids which died in hydrogen sulfide. Framboidal pyrites in these formations were formed in hypoxic condition. These observations suggested that the fossil ophiuroids were killed by hydrogen sulfide and buried calmly with mud at extremely low sedimentation rate. In the Iseyama Formation, the ophiuroids with pyrites were found intermittently from several horizons, suggesting that hydrogen sulfide influx occurred repeatedly.

\title{
Paracentrotus lividus attachment strength and burrowing behaviour in rocky shores of SW Portugal [oralpresentation]
}

\author{
David Jacinto $^{1} \&$ Teresa $^{\text {Cruz }}{ }^{1,2}$ \\ ${ }^{1}$ Laboratório de Ciencias do Mar / Centro de Oceanografia, Universidade de Évora, Sines, Portugal; E- \\ mail:djacinto@uevora.pt
}

${ }^{2}$ Departamento de Biologia, Universidade de Évora, Évora, Portugal

Keywords: Echinoidea, Paracentrotus, wave exposure, burrowing behavior, attachment strength, SW Portugal

The sea urchin Paracentrotus lividus is a common wave-swept organism that inhabits intertidal rock pools and shallow subtidal temperate shores. Under wave exposed conditions $P$. lividus occurs in cup-shaped burrows, created by mechanical action of spines and mouthparts, which usually fit the animals that permanently or temporarily occupy them. Burrows may provide shelter and resistance to dislodgement due to hydrodynamic forces or predatory attacks.

Observations made in SW Portugal suggest that P. lividus size structure and the proportion of individuals in burrows vary along vertical (depth) and horizontal (wave exposure) gradients: smaller individuals occur in burrows and are more frequent in more exposed and shallower rocky shores, while larger individuals occur deeper and in less exposed habitats and few are found freely over the rocky substrate.

If burrowing enhances urchin attachment strength (because both tube feet and spines may be used as attachment structures) and influence their ability to withstand hydrodynamic forces, we predict that: (1) smaller urchins in more exposed conditions occur in deeper burrows (in relation to urchin body size) than larger urchins living in less exposed habitats; and also that (2) for individuals occurring in the same habitat, there is a positive relationship between burrow size and urchin attachment strength.

We have studied the relationship between individual urchin size, burrow size and attachment strength in P. lividus by sampling urchins $(\mathrm{n}=50)$ in different habitats: 
intertidal rocky pools, intertidal channels $(0-1 \mathrm{~m}$ depth) and shallow subtidal rocky shores $(6 \mathrm{~m}$ depth) at two shores in SW Portugal subjected to different wave exposure.

Despite the observed urchin size variability, smaller individuals in intertidal rock pools ( $34.4 \pm 4.89 \mathrm{~mm}$, mean test diameter $\pm \mathrm{sd}$ ), medium sized urchins in intertidal channels $(48.0 \pm 6.57 \mathrm{~mm})$ and large urchins in subtidal rocky shores $(59.8 \pm 8.35 \mathrm{~mm})$, the average attachment force was similar among habitats and shores $(46.4 \pm 23.14$ Newtons, mean \pm sd).

As hypothesized, burrow size (the relation between burrow profile length and burrow opening width) varied between habitats: average burrow size in intertidal rock pools $(1.4 \pm 0.18$; mean \pm sd) was larger than in intertidal channels and in subtidal rocky shores $(1.2 \pm 0.14 \mathrm{~mm}$ and $1.3 \pm 0.14 \mathrm{~mm}$, respectively). Also, within each habitat, attachment strength was significantly and positively related with burrow size, suggesting that burrowing enhances attachment in P. lividus.

We will discuss how burrowing behaviour influences urchin ability to withstand hydrodynamic forces and its ecological implications in SW Portugal rocky shores.

\section{The asteroid Chomataster acules Spencer, 1913 from the upper Maastrichtian of northeast Belgium - pure frustration, despite perfect preservation [poster presentation]}

John W. M. Jagt

Natuurbistorisch Museum Maastricht, de Bosquetplein 6-7, NL-6211 KJ Maastricht, the Netherlands; E-mail:jobn.jagt@maastricbt.nl

Keywords: Asteroidea, Goniasteridae, Chomataster, Maastrichtian, Belgium, preservation

Although strata assigned to the Maastricht Formation (upper Maastrichtian) have yielded a fair number of asteroid taxa (e. g., astropectinids, benthopectinids, goniasterids, sphaerasterids, stauranderasterids and ?asteriids), the great majority of these are represented solely as dissociated ossicles, and the sturdier types amongst these, such as infero- and superomarginals, predominate. Finds of more or less complete specimens are very rare (see Scripta Geologica 121, pp. 377-503, 2000; Bulletin de l'Institut royal des Sciences naturelles de Belgique, Sciences de la Terre 75, pp. 183200, 2005). A flint nodule collected by W. van Rijsselt from the upper Nekum Member at the CBR-Romontbos quarry (Eben Emael, Liège, Belgium) several years ago, is the best-preserved specimen of the enigmatic taxon Chomataster acules on record to date. Not only are all ossicles preserved in their original anatomical position, most superomarginal ossicles also retain button-like 'spines', rather than pointed ones. Although portions of two arms are exposed on the outer surface of the nodule, the adoral and oral side of the disc, including details of the mouth frame, as well as ambulacral and adambulacral details are preserved inside that same nodule. Earlier attempts to etch away the calcium carbonate of the asteroid 
skeleton have proved both time consuming and tricky. Because this unique specimen is of prime importance in determining the systematic position of the genus (range: upper Campanian to lower Paleocene, with records all over Europe), further damage should be avoided. Recent CT scans of the specimen, produced at the Vrije Universiteit (Amsterdam), have proved of great value in unravelling the skeletal structure of this taxon. Previous assumptions by Andrew S. Gale that the interradius would have been broad and evenly rounded, with long and slender arms and large, crater-shaped spine pits that probably bore spherical spines, are shown to be correct. The ancestry of the genus is unknown; Gale expected that it evolved elsewhere and subsequently migrated into northwest Europe during the early late Campanian.

\title{
A phymosomatid echinoid death assemblage from the uppermost Maastrichtian in the southeast Netherlands [posterpresentation]
}

\author{
John W. M. Jagt ${ }^{1} \&$ Mart J. M. Deckers ${ }^{2}$ \\ ${ }^{1}$ Natuurbistorisch Museum Maastricht, de Bosquetplein 6-7, NL-6211 KJ Maastricht, the Netherlands; \\ E-mail:jobn.jagt@maastricht.nl
}

${ }^{2}$ Industriestraat 21, NL-5931 Tegelen, the Netherlands; E-mail: martdeckers@planet.nl

Keywords: Echinoidea, Phymosomatidae, Maastrichtian, Netherlands, death assemblage

At several localities within the type area of the Maastrichtian Stage (southeast Netherlands, northeast Belgium), representatives of the genus Gauthieria are not uncommon in the lower Maastricht Formation (see Scripta Geologica 121, pp. 181375, 2000). However, in the highest unit, the Meerssen Member, of latest Maastrichtian age, phymosomatids represented are mainly Trochalosoma? corneti and Phymotaxis tournoueri, Gauthieria gr. pseudoradiata auctt. being extremely rare. Seen in this light, the recent find of a death assemblage comprising some 50 specimens in subunit IVf-6 of that member at the ENCI-HeidelbergCement Group quarry (Maastricht) came as some surprise, even more so in view of the exquisite state of preservation of most tests. On a surface area of about 1200 square centimetres, and over a depth of some five centimetres, tests are closely spaced, lying either with apical (8 out of 17 ) or oral (5 out of 17 ) side up and are relatively small yet generally of comparable diameters [although some are slightly smaller]. Two 'normal-sized' specimens of the shallow-infaunal faujasiid Procassidulus lapiscancri are associated, testifying to sediment reworking (upper centimetres of sea floor) and rapid obrution. All phymosomatids preserve (portions of) their lanterns, peristomial plating and spine canopies, and seven of them retain apical disc plating, although details of plating are obscured by adhering matrix and some appear a bit jumbled. This obviously represents a live population (during spawning?) which was killed off by obrution; apparently, subsequent scavenging activity and/or biotur- 
bation was nil. Preservation of apical disc plating in phymosomatids is especially rare, and there are just a handful of records of such in Gauthieria, making the present find even more spectacular.

\title{
First record of a holopodid crinoid from the late Campanian white chalk facies of northern Germany [oral presentation]
}

\author{
John W. M. Jagt ${ }^{1}$, Christian Neumann ${ }^{2}$ \& Peter Girod ${ }^{3}$ \\ ${ }^{1}$ Natuurbistorisch Museum Maastricht, de Bosquetplein 6-7, NL-6211 KJ Maastricht, the Netherlands; \\ E-mail:jobn.jagt@maastricht.nl \\ ${ }^{2}$ Museum für Naturkunde, Invalidenstr. 43, D-10115 Berlin, Germany; \\ E-mail: christian.neumann@mfn-berlin.de
}

${ }^{3}$ Holteistr. 2, D-10245 Berlin; E-mail:p.girod@gmx.de

Keywords: Crinoidea, Holopodidae, Campanian, Germany, white chalk facies

A new representative of the stemless, cemented crinoid family Holopodidae is recorded from the deep-water white chalk facies ('Schreibkreide') of late Campanian age (grimmensis-granulosus Zone), as exposed at the disused Saturn quarry (Kronsmoor, northern Germany). Only a single, slender calyx, without primi- or secundibrachials [collected by one of us, PG], is available to date. However, this does reveal a set of morphological features (e. g., more or less smooth [i. e., lacking growth lines] outer surface with well-developed, thin and low radial crests and comparatively narrow articula for brachials) on the basis of which it appears warranted to erect a new species to accommodate it. These features also suggest it to be closer to Holopus than to Cyathidium, which would make it the second extinct member of that genus, the other species being $H$. spileccense from the Eocene of northern Italy (Bollettino della Società paleontogica Italiana 44, pp. 211-218, 2005). Cretaceous holopodids (i. e., species of Cyathidium) are more or less confined to relatively shallow-water, glauconitic and/or sandy facies, often containing boulders, such as the upper Cenomanian to lower/middle Turonian of Germany, Poland and the Czech Republic (C.depressum and allied forms), the Santonian of southern France (C. senesset), the lower Campanian of northern France and southern England (C. n. sp.; Jagt et al., in prep.) and the Maastrichtian of the southeast Netherlands (C. vlieksi). Younger representatives, e. g., C. holopus from the Paleocene of Denmark, southern Sweden and ?Austria generally inhabited deeper-water settings, comparable to extant species (Journal of Natural History 33, pp. 439-470, 1999; Palaeogeography, Palaeoecology, Palaeogeography 271, pp. 77-83, 2009). The new holopodid from Kronsmoor constitutes an interesting addition to the crinoid faunas from white chalk facies in northern Europe, which in general are dominated by isocrinids and/or bourgueticrinids, with subordinate numbers of comatulids. 
(J. W. M. Jagt acknowledges the financial support of the 'European Commission's Research Infrastructure Action via the SYNTHESYS Project' [DE-TAF-4567])

\section{Function of bioluminescence in the black brittle star Ophiocomina nigra [oral presentation]}

Alice Jones \& Jérôme Mallefet

Marine Biology Laboratory, Catholic University of Louvain, Batîment Kellner, etage -1, Place Croix du Sud, 3, 1348 Louvain-la-Neuve, Belgium;

E-mail:alice.jones@uclouvain.be_jerome.mallefet@uclouvain.be

Keywords: Ophiuroidea, Ophiocomina, bioluminescence, ethology, aposematism

The black brittle star Ophiocomina nigra, common in the English Channel, is known to emit a mucus when attacked. This mucus, already known for its antifouling capacities and its role in the feeding and the locomotion behaviours of the brittle star, would also emit weak light. We characterized this emission of bioluminescence and try to highlight its potential anti-predatory function. Predatory experiments were ran on luminous and control non luminous brittle stars (Ophiotbrix fragilis), during day and night. It appears that during the night, when bioluminescence is visible, the luminous brittle stars were less predated than the control ones. No significant difference appears during the day. Mechanical stimulations of ophiuroids show that they emit more light and mucus when stressed, and palatability experiments showed that the mucus emitted is deterrent for predators (the shore crab Carrinus maenas). Two components are thus combined in the mucus: a visible signal and a deterrent taste, what suggest an aposematic use of the light signal. Successive contacts between $O$. nigra and its predator demonstrated elsewhere that predators were able to learn to avoid the brittle star after one or two contacts, which confirms the hypothesis of the aposematic use of the luminous mucus.

\section{Adaptive evolution in Cenozoic spatangoid echinoids [oral presentation]}

\section{Ken'ichi Kanazawa}

Department of Biological Sciences, Faculty of Science, Kanagawa University, Japan;

E-mail: kanazawa@kanagawa-u.ac.jp

Keywords: Echinoidea, spatangoid echinoids, Cenozoic, adaptation, evolution

In the Eocene, new types of test morphology related to new modes of life suddenly and convergently appeared in the spatangoids which inhabited shallow water sandy habitats in tropical and subtropical regions. This morphological 
change was probably induced by gastropod predation. Flat tests with long, stout spines on dorsal and ventral sides were not for burrowing but for escape from gastropod attack and emergence onto sediment surface. Oval tests with specific ventral morphology for efficient burrowing allowed spatangoids to burrow deeply in sand to avoid gastropod predation. From Eocene to Miocene, the spatangoids with these new modes of life apparently struggled along with the co-existing gastropods by virtue of the attainment of large size which resulted from coevolution between predator and prey. Since the Miocene, however, many of the spatangoids left their habitats so as to avoid the predators which had reached at least twice the length of their prey. Some spatangoids evolved into shallower water regions, e. g. intertidal zones and gravelly rocky shores: the pre-adaptive morphologies for anti-predation seemingly enabled the sea urchins to inhabit the high energy environments. Others evolved into deeper water environments, where the morphology for escape from predation facilitated the originally sand-burrowing spatangoids to adapt to muddy bottoms by crawling on them.

In the spatangoids which had already adapted to finer sediment by the Eocene, no remarkable morphological change occurred, probably because the predatory gastropods would not have lived in such sediment. It is, however, interesting that the sea urchins also migrated into deep water environments. This might have occurred due to expansion or influenced by the migration of the other spatangoids which suffered from gastropod predation.

\title{
Endoparasitic bivalves in Philippine palaeopneustid sea urchins (Echinoidea: Spatangoida) [posterpresentation]
}

\author{
Andreas Kroh ${ }^{1}$, Oleg Mandic ${ }^{1}$, Alexander Ziegler $^{2} \&$ Ashley Miskelly ${ }^{3}$ \\ ${ }^{\prime}$ Naturbistorisches Museum Wien, Geologie \& Paläontologie, Burgring 7, 1010 Wien, Austria; E-mail: \\ andreas.kroh@nhm-wien.ac.at@oleg.mandic@nbm-wien.ac.at \\ ${ }^{2}$ Institut für Immungenetik, Charité-Universitätsmediæin Berlin, Thielallee 73, 14195 Berlin, Germany; \\ E-mail: alexander.zieglen@charite.de
}

${ }^{3} 9$ Kirkwood Ave, Blackheath, NSW, Australia; E-mail: seaurchins1@optusnet.com.au

Keywords: Echinoidea, Bivalvia, parasitism, Plesiozonus, echinoderm host, Entovalva

Recently, a large number of Philippine upper shelf sea urchins (Echinodermata: Echinoidea) became available, presumably due to shifting of local fishing activity from over-exploited shallow water habitats to deeper areas. The use of tangle nets and bottom fishing accounts for a huge number of by-catch, including echinoids. The faunal spectrum recovered from these fishing nets is rather selective, consisting mainly of large and epifaunal species, while burrowing or small species are underrepresented. Among the echinoids recovered, members of the genus Plesiozonus (Irregularia: Spatangoida) are especially large, often exceeding $120 \mathrm{~mm}$ 
test length and are thus commonly collected by the fishermen. Previously, Plesiozonus species were known by very few specimens only. Consequently, little is known on their biology, ecology, and physiology. While cleaning specimens of Plesiozonus hirsutus, we discovered double-valved bivalves in their rectum. Our first assumption, namely that these animals were simply swallowed by the depositfeeding sea urchins proved to be unlikely: in every specimen with preserved intestine, a single articulated bivalve was located close to the periproct and contained mummified tissue. This strongly suggested that the bivalves were actually living inside the intestine of the sea urchins, rather than having been accidentally swallowed during feeding. Considering the size of the bivalves, which approaches or exceeds that of the respective echinoid peristome, the latter possibility seems even less likely. The bivalves are characterized by an extremely thin shell as well as a reduced hinge region and represent yet unknown galeomatid or montacutid species. Both taxa are known to live in association with echinoderm hosts, mainly holothurians. From sea cucumbers, the minute endoparasite Entovalva mirabilis has been reported. In echinoids, endoparasitic bivalves have not yet been described, although three galeomatid species are known to live externally attached to the periproct of the spatangoid Brissus latecarinatus. We hypothesize that it is probably only a small evolutionary step from such a life style to an endoparasitic one. Especially so, as Entovalva has been observed to actively force its way back into the intestine of its holothurian host when artificially removed.

\title{
Asteroidea as a model taxon for investigation of biogeographic distribution patterns and biogeographic history across the centre of Maximum Marine Biodiversity [oral presentation]
}

\author{
David J. W. Lane
}

Department of Biology, Universiti Brunei Darussalam, Jalan Tungku Link, BE1410, Brunei Darussalam;E-mail:david.lane@ubd.edu.bn

Keywords: Echinodermata, Asteroidea, biogeography, maximum marine biodiversity, coral triangle

Studies of marine biodiversity patterns and origins in the region of maximum biodiversity, the so-called 'Coral Triangle', located in the Indo-Malesia region, have thus far focused on just a few taxonomic groups of plants, animals and Protista. These include, most notably, mangrove flora, sea grasses, scleractinian corals, including Fungiidae, various groups of molluscs, reef fish, some crustacea and foraminifera. Most patterns that have emerged generally agree in revealing peaks in richness in the central/southern Philippines and eastern Indonesia but the precise boundaries of the CT zone, however these are defined, vary from one study or taxon to another and the location(s) of potential epicenters in the various subbasins of the region remains a matter for further study and debate. Such diffe- 
rences undoubtedly reflect vicariance events, local and regional variations in habitat area and complexity, and taxonomically variable frequencies of dispersive versus non-dispersive life history traits. This study extends the maximum marine biodiversity analysis to another Phylum, namely the Echinodermata that, with the exception of perhaps the Echinoidea, has to date more or less been overlooked. The Asteroidea (sea stars) are arguably the most completely known Class and consequently are a logical candidate as a model taxon for study of peak biodiversity patterns. This analysis draws upon sea star distribution data from the literature, unpublished data from museum collections, the applicant's published works, plus his extensive unpublished data on sea stars in the Indo-west Pacific over the preceeding 25 years. The initial emerging asteroid diversity patterns confirm diversity maxima for non-shelf waters in eastern Indonesia.

\section{Potential for uni production by Strongylocentrotus intermedius using dry formulated feeds [poster presentation]}

John M. Lawrence ${ }^{1}$, Yaqing Chang ${ }^{2}$, Xuebin $\mathbf{C a o}^{2}$, Addison L. Lawrence ${ }^{3}$ \& Stephen A. Watts ${ }^{4}$

${ }^{1}$ Department of Integrative Biology, University of South Florida, Tampa, Florida, USA;

E-mail:lawn@usf.edu

${ }^{2}$ Key Laboratory of Mariculture, Dalian Ocean University, Dalian, Liaoning Province, People's Republic ofChina; E-mail:yqchang@dlou.edu.cn

${ }^{3}$ Texas AgriLIFE Research, Texas A\&M System, Port Aransas, Texas, USA;

E-mail:smpall@yahoo.com

${ }^{4}$ Department of Biology, University of Alabama at Birmingham, Birmingham, Alabama, USA;

E-mail:sawatts@uab.edu

Keywords: Echinoidea, Strongylocentrotus, uni, formulated feeds, aquaculture

Strongylocentrotus intermedius is the most important species for uni production in Japan and China. Demand has exceeded supply from fisheries as stocks have been depleted and field culture is limited in production. This had led to interest in onland aquaculture as a potential source to increase uni production. Studies have shown culture on land is feasible and that formulated feeds support gonad production. This paper reports high gonad production (gonad indexes of 35) using dry formulated feeds that exceeds maximum indexes for $S$. intermedius in the field and equals that reported for raft culture. The availability of a dry formulated feed that is effective in uni production increases the potential for land-based aquaculture of $S$. intermedius. 


\section{Autotomy of rays of Heliaster helianthus (Asteroidea: Echinodermata) [oral presentation]}

John M. Lawrence ${ }^{1} \&$ Carlos F. Gaymer ${ }^{2}$

${ }^{1}$ Department of Integrative Biology, University of South Florida, Tampa, Florida, US A; E-mail: lawn@usf.edu

${ }^{2}$ Departamento de Biología Marina and CEAZA, Universidad Católica del Norte, Coquimbo, Chile; E-mail:cgaymer@ucn.cl

Keywords: Asteroidea, Heliaster, autotomy

In species of the family Heliasteridae, the ossicles of the proximal parts of the side of each ray are joined by connective tissue to those of the adjacent ray. Autotomy of rays occurs in Heliaster helianthus in response to predatory attack by the asteroid Meyenaster gelatinosus. Autotomy of the ray does not occur at the base of the free part of the ray (arm) but near the base of the ray as in asteroids in general. In addition to the plane of autotomy at this location, a longitudinal plane of autotomy occurs in the connective tissue between the ossicles of the connected portion of the rays. Autotomy of the ray involves all these planes of autotomy resulting in loss of the entire ray.

\section{Population characteristics and biology of two populations of Archaster angulatus (Echinodermata: Asteroidea) in different habitats off the central-western Australian coast [poster presentation]}

John M. Lawrence ${ }^{1}$, John K. Keesing ${ }^{2}$ \& Tennille R. Irvine ${ }^{2}$

${ }^{1}$ Department of Integrative Biology, University of South Florida, Tampa, Florida, US A;

E-mail:lawr@usf.edu

${ }^{2}$ CSIRO Marine and Atmospheric Research,Wembley,WA, Australia; E-mail:John.Keesing@csiro.au

Keywords: Asteroidea, Archaster, regeneration, pseudocopulation, colour morph

We examined habitat, population size structure, colour dimorphism, reproductive behaviour, arm loss and the relation between arm regeneration to pyloric caeca indices in populations at Whitford Rock (WR) and Port Beach (PB) in January 2009. The sediment was fine sand at WR and a mix of larger particles at PB. Individuals at $\mathrm{PB}$ were predominantly orange and more uniform in colour than those at WR, which were predominantly grey. Body size and pyloric caeca index of individuals at WR were greater than those of individuals at PB, indicating the nutriational condition was better at WR. This suggests the quantity or quality of food at WR was better. Organic matter of the pyloric caeca and body wall of intact and regenerating individuals at both sites were similar, indicating loss of an arm did not 
affect gross proximate composition of the organs. Sea stars with regenerating arms made up 5.4 and $8.4 \%$ of the populations observed. Despite the very small size of the gonads, some individuals were in the pseudocopulatory position, indicating this behaviour occurs even when gametes are not present. In every case observed, the male of the pseudocopulating pair was situated above the female. Given the abundance of this species in nearshore habitats dominated by sediment, it is likely to be ecologically important. However much of the biology and ecology of the species, even its diet, remain unknown. This together with its unusual mode of reproductive behaviour involving pseudocopulation, which is only known from two other species of asteroids, underscore the need for more research on $A$. angulatus.

\title{
Deconstructing a chimaera: reinterpretation of the solute Plasiacystis mobilis from the Middle Ordovician of Bohemia [oral presentation]
}

\author{
Bertrand Lefebvre $^{1}$ \& Kraig Derstler ${ }^{2}$ \\ ${ }^{1}$ UMR CNRS 5125 Paléoenvironnement \& Paléobiosphère, Université Lyon 1, Villeurbanne, France; \\ E-mail:bertrand.lefebvre@univ-lyon1.fr \\ ${ }^{2}$ Department of Earth and Environmental Sciences, University of New Orleans, New Orleans, Louisiana, \\ USA 70148; E-mail:kderstle@uno.edu
}

Keywords: Soluta, Ordovician, Bohemia, chimaera

Solutes are an extinct clade (Cambrian-Devonian) of asymmetrical echinoderms. They are characterised by the presence, at opposite extremities of the body (theca), of a single erect ambulacrum and a flexible stem-like appendage (stele). Recently, a very atypical solute, Plasiacystis mobilis Prokop \& Petr, was described from the Sarka Formation (Middle Ordovician) of Bohemia (Czech Republic). As originally reconstructed, its morphology was believed to be quite different from that of all other solutes: (1) the presence of the feeding appendage was questioned; (2) the periproct was large and cystoid-like; (3) the proximal region of the stele was particularly long and fully unorganised; and (4) the distal stele was modified into a large 'beaver tail' (paddle-like structure). Isolated parts of P. mobilis had been previously described separetely and assigned to different organisms: the theca as a fistuliporite rhombiferan Echinosphaerites infaustus, the proximal stele as the machaeridian Lepidocoleus, and the distal stele as a portion of the mitrate stylophoran Promitrocystites barrandei. Our reexamination of the type-material in Prague, along with the discovery of additional material in the Lower Ordovician of Morocco and the Middle Ordovician of England, both confirmed the solutan affinities of 'beaver tail' structures. However, our work also demonstrates that the original reconstruction of Plasiacystis mobilis is a chimaera, mixing morphological features of at least three different echinoderms. The strongly flattened theca with a cystoid-like periproct belongs to a (new) very large solute, possessing both a single feeding appendage, and a long, stem-like distal stele. Long isolated portions of 'proximal 
steles' correspond to pyrgocystid-like edrioasteroids. Finally, 'beaver tail' elements belong to a second, smaller solute characterised by a single feeding appendage, a globular theca, an anal lobe, and a short, polyplated proximal stele. Based on holotype designation, the name Plasiacystis mobilis should be applied only for such 'beaver-tailed' solutes.

\title{
Mitochondrial phylogeny of the echinoid genus Arbacia [oral presentation]
}

\section{Harilaos A. Lessios}

Smithsonian Tropical Research Institute, Balboa, Panama; E-mail: Lessiosh@post.harvard.edu

Keywords: Echinoidea, phylogeography, COI, dispersal barriers, speciation

Arbacia is unique among genera of shallow water echinoids in that it contains both tropical and temperate species. This could be the result of unusual biological qualities, or it could be a taxonomic artifact of a wide delimitation of the genus. To answer this question, to study the phylogeography of this genus, and to determine oceanographic barriers that may have been responsible for speciation, I constructed a phylogeny based on 177 sequences of Cytochrome Oxidase I from all the species of Arbacia. It shows that two Southern hemisphere temperate species, $A$. cressispina and $A$. dufresnei, are closely related to each other but very distant from all other species, so they could be moved to a new genus. A. lixula, from the Mediterranean and the eastern Atlantic, on the other hand, is nested within the genus as a sister species to the West Atlantic A.punctulata. The A. lixulaA. punctulata clade is sister to the eastern Pacific $A$. stellata from which it was presumably isolated by the completion of the Isthmus of Panama. A. spatuligera, from the South eastern Pacific is an outgroup to these. A. lixula from Brazil is a separate, but fairly closely related, clade to $A$. lixula from the eastern Atlantic.

\section{The fossil echinoid fauna of Santa Maria Island, Azores (Northern Atlantic Ocean) [oral presentation]}

\author{
Patrícia Madeira ${ }^{1,2,3}$, Andreas Kroh ${ }^{4}$ \& Sérgio P. Ávila ${ }^{2,3,5}$ \\ ${ }^{1}$ Centro do IMAR da Universidade dos Açores, 9901-862 Horta, Azores, Portugal; \\ E-mail:tamissa@uac.pt \\ ${ }^{2} \mathrm{MPB}$ - Marine PalaeoBiogeography Working Group of the University of the Azores, Rua da Mãe de \\ Deus, 9501-801 Ponta Delgada, Azores, Portugal \\ ${ }^{3}$ Departamento de Biologia, Universidade dos Açores, 9501-801 Ponta Delgada, Azores, Portugal
}


${ }^{4}$ Natural History Museum Vienna, Department of Geology \& Palaeontology, Burgring 7, 1010 Vienna, Austria; E-mail: andreas.krob@nbm-wien.ac.at

${ }^{5}$ CIBIO - Pólo Açores, Departamento de Biologia, Universidade dos Açores, Rua Mãe de Deus, 9501 855 Ponta Delgada, Azores, Portugal; E-mail: sergio.pa.marques@azores.gov.pt

Keywords: Echinoidea, northern Atlantic Ocean, oceanic islands, Miocene-Pliocene, Pleistocene

The Azores is an archipelago composed of nine volcanic islands, located almost midway between the North American and European continents. In this relatively young island system, fossiliferous deposits are only found on the oldest island, Santa Maria. These strata are mainly Late Miocene to Early Pliocene in age. A second set of outcrops is associated with Pleistocene wave-cut platforms and presumably of Eemian age (Pleistocene). These deposits are relatively small, outcropping mostly in the coastal areas, and consist of lithic sandstones and carbonates intercalated by volcanic material, testifying periods of relative calm between intensive volcanic activity, during the formation of the island. During the international workshops 'Palaeontology in the Atlantic islands' (2002, 2006-2009), new echinoid material was collected, mainly composed of disarticulated fragmented skeletal material. The echinoid fauna found in the Mio-Pliocene outcrops of Santa Maria island, is dominated by tropical shallow waters taxa (Eucidaris tribuloides, Echinoneus cf. cyclostomus, Clypeaster altus, Meoma sp.), all locally disappeared with the exception of the temperate species Echinocyamus pusillus. Additionally, remains of two undetermined species of Echinocardium were also found. The Pleistocene material, in contrast, represents a fauna more typical of temperate waters: Sphaerechinus granularis, Arbacia lixula and Paracentrotus lividus. All three species are common present day inhabitants of Azorean rocky shores. In spite of the facies restriction and thus the palaeoenvironments preserved, it is clear that the fossiliferous deposits of the Santa Maria can aid in the understanding of how the fauna in this oceanic island system was shaped through time.

\section{First report of an echinoderm Lagerstätte in the Ordovician of the Ougarta Range, western Algeria [posterpresentation]}

Yamouna Makhlouf ${ }^{1}$, Bertrand Lefebvre ${ }^{2}$, Serge Régnault ${ }^{3} \&$ Aaron W. Hunter ${ }^{4,5}$

${ }^{1}$ Université des Sciences et de la Technologie Houari Boumediene, Faculté des Sciences de la Terre, de Géographie et de l'Aménagement du Territoire, Alger, Algeria; E-mail:yamouna.makblouf@gmail.com

${ }^{2}$ UMR CNRS 5125 Paléoenvironnement \& Paléobiosphère, Université Lyon 1, Villeurbanne, France; E-mail: bertrand.lefebvre@univ-lyon1.fr

${ }^{3}$ Muséum d'Histoire Naturelle, Nantes, France; E-mail: serge.regnaul@@mairie-nantes.fr 
${ }^{4}$ Department of Geosciences \& Petroleum Engineering, Petronas University of Technology, Tronoh, Perak, Malaysia; E-mail: aaron_hunter@petronas.com.my

${ }^{5}$ Georg-August-Universität Göttingen, Museum, Sammlungen \& Geopark, Goldschmidtstr. 1-5, D-37077 Göttingen, Germany

Keywords: Eocrinoidea, Ophiuroidea, echinoderm lagerstätten, Ordovician, Algeria

For historical reasons, Ordovician echinoderm faunas are extremely well-known in southern Morocco (Anti-Atlas). In the second half of the XXth century, the AntiAtlas was extensively sampled by Jacques Destombes, yielding abundant echinoderm remains thoroughly studied by Jean Chauvel throughout several major monographic contributions. In the early XXIst century, rich and diverse, exquisitely preserved new faunas were collected in several echinoderm Lagerstätten discovered in both Zagora (Lower Ordovician) and Erfoud areas (Upper Ordovician). Consequently, Moroccan echinoderm faunas constitute one of the best documented and most diverse assemblages reported for the Ordovician time interval in high latitude Gondwanan and peri-Gondwanan regions. In contrast, Ordovician echinoderm faunas have been extremely little investigated in Algeria. In the 1950s, Henri Termier reported the presence of both diploporan and rhombiferan blastozoans in the Middle Ordovician of northern Algeria (Boumerdès region). More recently, Arnaud Botquelen, Jean Le Menn and Alfredo Loi briefly described isolated echinoderm remains (crinoid columnals and rhombiferan thecal plates) in younger deposits (late Katian) of the same area. Here, we report for the first time the occurrence of an exquisitely preserved echinoderm fauna in Ordovician deposits of the Ougarta Range, western Algeria. This new echinoderm Lagerstätte was discovered close to the small village of Ougarta (Béchar region) by Abdelhafid Afalfiz during geological field work for Ceramines Agency. Although preserved in sandstones, most echinoderms are fully articulated, with even their most brittle portions preserved in connection (e. g., brachioles, tips of arms). The assemblage is apparently dominated by the eocrinoid Ascocystites, associated with ophiuroids. Ascocystites is known from the Middle Ordovician of France (Normandy) and Portugal, and the Upper Ordovician of Czech Republic (Bohemia) and Morocco (western Tafilalt). The association of Ascocystites with ophiuroids strongly reminds of the situation in both the Izegguirene (latest Darriwilian to early Sandbian, Morocco) and Letna (late Sandbian, Bohemia) formations, thus suggesting a possible latest Darriwilian or Sandbian age for the Algerian assemblage. This association also suggests strong palaeobiogeographic links between Algeria and other Gondwanan and peri-Gondwanan regions in Ordovician times. 


\title{
New list of luminous Ophiuroidea [posterpresentation]
}

\author{
Jérôme Mallefet ${ }^{1} \&$ Timothy D. O’Hara ${ }^{2}$ \\ ${ }^{1}$ Marine Biology Laboratory, Catholic University of Louvain, 3 Place Croix du Sud, B-1348 Louvain-la- \\ Neuve, Belgium; E-mail:jerome.mallefet@uclouvain.be \\ ${ }^{2}$ Museum Victoria, 3001 Melbourne, Australia
}

Keywords: Ophiuroidea, luminescence, distribution

\begin{abstract}
Although bioluminescence is well known in echinoderms, it is still poorly understood in terms of phylogenetic distribution. This amazing capability has been mostly studied in Ophiuroidea during the last 15 years but on a limited number of species. Recently, a comparative study on brittlestar luminescence was initiated and analyses were conducted after a large sampling effort. Results indicated that, out of 195 species, the total number of known luminous species increased from 33 in 1995 to 64 today. Informations on biotopes and luminous capabilities will be presented with an updated list of luminous species. New field surveys must be performed to increase the number of ophiuroid species tested in order to try to highlight a possible link between luminescence and ophiuroid taxonomy. This will be necessary in order to understand why so many brittlestars glow in the dark.
\end{abstract}

\section{A new luminous crinoid, first data [posterpresentation]}

Jérôme Mallefet ${ }^{1}$, Marc Eléaume ${ }^{2} \&$ Timothy D. O'Hara ${ }^{3}$

${ }^{1}$ Marine Biology Laboratory, Catholic University of Lowvain, 3 Place Croix du Sud, B-1348 Lowvain-laNeuve, Belgium; E-mail:jerome.mallefe@@uclowvain.be

${ }^{2}$ Muséum National d'Histoire Naturelle, Département Milieux et Peuplements Aquatiques, UMR7208BOREA-MNHN/UMPC/IRD, 43, rue Cuvier 75005 Paris, France

${ }^{3}$ Museum Victoria, 3001 Melbourne, Australia

Keywords: Crinoidea, luminescence

Despite the reasonable number of luminous species, little is known about echinoderm luminescence phylogenetic distribution. Within the echinoderm phylum, bioluminescence is not uniformly distributed across the classes: ophiuroids (64 species) and holothurians (31 species) represent $80 \%$ of luminous echinoderm species while asteroids (20 species) and crinoids ( 3 species) contribute to 17 and $3 \%$ respectively (Mallefet \& O'Hara 2009). A deep-sea expedition around Southwestern Australia provided unique opportunity to study echinoderm bioluminescence along the continental slope from $100 \mathrm{~m}$ down to $1000 \mathrm{~m}$ depth. One crinoid species attributed to Stiremetra cf. breviradia has been collected and luminescence was recorded. It is the first time that luminescence of this species is observed and characteristics will be presented. It is suggested that bioluminescence 
in echinoderms is more widespread than initially thought. A complete analysis and (re)description of this crinoid, based on 10 well preserved specimens, will be done in the near future.

\section{Genetic difference among the sea urchin populations of Strongylo- centrotus intermedius with different spawning seasons in northern Japan [oral presentation]}

Toshiyuki Matsui, Makoto Ogasawara, Masamichi Nakajima, Minoru Ikeda \& Yukio Agatsuma

Graduate School of Agricultural Science, Tohoku University, Sendai, Japan;

E-mail:toshi-matsui@bios.tohoku.ac.jp

Keywords: Echinoidea, reproductive cycle, spawning, population genetics

The spawning season of Strongylocentrotus intermedius in Hokkaido is classified into the three types: Sea of Japan type with intensive spawning in autumn, Funka Bay type with spawning in spring and autumn, and Sea of Okhotsk and Pacific Ocean type with spawning from spring to autumn. The different reproductive cycles in each sea area coincide with the oceanographic condition and the associated geographic distribution of the laminarian species as main foods. The adult and hatchery raised $S$. intermedius transplanted maintain their own fixed reproductive cycles. These findings raise the possibility that the populations of $S$. intermedius around Hokkaido are genetically distinct. In the present study, the gonad index (gonad wet weight $\times 100 /$ body wet weight) and the three gonad development stages: immature, mature and spent of $S$. intermedius collected at depths of 0.5 $1.0 \mathrm{~m}$ in Motoyoshi, Tohoku, in the Pacific Ocean were monitored from October 2007 to October 2008. Population genetic differences in S. intermedius from five localities in Hokkaido and two localities from the Pacific coast of Tohoku were analyzed using two mitochondrial DNA sequences of CO I and ND I regions. The gonad indices showed a defined seasonal cycle, reached a peak of about 20 at the mature stage in September, fell sharply to $<10$ at the spent stage in October, when the water temperature fell from $20^{\circ} \mathrm{C}$ to $13^{\circ} \mathrm{C}$. The indices rose with rise in water temperature after March at the immature stage. By contrast, mature gonads were observed in a few specimens from December to April, suggesting the possibility of mix of the Sea of Japan type and the Pacific Ocean type. Among seven geographically separated populations of $S$. intermedius in northern Japan, there were no significant genetic differentiations and major haplotypes were found in four populations. Possibly, this is attributable to the short historical time. 


\title{
About the taxonomic status of aspidochirotid holothurians inhabiting the Posidonia oceanica meadow in the Algerian area [oral presentation]
}

\author{
Karim Mezali ${ }^{1} \&$ Gustav Paulay ${ }^{2}$ \\ ${ }^{1}$ Département des Ressources Halieutiques, Faculté des Sciences Exactes, de la Nature et de la Vie, \\ Université Abelhamid Ibn Badis-Mostaganem, BP 300 rue Hocine Hamadou, 27000, Mostaganem, \\ Algérie; E-mail: mezalikarim@yahoo.fr \\ ${ }^{2}$ Florida Museum of Natural History, University of Florida, Gainesville, Florida 32611-7800, USA
}

Keywords: Holothuroidea, Aspidochirotida, molecular systematic, phylogeny, 16S mDNA, morphology

Aspidochirotid holothurians provide important marine ecosystem services enhancing nutrient cycling and local productivity in Posidonia oceanica meadows through their bioturbation and deposit feeding activities.

The Aspidochirotidae comprise a diverse assemblage of holothuroids, most of which occur in the Mediterranean Sea. The systematic study was carried out by using modern molecular systematic methods. Phylogenetic analyses from the fraction of mitochondrial gene (16S mDNA) sequenced for 169 individuals (6 species sampled in various localities of the Algerian shallow water areas) clarified taxonomic uncertainties, species relationships.

The results enabled us to differentiate six sampled holothurian forms [Holotburia (Holothuria) tubulosa, Holothuria (Roweothuria) poli, Holotburia (Holothuria) stellati, Holothuria (Panningothuria) forskali and both morphotypes of Holothuria (Platyperona) sanctori]. This study has led to a definitive test of species boundaries in the Mediterranean species and showed that: (1) The two color morphs of Holothuria (P.) sanctori that have been debated in some of the literature are genetically identical and thus represent the same species; (2) Holotburia (H.) stellati, whose confusion was always admitted, is a genetically distinct and well defined species and presents characteristics which characterize it as well on the morphological and genetic levels; (3) Holothuria (H.) tubulosa, the most common species, and the "best known" species in the Mediterranean Sea, is not one species, but two cryptic species that have not been previously recognized or even suspected. Few specimens of holothurians analyzed in our collection have given unusual DNA sequences. However, it is clear that one specimen will probably represent either another species previously unknown, or a hybrid between two known species [i. e. H. (R.) polii and $H$. (H.) stellati]. 


\title{
The test architecture of Clypeaster (Echinoidea, Clypeasteroida) and its phylogenetic significance [oral presentation]
}

\author{
Morana Mihaljević ${ }^{1}$, Andrew B. Smith ${ }^{2} \&$ Iwan Jerjen ${ }^{3}$ \\ ${ }^{1}$ Palaeontological Institute and Museum, University of Zurich, Switzerland; \\ E-mail:echinoideamo@access.ugh.ch \\ ${ }^{2}$ Palaeontology Department, Natural History Museum, London, UK; E-mail: a.smith@nhm.ac.uk \\ ${ }^{3}$ Empa - Swiss Federal Laboratories for Materials Science and Technology, Dübendorf, Switzerland; \\ E-mail:Iwan.Jerjen@empa.ch
}

Keywords: Echinoidea, Clypeaster, test structure, buttressing, phylogeny

Clypeaster is a specious echinoid genus with over 40 nominal extant and over 350 extinct species, encompassing a great heterogeneity of form. While some attempts to subdivide this genus have been made, none has gained widespread support, and all recent taxonomic treatments have left the genus intact. Here we report new data on internal buttress arrangement, determined from X-Ray tomography, and plate architecture, and use this to establish relationships amongst 14 extant species encompassing 8 of the 10 nominal subgenera that have been proposed. A cladistic analysis of these characters allows us to divide Clypeaster into two major clades, which differ primarily in their pattern of internal buttressing. Our analysis also shows that Clypeaster is paraphyletic with the clypeasteroid families Arachnoididae and Ammotrophidae (as represented by Arachnoides and Ammotrophus) nested amongst members of the genus. A revised phylogenetic classifycation of the group is presented which recognizes four genera: Clypeaster Lamarck 1801, Stolonoclypus Agassiz, 1863, Orthanthus Clark, 1941 and Leptoclypus Koehler 1922.

\section{New data on Carboniferous crinoids from the Moscow Region [poster presentation]}

\section{George V. Mirantsev \& Sergey V. Rozhnov}

A. A. Borissyak Palaeontological Institute, Russian Academy of Sciences, Moscow, Russia;

E-mail:gmirantsev@gmail.com

Keywords: Crinoidea, Cromyocrinidae, Carboniferous, Pennsylvanian, Moscow region

In recent years, through the acquisition of new collections, as well as new finds the collections of Carboniferous crinoids of PIN RAS have been greatly increased. This allowed for a more detailed study of them, which continues today. According to the preliminary data the collections have more than 2000 specimens of cups and crowns of crinoids from the Moscow Region, of which there are at least 70 new 
species. Among the existing crinoids in the collection there are representatives of such families as Pirasocrinidae Moore \& Laudon, 1943, that are abundant in the Pennsylvanian of the USA, and previously unknown in the Carboniferous of the Moscow Region, as well as representatives of such genera as Allosocrinus Strimple, 1949 and Cibolocrinus Weller, 1909 - also previously unknown in the Moscow Region.

Most of the specimens belong to Cromyocrinidae Bather, 1890, which is currently the most studied family. In the Moscow Region cromyocrinids are represented by 5 genera - Ureocrinus Wright \& Strimple, 1945, Cromyocrinus Trautschold, 1867, Dicromyocrinus Jaekel, 1918, Mooreocrinus Wright \& Strimple, 1945 and Ulocrinus Miller \& Gurley, 1890, whose presence could be established based on the new finds and collections.

Crinoids from the collections of the Paleontological Institute RAS, are well preserved, much of the collections has been professionally prepared. For the many genera, including those for cromyocrinids there are growth stages in which one can trace the change from juvenile to senile forms. There are a large number of aberrant specimens of crinoids in these collections as well as specimens with crinoid-Platyceras interaction and traces of parasites such as a myzostomids.

These collections have a great interest and can more accurately track the evolution and the biodiversity of crinoids in the Carboniferous of the European part of Russia, as well as identify and trace the relationship with the coeval formations in North America and other regions.

\section{The ontogeny of blastoids (Blastozoa): an example of the Middle Devonian hyperoblastids from the Rhenish Massif (Germany) [posterpresentation]}

Elise Nardin ${ }^{1}$, Jan Bohatý ${ }^{1}$ \& Uwe Hein ${ }^{2}$

${ }^{1}$ Institut für Geologie und Mineralogie, Universität Köln, D-50674 Köln (Cologne), Germany;

E-mail:elnardin@gmail.comevan.bohaty@mail.com

${ }^{2}$ Klingenstr.204A,D-42651 Solingen, Germany; E-mail: unvealexa@t-online.de

Keywords: Blastoidea, Devonian, ontogeny

Among echinoderms, blastozoans and crinoids are the most diversified groups in the Palaeozoic. In comparison with crinoids, ontogenetic trends among blastozoans are poorly known, because of the lack of appropriate material and a relatively complex morphology associated to high class-level diversity. Most of the ontogenetic studies have focused on the abundant populations of the primitive blastozoan group Eocrinoidea or on the youngest representatives (MississippianGuadalupian) of the highly derived class Blastoidea. Here we propose to partially 
fill the gap with an investigation of the ontogeny of the Devonian blastoids and to compare our results with the previous studies on younger forms.

More than 500 well-preserved specimens of the fissiculate blastoid species Hyperoblastus eifelensis have been recently collected in the Eifelian strata (Middle Devonian) of the Rhenish Massif (Germany). This species is characterised by a pyriform theca with five wide and subquadrangular radial plates overlapping deltoids. The five ambulacra are deep, linear and narrow. At least one third of the material could be considered as juvenile or immature individuals, based on the size of the theca. Measurements describe the size and shape of the theca and its radial plates, the ambulacra and the zone of the stem insertion. Ambulacral growth is evaluated by the length and curvature of the ambulacra $\mathrm{A}$ and $\mathrm{C}$ regarding the length and the curvature of the theca. Preliminary results suggest that the shape of the theca is relatively stable during the growth, as the width of the ambulacra. The global shape and the curvature of the theca seem to be driven by the growth of the ambulacra.

Controlling over-population of Diadema aff. antillarum sea urchins through their socio-economic valorization as a new shellfish resource in Canary Islands (Central-Eastern Atlantic). Project "DIADEMAR" [oral presentation]

Pablo G. Navarro, Juan M. Barrio, Oreto Briz \& Nieves González

Department of Coastal Management and Sustainable Development, Canarian Institute of Marine Sciences, Canary Islands, Spain; E-mail:pablorestinga@yahoo.es

Keywords: Echinoidea, Diadema, control, resource, Canary Islands

The overall objective of this project is to develop a valid method of control of the sea urchin Diadema aff. antillarum which can help to improve the quality of the coastal ecosystems of Canary Islands by reducing the current high densities and in turn, contribute to economic and social benefits as a new shellfish resource. All the actions in the project are being implemented through a close cooperation between companies, fishermen, administration and research institutions.

The use of Diadema urchin for food purposes is a novel action in the Canary Islands, both ecologically and socio-economically. This operation can provide environmental benefits first, by reducing the densities of the echinoderms and thus restore balance in the ecosystem, and also economic benefits, because of the high value that these products can reach on national and international markets.

Some other sectors that could benefit from this new resource are: (i) agriculture, as a soil acidity corrector and fertilizer (calcium carbonate); (ii) livestock, as dietary supplement and alternative protein source (calcium carbonate and gonads); (iii) textile industry, as dye for fabrics. 
The project is based on three main lines of research: (1) establish the optimal methodology and technology of extraction of Diadema aff. antillarum for the proper conservation of coastal ecosystems, (2) evaluate the effectiveness of several techniques for resource use and (3) management and awareness actions.

Population density and size distribution of Holothuria sanctori, Holothuria dakarensis and Holothuria arguinensis (Holothuroidea: Aspidochirotida) on Gran Canaria, Canary Islands (Central-Eastern Atlantic) [oral presentation]

\author{
Pablo G. Navarro ${ }^{1}$, Fernando Tuya ${ }^{2} \&$ Nieves González ${ }^{1}$ \\ ${ }^{1}$ Department of Coastal Management and Sustainable Development, Canarian Institute of Marine \\ Sciences, Canary Islands, Spain; E-mail:pablorestinga@yahoo.es \\ ${ }^{2}$ Laboratory of Coastal Biodiversity, CIIMAR, Porto, Portugal
}

Keywords: Holothuroidea, Aspidochirotida, Holothuria, distribution, size, Canary Islands

Seasonal population patterns of the most common holothurians found in Canary Islands - Holothuria sanctori, Holotburia dakarensis and Holothuria arguinensis - were monitored during twelve consecutive months between February 2009 and January 2010. The study was carried out with SCUBA in three vegetated rocky bottom localities in Gran Canaria island: Playa del Cabrón, Risco Verde and Sardina del Norte. Abundance, size and bottom rugosity were recorded on each dive. $H$. sanctori showed the highest mean density $1.13 \pm 0.29$ ind $\mathrm{m}^{-2}$ (Mean $\pm \mathrm{SD}$, $\mathrm{n}=2.032$ ), while the other two species were considerably less abundant throughout the whole monitoring, $H$. dakarensis $0.16 \pm 0.22$ ind $\mathrm{m}^{-2}(\mathrm{n}=280)$ and $H$. arguinensis $0.04 \pm 0.05$ ind $\mathrm{m}^{-2}(\mathrm{n}=71)$. H. sanctori showed the smallest mean size, $181.35 \pm$ $29.15 \mathrm{~mm}$. (Mean $\pm \mathrm{SD}$ ), while $H$. arguinensis and $H$. dakarensis were considerably larger $255.07 \pm 55.49 \mathrm{~mm}$ and $234.29 \pm 45.10 \mathrm{~mm}$, respectively. Neither H. dakarensis nor H. arginensis specimens were recorded on Sardina del Norte locality.

\title{
Preservation potentials, taphonomic gradients and taxonomic reso- lution among echinoid taxa [oral presentation]
}

James H. Nebelsick

Institute for Geosciences, University of Tübingen, Sigwartstr. 10, D-72076 Tübingen, Germany;

E-mail:nebelsick@uni-tuebingen.de

Keywords: Echinoidea, taphonomy, diversity, preservational potential 
Taphonomic processes affect the preservation and thus identification of shells in fossil sediments. The degree to which this occurs is fundamental for high resolution ecological and diversity studies. In this study, the different preservation and fossilization potentials of echinoids are compared with occurrence in the fossil record. Taphonomic effects on taxonomic resolution vary greatly according to the shell morphologies of the organisms involved, the ambient taphonomic processes in the respective environment of deposition as well as state of shell preservation along taphonomic gradients. The base of this comparison is studies on the taphonomic gradients of various Recent echinoid taxa. Specific studies are presented for clypeasteroid echinoids for which detailed analyses are presented with respect to both environmental distribution and the effects of taphonomic processes on characters. In general, increasing taphonomic impact on the preservation of surface characters leads to an expected poorer resolution of taxonomic identification. This is, however, not straightforward and highly dependent on the specific taxa involved and the distinct taphonomic pathways affecting the shells.

\title{
Symbiont-induced alterations of the echinoderm skeleton
}

[oral presentation]

\section{Christian Neumann}

\author{
Museum für Naturkunde, Invalidenstrasse 43, 10115 Berlin, Germany; \\ E-mail: christian.neumann@mfn-berlin.de
}

Keywords: Crinoidea, Echinoidea, biotic interactions, symbiosis

Direct evidence of biotic interactions (such as symbiosis) among extinct organisms is rarely preserved in the fossil record, and even when clear evidence for some type of an association exists, interpretation is difficult. Echinoderms such as crinoids and echinoids may act as an exceptional model system for studying symbiosis in deep time. The calcareous echinoderm skeleton represents a living tissue and thus, reacts directly to disturbances such as parasite/symbiont attacks. These reactions may include callus formation (neoplasia) and embedment of the parasite by the host tissue (bioclaustration) as well as bioerosion (e. g., borings) of the host skeleton. Confusion of symbiont traces and those produced by predation may represent pitfalls in ecological and paleoecological studies. Thus, a proper knowledge of both is required.

I studied various symbionts dwelling inside crinoid and echinoid skeletons and the response of both fossil and Recent echinoderm skeletal tissues to endoparasitic infestation. The evolution of complex structures such as galls is of particular interest. Do galls represent simple adaptive structures or the gallmakers' extended phenotype? Examples presented here show that galls can be used to reconstruct host-symbiont systems in deep time and reveal co-evolutionary processes such as host/symbiont co-speciation. 
Different non-destructive techniques of computer tomography (neutron- microand synchrotron-CT) were applied which proved to be a powerful tool. On the basis of different examples, I compare these various techniques and will discuss their advantages and drawbacks in practical operation.

\section{New echinoderm-Lagerstätten from the Lower Ordovician of central Anti-Atlas (Zagora area, Morocco): a Gondwanan perspective of the Great Ordovician Biodiversification Event [oral presentation]}

Fleur Noailles ${ }^{1}$, Bertrand Lefebvre ${ }^{2}$, Thomas E. Guensburg ${ }^{3}$, Aaron W. Hunter $^{4,5}$, Elise Nardin ${ }^{6}$, Colin D. Sumrall ${ }^{7}$ \& Samuel Zamora ${ }^{8}$

'Department of Earth Sciences, University of Bristol, Bristol, UK; E-mail: Fleur.Noailles@bristol.ac.uk

${ }^{2}$ UMR CNRS 5125 Paléoenvironnement \& Paléobiosphère, Université Lyon 1, Villeurbanne, France; E-mail:bertrand.lefebvre@univ-lyon1.fr

${ }^{3}$ Physical Science Division, Rock Valley College, Rockford, Illinois, US A;

E-mail:t.guensburg@rockvalleycollege.edu

${ }^{4}$ Department of Geosciences \& Petroleum Engineering, Petronas University of Technology, Tronob, Perak, Malaysia; E-mail:aaron_bunter@petronas.com.my

${ }^{5}$ Georg-August-Universität Göttingen, Museum, Sammlungen \& Geopark, Goldscbmidtstr. 1-5, D-37077 Göttingen, Germany

${ }^{6}$ Institute of Geology and Mineralogy, University of Cologne, Köln, Germany;

E-mail:elnardin@gmail.com

${ }^{7}$ Department of Earth and Planetary Sciences, The University of Tennessee, Knoxville, Tennessee, USA; E-mail: csumrall@utk.edu

${ }^{8}$ Area y Museo de Paleontologia, Departamento de Ciencias de la Tierra, Universidad de Zaragoza, Zaragoza,Spain; E-mail: samue@unizar.es

Keywords: Blastozoa, Crinoidea, Edrioasteroidea, Eocrinoidea, Soluta, Somasteroidea, Stylophora, echinoderm Lagerstätten, Ordovician, Gondwana, Morocco

Until recently and with few exceptions (e.g., the eocrinoid Rhopalocystis), echinoderms were considered extremely rare fossils in the Lower Ordovician of the AntiAtlas, southeastern Morocco. Their first report in the Drâa valley dates back only to the 1950s (one concretion containing specimens of the glyptocystitid rhombiferan Macrocystella bohemica). In the second half of the XXth century, extensive field work conducted by Jacques Destombes provided more abundant material, thoroughly investigated by Georges Ubaghs (Rhopalocystis destombesi), and mostly by Jean Chauvel. This resulted in the description of 10 genera of blastozoans (Aristocystites?, Balantiocystis, Macrocystella, Palaeosphaeronites, Rhopalocystis), crinoids (Ramseyocrinus), edrioasteroids (Hemicystites?), and stylophorans (Anatifopsis, Chawvelicystis, Thoralicystis). However, the majority of taxa are only known from just a 
handful of specimens (including the holotype). In the early 2000s, the discovery of the Fezouata Biota (latest Tremadocian-mid Floian) corresponds to a dramatic turnover in the knowledge of Early Ordovician echinoderm faunas from southeastern Morocco. Exceptionally preserved fossils of the Fezouata Biota comprise not only abundant remains of Burgess Shale-type fossils (e. g., anomalocaridids, various stem arthropods, demosponges, halkierids, armoured lobopods, marrellomorphs, wapkiids), and non-biomineralized early representatives of post-Cambrian taxa (e. g., cheloniellid and xiphosuran arthropods, machaeridians), but also diverse and extremely numerous echinoderms (thousands of specimens belonging to at least 20 new genera). Late Tremadocian echinoderm assemblages are dominated by eocrinoids and cornute stylophorans. These occur in relatively dark shales containing abundant graptolites, and generally interpreted as relatively deep deposits (outer shelf). Early to mid Floian echinoderm assemblages are far more diverse. They are dominated either by eocrinoids, glyptocystitid rhombiferans, solutes, or stylophorans (mostly cornutes). Other taxa include crinoids, edrioasteroids, and somasteroids. Echinoderms are often associated with a rich and diverse benthic fauna (e. g., bivalves, gastropods, trilobites). They occur either in light, micaceous shales, or in concretions. Such deposits are generally interpreted as moderately deep (midshelf, below storm wave base). Consequently, the successive assemblages of the Fezouata Biota offer an unprecedented opportunity to document the early stages of the Great Ordovician Biodiversification Event within the echinoderm faunas of high latitude Gondwanan regions.

\section{Molecular phylogeny of the order Euryalida (Ophiuroidea)} [oral presentation]

\section{Masanori Okanishi ${ }^{1} \&$ Toshihiko Fujita $^{2}$}

${ }^{1}$ Department of Biological Sciences, Graduate School of Science, The University of Tokyo, National Museum of Nature and Science, Hyakunin-cho 3-23-1, Shinjuku-ku, Tokyo, 169-0073 Japan; E-mail: okanishi@kahaku.go.jp

${ }^{2}$ Department of Zoology, National Museum of Nature and Science, Hyakunin-cho 3-23-1, Shinjuku-ku, Tokyo,169-0073Japan; E-mail:fujita@kahaku.go.jp

Keywords: Ophiuroidea, taxonomy, molecular phylogeny, rRNA, western Pacific

The order Euryalida includes snake stars and their relatives, currently comprises four families, Asteronychidae, Asteroschematidae, Euryalidae and Gorgonocephalidae. Euryalid ophiuroids are generally distributed in deep waters at approximately $100 \mathrm{~m}$ or greater depth, and often live on the hard bottom or attached to octocoral colonies. They are not so frequently collected, and their taxonomy and phylogeny are poorly known. In this study, the first molecular phylogeny of the euryalid ophiuroids using more than 50 species (including 5 undescribed species), collected from Japan, Australia, New Zealand, Antarctic Ocean, was constructed. 
Bayesian, maximum likelyhood and maximum parsimony trees were estimated from partial nuclear and mitochondrial genes, and resolutions of each node of mitochondrial gene trees were higher than of nuclear gene trees. The trees showed that monophyly of the order Euryalida is highly supported and that Ophiomixidae which were traditionally considered closely related to Euryalida was clearly distinguished from Euryalida. Asteronychidae and Gorgonocephalidae were monophyletic, and these two families were clearly recognized taxa. Monophyly of the clade Euryalidae and Asteroschematidae was highly supported. In this clade, Asteroschematidae was paraphyletic to Euryalida. In particular, positions of Asteroschema, Astrocharis and Astrobrachion have some problems in the tree. Based on the molecular phylogeny and detailed observation of ossicle morphology, taxonomy of Asteroschematidae and Euryalida were revised, and diagnoses of these families were revised.

\title{
Regulation of Regeneration and Development in Echinoderms [oral presentation]
}

\author{
Olga Ortega-Martinez ${ }^{1}$, Sam T. Dupont ${ }^{1} \&$ Mike S. Thorndyke ${ }^{2}$
}

${ }^{1}$ Department of Marine Ecology, University of Gothenburg, Sweden;

E-mail:olga.ortega-martinez@marecol.gu.se@sam.dupon@@marecol.gu.se

${ }^{2}$ The Royal Swedish Academy of Sciences, Sweden; E-mail: mike.thorndyke@marecol.gu.se

Keywords: Ophiuroidea, regeneration, skeletogenesis, ocean acidification

Our overall aim is to achieve a better understanding of gene regulatory pathways shared by embryonic/larval development and adult regeneration in echinoderms, especially brittlestars. Our focus is on early events in cell lineage regulation and key events in skeletogenesis/biomineralization, critical stages for both larval development and adult growth/regeneration but temporally and spatially separated.

Echinoderms are deuterostomes and close to the common ancestor of chordates, thus a better understanding of their developmental pathways is also highly relevant to chordate evolution. This regulatory system is also likely to be highly sensitive to environmental stressors, e. g. OA is likely one of the biggest challenges to face mankind in the present century and predicted changes are likely to have significant impacts on our ecosystems. Genetic information about brittle stars has been until now extremely limited. We have developed and sequenced a 454 EST collection (400K reads at 400-800 bps each). This new information together with the huge advances made in genomics, cell and molecular biology is helping us to understand the basic features of development and regeneration in a tractable deuterostome model system and employ these tools to inform on and predict the global consequences of $\mathrm{OA}$ on key marine invertebrate taxa. We shall present recent data that is helping us to: (a) develop a deep understanding of key early developmental events in larval and adult echinoderms, with special emphasis on 
cell lineage and skeletogenesis; (b) analyse the affects of predicted near-future levels of $\mathrm{OA}$ on development and regeneration.

Casual hermaphroditism in a population of the gonochoric sea cucumber, Isostichopus badionotus Selenka (Echinodermata: Holothuroidea) of north eastern Venezuela [posterpresentation]

\section{José Luis Palazón-Fernández}

Universidad de Oriente, Núcleo de Nueva Esparta, Instituto de Investigaciones Cientificas, Apdo. 147, Isla de Margarita, Venezuela; E-mail:jose.palazon@ne.udo.edu.ve o jluis.palazon@icman.csic.es

Keywords: Holothuroidea, Aspidochirotida, reproduction, casual hermaphroditism

Hermaphroditic specimens of the sea cucumber Isostichopus badionotus were captured in northeastern Venezuela (south Caribbean Sea) as part of a study on the reproductive biology of the species. The proportion of hermaphrodites was 7 of $339(2.06 \%)$. The gonads of the hermaphrodites were all mature or partially spawned and their histological characteristics did not differ from those of the gonochoric individuals. Female tubules predominate. During sampling, the specimens were macroscopically sexed as females. Male tubules presented mature spermatozoa, and female ones had mature oocytes. Consequently it is possible that both types of gametes could be released simultaneously, and self fertilization may occur. Causal hemaphroditism has been observed in other Isostichopus species, as well as in other tropical species, as Holothuria atra. It has been also observed in another population of I. badionotus from Morrocoy Bay (northwestern Venezuela) but not in specimens from southeast Brazil. Casual hermaphroditism can be a product of over-fishing of the species.

Images of Echinoderms from Bathyal Depths off South Carolina, USA: Some Sidelights on Seasonal Cidaroid Sex in the Sea

[poster presentation]

David L. Pawson ${ }^{1}$, George R. Sedberry ${ }^{2}$, Susan T. DeVictor ${ }^{3}$ \& Doris J. Pawson $^{1}$

${ }^{1}$ Department of Invertebrate Zoology, National Museum of Natural History, Smithsonian Institution, Washington DC 20013-7012, USA; E-mail:pawsond@si.edu

${ }^{2}$ Gray's Reef National Marine Sanctuary, 10 Ocean Science Circle, Savannah, Georgia 31411, USA

${ }^{3}$ Southeastern Regional Taxonomic Center, Marine Resources Research Institute, PO Box 12559, Charleston, SC 29422, USA

Keywords: Echinoidea, Stylocidaris, deep-sea, breeding, feeding 
Two photographs of small clusters of cidaroid sea urchins (possibly Stylocidaris sp.) on the deep-sea floor were published by Pawson (1976), who suggested that these may be a breeding aggregation, rather than a feeding aggregation. Aggregations of echinoderms, perhaps for reproduction, were briefly discussed by Gage \& Tyler (1991), and they referenced images of another echinoid species and an elasipod holothurian. In their excellent study of aggregation of small numbers of Stylocidaris lineata, Young et al. (1992) found that these cidaroids were clustering during the breeding season; presumably the clustering would enhance the chances of fertilization of newly-released eggs by sperms released into the seawater by a male nearby. Similar inferences were made concerning clusters of synallactid holothurians by Tyler et al. (1992). Further support for the 'breeding, not feeding' interpretation was provided by some superb images of echinoderms taken recently by an ROV operated from the NOAA ship Pisces off South Carolina, USA. Two images taken at $200 \mathrm{~m}$ show four closely clustered individuals of Stylocidaris lineata sensu lato, but here two of the individuals are almost upside-down, with their mouths facing away from the substratum - suitable when they are releasing eggs or sperms into the seawater, but definitely not a good position to be in if these urchins are simply a feeding aggregation!

\title{
Exceptional Tortonian Echinoderm Palaeodiversity at Lagoa de Albufeira (Setúbal Peninsula, Portugal) [oral presentation]
}

\author{
Bruno Pereira ${ }^{1}$, Pedro Pereira ${ }^{2,3}$ \& Mário Cachão ${ }^{1,3}$ \\ ${ }^{1}$ Geology Department, Sciences Faculty, University of Lisbon, Campo Grande, Lisbon, Portugal; \\ E-mail: bmcpereira@gmail.com \\ ${ }^{2}$ Sciences and Technology Department, Portuguese Open University, Lisbon, Portugal; \\ E-mail:pecten@uab.pt \\ ${ }^{3}$ Geology Centre of the University of Lisbon, Campo Grande, Lisbon, Portugal; \\ E-mail:mcachao@fc.ul.pt
}

Keywords: Echinodermata, Tortonian, palaeobiodiversity, Setúbal Peninsula, Portugal

The study of several coastal cliff outcrops around Lagoa de Albufeira, $25 \mathrm{~km} \mathrm{SSW}$ of Lisbon (Setúbal Peninsula, Portugal), disclosed rich and diversified assemblages of fossilized echinoderm ossicles. The sedimentary matrix is constituted by a fine to very fine gray, yellowish to white micaceous sandstone. Planktonic Foraminifera and calcareous nannofossils provide a biostratigraphic framework for these outcrops within the Lower Tortonian age. The first and second layers of the outcrop were sampled. Four bulk samples were wet sieved and the fraction larger than $1 \mathrm{~mm}$ dry picked. The silty-clay fraction $(<63 \mu \mathrm{m})$ was subsequently subjected to permanent smear slide preparations. 
All five echinoderm classes (Echinoidea, Asteroidea, Ophiuroidea, Crinoidea and Holothuroidea) are represented in the same assemblage, mostly by isolated ossicles and some small echinoid tests still intact. Fossil preservation is excellent, with no evidences of transport and dissolution. Specifically, approximately three hundred isolated ophiuroid ossicles were found in each kilogram of dry sediment, namely vertebrae, lateral, dorsal and ventral arm shields, oral shields, oral plates and radial shields. Some of those ossicles were tentatively assigned to Ophiura sp., others were not yet possible to determine. Regarding the crinoids, they are also mostly represented by isolated ossicles attributed to the comatulid Palaeantedonsp. Approximately three hundred isolated brachials and cirrals and some centrodorsals that still hold the radials in connection were found in each kilogram of dry sediment. The echinoids are represented by tests of Echinocyamus sp., spine fragments of Diadematidea, test fragments of Genocidaris sp. and Psammechinus sp. and five camarodont demipyramids. Ossicles of both asteroids Astropecten sp. and Luidia sp. were identified. Astropecten is represented by supramarginal, inframarginal and ambulacral ossicles, while for Luidia sp. only inframarginal and ambulacral ossicles were found. Some paxillae were also recognized but still not classified. Finally, holothuroid ossicles (button type) were recognized in the silty-clay fraction but no detailed identification is yet possible. Further work, namely on present day comparison material is in progress.

\section{Effect of the Pleistocene glaciations on the phylogeography of Marthasteria glacialis: two lineages in the Mediterranean [oral presentation]}

\section{Rocío Pérez-Portela ${ }^{1} \&$ Adriana Villamor ${ }^{2}$}

${ }^{1}$ Department of Animal Biology, Faculty of Biology, University of Barcelona, 645 Diagonal Avenue, E-08028, Barcelona, Spain; E-mail: rocio_perez@ub.edu

${ }^{2}$ Centre d'Estudis Avançats de Blanes (CSIC), Accés a la Cala St. Francesc 14, Blanes, Girona, E-17300,Spain; E-mail: villamor@ceab.csic.es

Keywords: Asteroidea, cryptic species, speciation, phylogeography, DNA sequences

We explore the phylogeography of the broadcast spawner Marthasterias glacialis along south Europe, Azores and South Africa. Sequences from three different mitochondrial markers (the Cytochrome c oxidase, 16S and Control Region) together with an intron of the nuclear protein-coding gene (ATP synthase beta subunit) were analyzed. Sequences obtained from all the genes grouped within three distant lineages (divergence $3 \%$ approx.) which may indicate the presence of three different cryptic species. One of the lineages was Atlanto-Mediterranean whereas the other two were exclusively Mediterranean and South-African, respectively. Estimation of lineages split goes back to 460,000-630,000 years ago. This suggests that sea level oscillations during the Pleistocene glaciations promoted gene 
flow interruption and lineage divergence between basins. Population genetic analyses applied to the European populations demonstrated that secondary contact between populations allowed a re-colonization of the Mediterranean by the Atlantic lineage. When animals of the Atlanto-Mediterranean lineage were considered separately Fst index and AMOVA did not show significant differences either between populations along the Iberian Peninsula or basins. Isolation by distance between populations was not detected at European level, and only populations of Plymouth and Azores showed significant differences to all the others. The remoteness of Azores islands might explain the structure of this population. Haphazard arrival of larvae and local extinctions rather than contemporary restricted gene flow might be responsible for the distinctive population structure of Plymouth.

\section{Biogeography and macroecology of Antarctic and sub-Antarctic echinoids [oral presentation]}

Benjamin Pierrat ${ }^{1}$, Thomas Saucède ${ }^{1}$, Chantal De Ridder ${ }^{2}$, Alain Festeau ${ }^{1}$, Rémi Laffont $^{1} \&$ Bruno David ${ }^{1}$

${ }^{1}$ Université de Bourgogne-CNRS, UMR 5561 Biogéosciences, Dijon, France;

E-mail: benjamin.pierrat@u-bourgogne.fr

${ }^{2}$ Laboratoire de Biologie Marine, Université Libre de Bruxelles, 50 avenue F.D. Roosevelt, 1050 Bruxelles, Belgium; E-mail: cridder@ulb.ac.be

Keywords: Echinoidea, biogeography, macroecology, niche modelling, Antarctic

Many facts already show how impacted Polar seas are by the present-day global warming. To cope with climate-induced changes and survive, Antarctic and Subantarctic marine organisms can either migrate or adapt to the new prevailing conditions. Besides, new biogeographic distributions have already been documented so that unpredictable biotic interactions between southernmost species and subantarctic invaders can be expected. Prior to any prediction about biogeography in the future, it is essential to map present-day distributions and understand the underlying forcing factors. At local scale (sampling station scale), species distribution is mostly explained by proximate environmental parameters (chemical, physic$\mathrm{cal}$ and biological). At larger scale (from the region to the entire ocean), Earth and clades history are to be considered instead, though environmental factors and history may work in concert to control species distribution.

In the present work, the biogeographic mapping of Antarctic echinoids (south of $45^{\circ} \mathrm{S}$ latitude) was performed both using data from the literature and new records of many cruises recently led around Antarctica. Our objective was to identify and characterize the main factors that control echinoid distribution in the Southern Ocean. To obtain a comprehensive model that integrates echinoid biogeography and macroecological patterns, oceanographic and physical data were matched to 
echinoid distribution using a niche habitat modelling procedure. Three alternative hypotheses were tested: (1) is the Antarctic echinoid distribution controlled by oceanographic and physical factors such as water temperature, sediment nature, depth, etc. (environmental hypothesis), (2) is echinoid distribution better explained by historical biogeography (provincialism hypothesis), or (3) do environmental parameters and historical biogeography work in concert and structure the echinoid distribution? Our results show that depth, primary production (chlorophyll $\alpha$, oxygen and nitrogen oxides concentrations) and seafloor characteristics (sediment nature, seafloor temperature) best explain the distribution of Antarctic echinoids.

The discrepancy between observed and expected distributions reveals the part played by history.

\title{
Biodiversity of echinoderms (Echinodermata) of the southern Gulf of California, Mexico, from 0 to $300 \mathrm{~m}$ depth [oral presentation]
}

\author{
Tania Pineda-Enríquez \& Francisco Alonso Solís-Marín
}

Instituto de Ciencias del Mar y Limnología (ICMyL), Laboratorio de Sistemática y Ecología de Equinodermos (LSEE), Universidad Nacional Autónoma de México (UNAM);

E-mail:tania_pinedae@hotmail.comerfasolis@cmarl.unam.mx

Keywords: Echinodermata, deep sites, shallow sites, Gulf of California, México

The Gulf of California, Mexico, holds a considerable biodiversity of echinoderms. The faunistic inventories of Mexican echinoderms have few actual records on deep sites, because most of the studies were made on littoral sites. This is the first time that a research submersible 'DeepSee' was used for collecting porpoises at the south part of the Gulf of California. 'DeepSee 2008 Expedition' was carried out during 10 days, from August 22 $2^{\text {nd }}$ to September $2^{\text {nd }}$ 2008. The collecting area expands from Loreto to La Paz Bay, Baja California, Mexico, on shallow (0 to $30 \mathrm{~m}$ ) and deep sites (100 to $300 \mathrm{~m}$ ). The study area is characterized principally by abrupt inclinations $\left(\sim 70^{\circ}\right)$ on rocky substrates. The aim of this study was to increase the knowledge on the biodiversity of the Phylum Echinodermata that inhabits the Gulf of California, Mexico. A photograph catalog, identification keys and the comparison of the taxonomic composition between the shallow and deep sites is presented. A total of 60 species of echinoderms are presented, included in 43 genera, 29 families, 13 orders and 4 classes. The shallow areas were the most diverse by far, including 39 species. Five new records for the Gulf of California are presented: Luidia phragma H. L. Clark, 1910, Amphiaster insignis Verrill, 1868, Narcissia gracilis A. H. Clark, 1916, Henricia nana Ludwig, 1905 and Ophioderma vansyoci Hendler, 1996, sometimes also showing bathymetric and/or geographic extension. The Class Asteroidea and Ophiuroidea are the most representative, with 20 species each one; meanwhile, the Class Echinoidea with 12 species and the Class Holothuroidea by 8 species. 


\title{
Göttingen - a place of long tradition and history in echinoderm research [poster presentation]
}

\author{
Mike Reich ${ }^{1,2}$ \\ ${ }^{1}$ Georg-August-Universität Göttingen, Museum, Sammlungen \& Geopark, Goldschmidtstr. 1-5, \\ D-37077 Göttingen, Germany; E-mail:mreich@gwdg.de \\ ${ }^{2}$ Georg-August-Universität Göttingen, Abt. Geobiologie, Goldschmidtstr. 3, D-37077 Göttingen, \\ Germany
}

Keywords: Echinodermata, Göttingen, history of sciences, zoology, palaeontology

The Georg-August University of Göttingen (Georgia Augusta) is named after its founder, the Duke Georg August of Hanover (1683-1760), also George II King of Great Britain and Ireland, and Archtreasurer and Prince-elector of the Holy Roman Empire. The idea behind the foundation in 1737, the actual lectures began in 1734, was to create a new form of university, which would, for the purpose of enlightenment, be free of any theological censure. New professorships were created that were exclusively occupied by prominent representatives of each subject. The foundation of the Göttingen Academy of Sciences in 1751 paved the way for the university to become a high ranking scientific institution in Europe. Creating a direct connection between academic research and teaching was a superior motive. Especially throughout the $18^{\text {th }}$ century, the Georgia Augusta was one of the most thriving of the German universities, and well-known for its extremely free spirit and atmosphere of scientific exploration and research. By the first half of the $19^{\text {th }}$ century, Göttingen had become an internationally acknowledged modern university with its library of more than 250,000 volumes.

Therefore, it is not surprising that numerous famous naturalists, zoologists, palaeontologists, and collectors, like, (in chronological order) Samuel Christian Hollmann (1696-1787), Pehr Forsskål (1732-1769), Peter Simon Pallas (17411811), Johann Friedrich Gmelin (1748-1804), Johann Friedrich Blumenbach (17521840), Ernst Friedrich von Schlotheim (1764-1832), Johann Ludwig Christian Carl Gravenhorst (1777-1857), Lorenz Oken [Okenfuss] (1779-1851), Friedrich Tiedemann (1781-1861), Carl Heinrich Mertens (1796-1830), Karl Theodor Ernst von Siebold (1804-1885), Friedrich Adolf Roemer (1809-1869), Carl Ferdinand Roemer (1818-1891), Heinrich Frey (1822-1890), Rudolf Leuckart (1822-1898), Georg Meissner (1829-1905), Wilhelm Moritz Keferstein (1833-1870), Carl Claus (1835-1899), Heinrich Bolau (1836-1920), Adolf von Koenen (1837-1915), Christian Karl Hoffmann (1841-1903), Emil Selenka (1842-1901), Wilhelm Bölsche (1843-1893), Rudolph von Willemoes-Suhm (1847-1875), Johann(es) Brock (18521889), Hubert Ludwig (1852-1913), Carl Friedrich Chun (1852-1914), Georg Böhm (1854-1913), Wilhelm ('Guillermo') Bodenbender (1857-1941), Theodor Ebert (1857-1899), Otto Hamann (1857-1925), Johannes Frenzel (1858-1897), Alexander Tornquist (1868-1944), Hermann Schmidt (1892-1978), Johannes Wolburg (1905-1976), Arno Hermann Müller (1916-2004), and Gerd Lüttig (1926- 
2010), were in direct connection with the University of Göttingen or studied and/or worked on echinoderms in Göttingen during the last 250 years. Not included above are many scientists who are currently working on or have recently contributed to echinoderm research (Adolf Seilacher, Dorothea Menker, Reimund Haude, Ulrich Ehlers etc.).

Two historical echinoderm collections (fossil crinoids) of the early $18^{\text {th }}$ century were in a close relation to the city of Göttingen and the Göttingen university, including the original material published by Michael Reinhold Rosinus (1678-1725) in 1719 (Tentaminis de Lithozois ac Lithophytis olim marinis jam vero subterraneis Prodromus) and by Eberhard Friedrich Hiemer (1682-1727) in 1724 (Caput Meduse utpote novum Diluvii Universalis monumentum detectum in agro Würtembergico et brevi dissertatiuncula epistolari expositum).

The present overview will give details, pictures, and short biographical and other information, on the listed persons.

\section{How many species of fossil sea cucumbers are there?}

[poster presentation]

\section{Mike Reich ${ }^{1,2}$}

${ }^{1}$ Georg-August-Universität Göttingen, Museum, Sammlungen \& Geopark, Goldschmidtstr. 1-5, D-37077 Göttingen, Germany; E-mail: mreich@gwdg.de

${ }^{2}$ Georg-August-Universität Göttingen, Abt. Geobiologie, Goldschmidtstr. 3, D-37077 Göttingen, Germany

Keywords: Holothuroidea, palaeobiodiversity, Göttingen, history of sciences, zoology, palaeontology

Compared to other modern echinoderm groups, the evolutionary history and diversity of sea cucumbers is poorly understood. A total of more than 1,430 valid species of Recent Holothuroidea was reported recently - but how many species of fossil sea cucumbers are there?

In $1954 \mathrm{~J}$. Wyatt Durham reported $\sim 115$ valid fossil holothurian species names, and some years later, Don L. Frizzell \& Harriet Exline catalogued 128 and 153 fossil species in 1956 and 1958, respectively. In the Treatise on Invertebrate Paleontology (1966), both authors listed 295 holothurian paraspecies and species. In the next decades, the total number of fossil sea cucumber species increased: 454 (1980), 559 (1993), 794 (2004) based on sclerites and body fossils, but published by a handful of authors only (e.g., Edith Kristan-Tollmann, Helfried Mostler, Kuldip S. Soodan, Heinz Kozur, Walid Sadeddin).

Here, I offer a modern summary of fossil holothurian diversity and the most important localities (Fossillagerstätten) of holothurian body fossils as a baseline for future research. The species-level diversity of fossil Holothuroidea is summarised for each geological period since Ordovician times. In chronological order they are: 
Ordovician (6 published fossil paraspecies / species names), Silurian (0), Devonian (41), Carboniferous (68), Permian (26), Triassic (256), Jurassic (266), Cretaceous (105), Paleogene (103), Neogene (43), Quaternary: Pleistocene (17). Based on a compilation of more than 1,300 primary literature references on fossil sea cucumbers (since the $17^{\text {th }}$ century), around 600 valid species can be recognised from 930 published names. Triassic and Jurassic holothurian taxa thus appear to dominate the fossil record, compared to their Phanerozoic diversity. By contrast, Early and Late Paleozoic as well as Neogene holothurians are noticeably underrepresented as fossils, due to different reasons, such as taphonomic conditions or simple lack of work.

\title{
Middle Miocene holothurians (Echinodermata) from Austria [poster presentation]
}

\author{
Mike Reich ${ }^{1,2} \&$ Andreas $\mathbf{K r o h}^{3}$ \\ ${ }^{1}$ Georg-August-Universität Göttingen, Museum, Sammlungen \& Geopark, Goldschmidtstr. 1-5, \\ D-37077 Göttingen, Germany; E-mail:mreich@gwdg.de \\ ${ }^{2}$ Georg-August-Universität Göttingen, Abt. Geobiologie, Goldschmidtstr. 3, D-37077 Göttingen, \\ Germany \\ ${ }^{3}$ Naturbistorisches Museum Wien, Geologie \& Paläontologie, Burgring 7, 1010 Wien, Austria; \\ E-mail:andreas.krob@nhm-wien.ac.at
}

Keywords: Holothuroidea, Miocene, Badenian, Central Paratethys, Vienna Basin, Austria

Compared to other modern echinoderm groups, the evolutionary history of holothurians is poorly understood, owing to their preservation almost exclusively as microfossil. In comparison to older strata, the Cenozoic fossil record of sea cucumbers is particularly scarce. This is in stark contrast to most other invertebrate groups, in which the fossil record tends to improve with declining age.

The Central Paratethys (Europe) is one of the most intensely studied Neogene basins and has yielded a rich echinoderm fauna including representatives of all moden echinoderm classes. Unfortunately, most of the holothurian sclerites reported from that area by previous authors have been lost. Here we present new data based on a survey of old micropalaeontological samples (second half of the 19th century), deposited in the Natural History Museum of Vienna, as well as new samples collected from deposits rich in echinoderm remains. The samples studied derive from silty clays and marls from the Austrian part of the Vienna Basin and are Badenian (= Langhian to Early Serravallian) in age. The samples were processed to preserve the fine fractions needed for the successful recovery of holothurian sclerites. Out of more than twenty-five samples, only two yielded wellpreserved holothurian echinoderms. 
The present material includes most of the sclerite morphotypes reported by earlier authors and thus allows a critical review of the numerous holothurians parataxa introduced for Paratethyan material, based on sclerite association based taxon reconstruction.

At least ten biological species of the Molpadiida (Molpadiidae), Dendrochirotida, Aspidochirotida (Holothuriidae), Apodida (Synaptidae, Chiridotidae, and Myriotrochidae) could be documented in form of sclerites from the body wall, as well as calcareous ring elements. Especially the classic 'Badener Tegel'-samples of Baden near Wien (former brickyards between Baden and Sooss) yielded exceptionally well-preserved material. Infaunal molpadiid representatives dominate the faunal holothurian association of the 'Badener Tegel'. This includes the first fossil record of small amorphous ferric phosphatic dermal granules, which are typical for members of the Molpadiidae and a unique biomineralogical phenomenon for the Echinodermata as a whole. The recorded holothurians are deposit feeders (Molpadiida, Aspidochirotida, Apodida) and suspension feeders (Dendrochirotida) with an epibenthic or cryptic (Aspidochirotida, Dendrochirotida in part) as well as an infaunal/semi-infaunal (Molpadiida, Apodida) lifestyle. The associated echinoderm fauna consists mostly of cidaroid and spatangoid echinoids and disarticulated ophiuroid and asteroid ossicles.

The new holothurian finds and the assemblage support in part the assumption that the echinoderm palaeo-community of the 'Badener Tegel' is characteristic for low-energy mud-bottoms below the photic zone. The deposition of the sediment occurred at a water depth of around $200 \mathrm{~m}$ in a relatively warm, well-stratified water column within the Vienna Basin of the Central Paratethys.

\title{
Modern holothurian calcareous ring anatomy and stereom structure - the need for more detailed studies and research [posterpresentation]
}

\author{
Mike Reich ${ }^{1,2} \&$ P. Mark O'Loughlin ${ }^{3}$ \\ ${ }^{1}$ Georg-August-Universität Göttingen, Museum, Sammlungen \& Geopark, Goldschmidtstr. 1-5, \\ D-37077Göttingen, Germany; E-mail:mreich@gwdg.de \\ ${ }^{2}$ Georg-August-Universität Göttingen, Abt. Geobiologie, Goldschmidtstr. 3, D-37077 Göttingen, \\ Germany \\ ${ }^{3}$ Marine Science Department, Museum Victoria, GPO Box 666, Melbourne 3001, Australia; \\ E-mail:pmo@bigpond.net.au
}

Keywords: Holothuroidea, calcareous ring, stereom structure, x-ray computed tomography, SEM

Of the five extant classes of echinoderms, the sea cucumbers have by far the poorest fossil record, largely because their skeleton is usually reduced to microscopic elements loosely distributed inside a collagenous integument. The group, 
however, is diverse, with approximately 1,450 described species that can be found living in most marine habitats. Diagnostic calcitic ossicles of holothurians extend back to at least the Middle Ordovician (465 Ma), although only a handful of Lagerstätten yielding body fossils are scattered throughout the remaining Phanerozoic. The other diagnostic characteristic of sea cucumbers is the calcareous ring (cr), a defining feature, which is possessed by nearly all modern holothurian species. The cr supports the pharynx, the anterior section of the water vascular system and provides points of attachment for the longitudinal and (if present) retractor muscles; furthermore, it is known that in some groups, a notch or a perforation in radial elements is present for the passage of radial nerves. However, almost nothing is known about the 3D-morphology and the stereom structure of the holothurian calcareous ring; similarly, the evolutionary origin of this structure is also uncertain. According to taxonomical studies on modern holothurians, the $\mathrm{cr}$ is considered to be highly important because of major differences in the calcareous rings of the various orders and/or families. There are a few reports on fossil calcareous ring elements, but this structure was nearly completely neglected by palaeontologists. Isolated fossil calcareous ring elements were mostly misinterpreted as aberrant ossicles or 'fused side shields' of ophiuroids. However, this structure offers more information, but this can only be deduced through a better '3-D' understanding of the calcareous ring of modern sea cucumbers, which is still largely missing.

Here we offer preliminary results from detailed studies of hard parts using X-ray computed tomography and scanning electron microscopy of members $(>15$ species) of the Apodida (Chiridotidae, Myriotrochidae), Aspidochirotida (Holothuriidae, Synallactidae), Dactylochirotida (Ypsilothuriidae), Dendrochirotida (Cucumariidae, Psolidae), Elasipoda (Elpidiidae, Laetmogonidae), and Molpadiida (Caudinidae, Eupyrgidae, Molpadiidae).

\title{
A new deep-sea holothurian representative from the Palaeozoic Hunsrück Slate Fossillagerstätte (Early Devonian, Germany)
} [poster presentation]

\author{
Mike Reich ${ }^{1,2} \&$ Andrew B. Smith ${ }^{3}$ \\ ${ }^{1}$ Georg-August-Universität Göttingen, Museum, Sammlungen \& Geopark, Goldschmidtstr. 1-5, \\ D-37077 Göttingen, Germany; E-mail:mreich@gwdg.de \\ ${ }^{2}$ Georg-August-Universität Göttingen, Abt. Geobiologie, Goldschmidtstr. 3, D-37077 Göttingen, \\ Germany \\ ${ }^{3}$ Natural History Museum, Palaeontology Department, Cromwell Road, London SW7 5BD, UK; \\ E-mail:a.smith@nhm.ac.uk
}

Keywords: Holothuroidea, Elasipodida, Devonian, Hunsrück Slate, Germany 
Among all five groups of modern Holothuroidea, the elasipodid sea cucumbers are unique in being confined to the deep sea. There are nearly 150 species of 5 families widely distributed in depths over 200-400 $\mathrm{m}$, and many of them are cosmopolitan in distribution. Modern elasipodid holothurians are characteristic of abyssal and hadal depths, where they can be found in deepest trenches, constituting up to $90 \%$ of the total biomass. All elasipodids are strongly bilaterally symmetrical, and they often possess bizarre body forms with elongate projections or transparent veils, whereas the body wall of these forms is fragile and often quite gelatinous. Consequently, the fossil record of elasipodid holothurians is very poor and incomplete. Approximately half of all modern members of Elasipoda are believed to be capable of swimming, and a few species apparently spend most of their life swimming. Elasipods are divided into families based primarily on their calcareous body wall ossicles and calcareous ring structure.

While studying 'Palaeocucumaria' specimens from the Early Devonian (Emsian) Hunsrück Slate, we came across two sea cucumbers that were clearly different. These two new specimens are considerably larger than the previously known Palaeocucumaria' specimens from the Hunsrück Slate and show no evidence of having the large plated tube-feet that characterise that genus. Furthermore, detailed inspection using X-ray computed tomography of the calcareous ring preserved in situ shows it to be composed of 5 interradial and radial elements, the latter $\mathrm{x}$ shaped, having typically 4 processes as in modern deimatid deep-sea holothurians.

The new find represents the first unequivocal record of a deep-sea holothurian body fossil from the Palaeozoic, and it implies a deep split between Deimatidae and Laetmogonidae (Elasipoda). This indicates that crown group holothurian divergence had taken place by the early Devonian as suggested recently by the authors. Furthermore, the new genus and species is the earliest holothurian body fossil in which there is a clear differentiated sole and ventral mouth - implying this to have been an epifaunal detritus feeder. The next youngest body fossil with a sole was reported from the Middle Triassic.

Finally, there is one open question: It is widely accepted that the water depths represented by the Hunsrück Slate did not exceed $200 \mathrm{~m}$, so when did elasipodid holothurians disappear from the continental shelf record?

\title{
Holothurians (Apodida) from the Late Palaeozoic Mazon Creek Fossillagerstätte (Illinois, USA) [poster presentation]
}

\author{
Mike Reich $^{1,2} \&$ Tanja Stegemann ${ }^{1}$ \\ ${ }^{1}$ Georg-August-Universität Göttingen, Museum, Sammlungen \& Geopark, Goldschmidtstr. 1-5, \\ D-37077Göttingen, Germany; E-mail:mreich@gwdg.de \& tstegem@gwdg.de \\ ${ }^{2}$ Georg-August-Universität Göttingen, Abt. Geobiologie, Goldschmidtstr. 3, D-37077 Göttingen, \\ Germany
}

Keywords: Holothuroidea, Apodida, fossillagerstätte, Carboniferous, Illinois, USA 
The Mazon Creek biota of northeastern Illinois provides the most complete record known of late Palaeozoic life. All fossils occur almost exclusively in siderite concretions in the Francis Creek Shale Member of the Upper Pennsylvanian Carbondale Formation (Westphalian D). This Fossillagerstätte is famous for organisms with non-mineralised skeletons, like hydrozoan, scyphozoan and cubozoan cnidarians, or priapulid and echiurid 'worms'. Apart from one single crinoid specimen, the only other echinoderm found is a holothurian, which is actually quite common in the Essex fauna (Pit 11) of the southern Mazon Creek area. The holothurian was often listed or named as 'Achistrum', but this is actually a paragenus name for hook-like ossicles. In contrast to the Braidwood fauna, the Essex fauna represents a brackish and restricted marine habitat, associated with a deltaic environment.

After a first mention in the 1950s by Eugene Richardson, these findings were negated over decades. It is suprising that only two preliminary descriptions exist up to now regarding the sparse holothurian fossil record, consisting mostly of disarticulated material.

During the last years, we studied more than 3,500 holothurian body fossil specimens, mostly stored in the Royal Ontario Museum in Toronto, Canada. At the present stage of our work, all specimens represent a single chiridotid species of the Taeniogyrinae (Apodida) with a body length of $2-11 \mathrm{~cm}$ and a diameter of $0.5-$ $1.5 \mathrm{~cm}$. Well-preserved specimens contain a typical apodid band-like calcareous ring (diameter $4 \mathrm{~mm}$ ) of 5 interradial and 5 radial elements as well as hook-shaped ossicles of bimodal size (150-250 $\mu \mathrm{m}$ and $550-800 \mu \mathrm{m})$, comparable to modern taeniogyrinid sigmoid rods. Almost all ossicles in situ are clearly arranged in rows as in modern forms. Soft-tissue preservation is known from gut traces, but no tentacles have yet been clearly observed.

Numerous fossils of the Mazon Creek biota suggest rapid deposition, e. g. buried in life position, which we can also assume for all well-preserved holothurians. There are also a few comparable modern brackish environments with burrowing, small to medium-sized, apodid holothurians (e. g. Protankyra, Synaptidae).

This new genus and species represents the only holothurian body fossil with body wall ossicles and the entire calcareous ring preserved in situ as well as softtissue preservation. It also implies a deep split between all apodid families and a very early diversification of this group, as suggested recently by the first author. 


\title{
Hard-part morphology of the sea cucumber Eupyrgus scaber (Holothuroidea: Molpadiida: Eupyrgidae) [posterpresentation]
}

\author{
Mike Reich ${ }^{1,2}$ \& Sabine Stöhr ${ }^{3}$ \\ ${ }^{1}$ Georg-August-Universität Göttingen, Museum, Sammlungen \& Geopark, Goldschmidtstr. 1-5, \\ D-37077 Göttingen, Germany; E-mail:mreich@gwdg.de \\ ${ }^{2}$ Georg-August-Universität Göttingen, Abt. Geobiologie, Goldschmidtstr. 3, D-37077 Göttingen, \\ Germany \\ ${ }^{3}$ Swedish Museum of Natural History, Department of Invertebrate Zoology, Box 50007, S-10405 \\ Stockholm,Sweden; E-mail: sabine.stohr@nrm.se
}

Keywords: Holothuroidea, Molpadiida, Eupyrgidae, calcareous ring, ossicles, morphology

The placement of the two rare families, currently referred to the Molpadiida, Gephyrothuriidae and Eupyrgidae, is still uncertain. The latter contains only a single genus Eupyrgus, which is known from the Arctic (probably circumpolar) and from off Korea with E. scaber and E. pacificus, respectively.

Since the erection of the Eupyrgidae by Semper in 1868, the status has been questioned again and again, and also synonymised with the Caudinidae by some authors. Both molpadiid families are similar in having no phosphatic deposits, but are different in morphology and presence of tentacles, tentacle ampullae and calcareous ossicles.

Here we offer a detailed study of hard parts, like calcareous ring elements, bodywall ossicles and anal plates, of E. scaber. It was long thought by a few authors that the low calcareous ring of Eupyrgus has no posterior prolongations, which is also a definite feature of the current family diagnosis. In contrast, recent SEMinvestigations of the calcareous ring clearly show that all ventral radial pieces have small posterior prolongations, as well as a slit-shaped perforation for the passage of the radial nerve. This obviously confirms the affinities to the Molpadiida, with resemblance to the Caudinidae concerning, among other hard parts, the calcareous ossicles.

\section{Swimming in deep-sea holothurians: an adaptation to the mid-ocean ridge environment? [oralpresentation]}

Antonina Rogacheva ${ }^{1}$, Andrey Gebruk ${ }^{1}$ \& Claudia $\mathbf{A l t}^{2}$

${ }^{1}$ P. P. Shirshov Institute of Oceanology, Russian Academy of Sciences, Nakbimovsky Pr., 36, 117997, Moscow, Russia; E-mail: antonina@ocean.ru

${ }^{2}$ National Oceanography Centre, University of Southampton, Waterfront Campus, European Way, Southampton, SO14 3ZH, UK

Keywords: Holothuroidea, adaptations, diversity 
At least 18 species of deep-sea holothurians able to swim were found during the RRS James Cook ECOMAR cruise in 2010 to the Mid-Atlantic Ridge. Holothurians were observed, photographed and video recorded using the ROV Isis at four sites around the Charlie-Gibbs Fracture Zone area at depths $2400-2750 \mathrm{~m}$. For 13 species swimming ability is reported for the first time. A number of species were observed on rocks, cliffs and steep slopes, the habitat unusual for deep-sea holothurians traditionally thought to inhabit flat areas with soft sediment rich in detritus. We suggest that swimming is essential adaptation for species living in the mid-ocean ridge environment characterised by active hydrodynamics, rough topography and a variety of habitats like cliffs, slopes and flat areas.

\title{
Symmetry of echinoderms: from initial bilaterally-asymmetric metamerism to pentaradiality [oral presentation]
}

\author{
Sergey V. Rozhnov
}

\section{A. A. Borissyak Palaeontological Institute, Russian Academy of Sciences, Moscow, Russia; E-mail:Rozbnov@paleo.ru}

Keywords: Echinodermata, symmetry, asymmetry, pentaradiality

Extant echinoderms as well as the majority of extinct echinoderms are characterized by pentaradial symmetry combined with metamerism and internal asymmetry, which is pronounced in coelom development and in the spirally twisted gut. Tripartite metamerism combined with bilateral asymmetry is manifested in echinoderm ontogeny. The morphology of some carpozoan echinoderms without radial symmetry corresponds to the bilaterally-asymmetric development of coeloms among extant echinoderms. Carpozoan echinoderms have primary bilateral asymmetry that appears in the theca shape and ambulacra arrangement. The ambulacra constitute a morphogenetic and functional whole structure consisting of water-vascular system and food-gathering grooves, covered with the ciliated epithelium. Therefore, the development of the number and location of ambulacra in the evolution was associated with the development of hydrocoel sacculate with one ambulacrum, such as solutes, to a horseshoe-shaped and closed ambulacral ring in pentaradial echinoderms. Solutes are primary bilaterally asymmetrical echinoderms; their ancestors did not possess radial symmetry, and stele and holdfast (Cambrian Coleicarpus sprinklei) are not homologous with the stalk and the holdfasts of pelmatozoan echinoderms. This is demonstrated by the absence of elevation traces in the morphology of this group the morphogenetic process, that is well known in the ontogenetic development of extant crinoids and that appears in the morphology of many fossil stalked echinoderms. The direct ancestor of echinoderms was bilaterally asymmetrical. The morphogenetic marked bilateral symmetry, like the asymmetry, appears in the time when the development of the right and left parts of the body in the ontogenesis 
begins controlled differently. With the development of bilateral symmetry, control factors become synchronized and identical in the right and left, and with the development of bilateral asymmetry they act differently. The development of asymmetry in echinoderms has led to the modular development of the right and left coeloms. This is the basis for coelomic stacking appearance in the extraxial region and twisted growth of the hydrocoel around primary A/P axis. The initially triradial symmetry showing through the pentaradiality is tied with ancestral three segmented metamerism. Pentaradial symmetry of echinoderms is the evolutionary development of the original bilateral asymmetry carried to its logical conclusion.

\section{Reinterpretation of Heckerites multistellatus Rozhnov, 1987 from the Ordovician of the Baltic Region as an unusual paracrinoid, based on new findings [posterpresentation]}

\section{Sergey V. Rozhnov \\ A. A. Borissyak Palaeontological Institute, Russian Academy of Sciences, Moscow, Russia; E-mail: Rozhnov@paleo.ru}

Keywords: Paracrinoidea, morphology, systematics, Ordovician, Baltic region

Heckerites multistellatus Rozhnov, 1987 was described and reconstructed based on several fragments of theca, from the bioherm deposits of Keila regional stage of Upper Ordovician (Katian) of northern Estonia (Vazalemma quarry). These species and genus formed a monotypic family, which is characterized by a large flat theca folded by stellate plates with pores between them, surrounded by subcylindrical marginal plates and a long series of marginal and brachiol-bearing plates, a gradually thinning stem. These characteristics enabled to bring together this family with eocrinoids that have a flat theca. New findings of theca fragments from the type locality led to the discovery of a hydropore, a gonopore and an anal cone in this species. The location and the shape of a hydropore, a gonopore, size, the structure and the position of the anal cone on the opposite side to hydropore of the theca have proved to be similar to those of the North American paracrinoids. These additional data allow us to bring together these unusual echinoderms with the North American paracrinoids. Nevertheless, a flat theca folded by stellate plates, framed by marginal plates, and biserial arms make the position of this taxon among paracrinoids unclear. Life reconstruction shows that this animal was located vertically in sedentary water, and was slightly anchored by its thin end of the stem in the muddy ground. Heckerites differs a lot from another Upper Ordovician paracrinoid genus from Baltic Region - Archadocystites, by its form of theca, structure of arms and stem. Archadocystites, in turn, differs sharply from the North American paracrinoids. Apparently paracrinoids from the Baltic Region represent two phylogenetic branches that have evolved and migrated into the Baltic Region, regardless of the North American branch of paracrinoids. 


\title{
Enzymatic food utilization in the common starfish Asterias rubens (L.) [poster presentation]
}

\author{
Reinhard Saborowski, Karin Boos \& Lars Gutow
}

Alfred Wegener Institute for Polar and Marine Research, Am Handelshafen 12, 27570 Bremerhaven, Germany; E-mail: Reinhard.Saborowski@awi.de

Keywords: Asteroidea, Asterias, digestion, enzymes, stomach, pyloric caeca

The common starfish, Asterias rubens, is a voracious predator on mussel and oyster beds. It also feeds on other sessile or infaunal invertebrates, on dead animals, and on organic surface films. Asteroids are capable of extra-intestinal digestion. Hereby, the cardiac stomach is everted and, for example, injected into the shell of a living mussel - even through almost microscopic slits. The mussel or other prey is then subject to enzymatic degradation. The mechanism of how and where the enzymes are released or are transported to the location where they act is not yet fully understood. In order to study the enzymatic food utilization of $A$. rubens we investigated the activities of digestive enzymes in different parts of the digestive tract. Animals were collected around Helgoland in the North Sea. The principal digestive organs, the stomach and the pyloric caeca, were dissected and homogenized for enzyme analysis. The samples were assayed for a set of important digestive enzymes including proteases, glucanases, and esterases. Enzyme activities were generally low in the cardial part as well as in the pyloric part of the stomach. Typical digestive enzymes like trypsin, chymotrypsin or lipase were hardly detectable in neither of the tissues. In all parts of the pyloric caeca, however, activities of digestive enzymes were up to 60 -fold higher than in the stomach. Only acid phosphatase, a leucine-aminopeptidase, and some esterases showed similar activity levels in the stomach tissue and in the pyloric caeca. The results indicate that the pyloric caeca is the principle location of enzyme synthesis while the stomach seems to contribute only few enzymes. The enzymes which are involved in extra-oral digestion may be secreted by the pyloric caeca and then transferred to the site of enzymatic action via vibratile organelles of the epithelial cells in the stomach. 


\title{
Adaptation to shallow water environment in spatangoids
}

[poster presentation]

\author{
Masaya Saitoh $^{1} \&$ Ken'ichi Kanazawa ${ }^{2}$ \\ ${ }^{1}$ Graduate school of science, Kanagawa University, Hiratsuka, Japan; \\ E-mail:r200970168ui@kanagawa-u.ac.jp \\ ${ }^{2}$ Department of biological sciences, Kanagawa University, Hiratsuka, Japan; \\ E-mail:kanazawa@kanagawa-u.ac.jp
}

Keywords: Echinoidea, spatangoid echinoids, adaptation, ecology, growth, longevity

For three years we periodically made ecological observations of four spatangoid species by scuba diving at depths of 5-20 $\mathrm{m}$ at Oki-Island in the Japan Sea. In the spatangoids observed, there are two modes of adaptation to shallow water environment where disturbance of sediment surface occasionally happens by a storm. Metalia spatagus and Brisssus agassizii burrow deeply (usually more than $15 \mathrm{~cm}$ ) in gravelly, coarse grained sand to avoid the surface disturbance. They grow slowly (about $1.5 \mathrm{~cm}$ in test length during a period of seven months) and have a long life span (more than three years). On the other hand, Pseudomaretia alta and Lovenia elongata burrow shallowly (usually $2-3 \mathrm{~cm}$ ) in sand where disturbance of sediment surface occurs. They grow rapidly (about $3 \mathrm{~cm}$ in seven months for $P$. alta, about $6 \mathrm{~cm}$ in ten months for L. elongata) and have a short life span (one year for P. alta, more than two years for L. elongata), resulting in a rapid alternation of generations. L. elongata possesses specific functional morphology, many long spines on dorsal and ventral sides, for rapid righting and re-burrowing, which presumably allows the sea urchin to survive in disturbance of sediment surface by a storm, and to have a longer life span than $P$. alta that has no such specific functional morphology.

\section{First proteomic characterization of sea urchin tube feet and its adhesive secretion [oralpresentation]}

Romana Santos ${ }^{1,2}$, Ângela Barreto ${ }^{1}$, Catarina Franco $^{1}$ \& Ana Varela Coelho ${ }^{1}$

${ }^{1}$ Instituto de Tecnologia Química e Biológica, Universidade Nova de Lisboa Oeiras, Portugal

${ }^{2}$ Unidade de Investigação em Ciências Orais e Biomédicas, Faculdade de Medicina Dentária, Universidade de Lisboa, Portugal; E-mail: romana_santos@yahoo.com

Keywords: Echinoidea, temporary adhesion, tube feet, secreted adhesive, proteomics, mass spectrometry

Sea urchins are common inhabitants of wave-swept shores and therefore rely on their specialized oral tube feet to withstand the action of waves. The latter are extremely well-designed for temporary adhesion, possessing an apical disc that produces an adhesive secretion to fasten the sea urchin to the substratum and a de- 
adhesive secretion that allows the animal to move. Despite their technological potential for the development of new biomimetic adhesives, very little is known about the biochemical composition of sea urchin adhesives besides that they are composed of a mixture of proteins and carbohydrates. The present study intends to make a contribution in this direction through the characterization of the proteins present in the adhesive organs as well as in the secreted adhesive of the sea urchin Paracentrotus lividus. The proteome analysis of the tube feet disc extracts resulted in the identification of 457 different proteins by mass spectrometry and homology-database search. Among these, 267 were found to be homologous to proteins from generalist databases and 197 were only present in the purple sea urchin, Strongylocentrotus purpuratus, predicted-protein database. Several proteins were found that can be either involved in the adhesive process itself or in the secretion of the adhesive: extracellular proteins with known adhesive properties protein involved in exocrine secretion, proteins with anti-bacterial activity and proteins involved in $\mathrm{N}$ - and $\mathrm{O}$-linked oligosaccharide synthesis. As for the secreted adhesive, it was found to be composed of 13 proteins, 6 successfully identified in generalist databases and 7 with no homology with any available database. For the latter 5 de novo-peptide sequences were generated that were again not present in any available protein database, thus suggesting that they might be either novel or highly modified proteins ${ }^{(1)}$. To our knowledge, this study provides the first comprehensive list of proteins from sea urchin tube feet and its adhesive secretion, validating many predicted genes of the only sequenced sea urchin, $S$. purpuratus, confirming the existence of the corresponding proteins and constituting an important basis for future studies aiming to further understand temporary adhesion in echinoderms.

\title{
References
}

(1) Santos R., Costa G., Franco C., Alves P., Flammang P. \& Coelho, A. V. (2010): First insights into the biochemistry of the tube foot adhesives from the sea urchin Paracentrotus lividus. Marine Biotechnology 11: 686-698.

\section{Application of graph theory to evolution of plate architecture in Atelostomata (Echinoidea) [oral presentation]}

\author{
Thomas Saucède, Rémi Laffont, Eric François, Gunther Eble \& Bruno David \\ Université de Bourgogne-CNRS, UMR 5561 Biogéosciences, Dijon, France; \\ E-mail: thomas.saucede@u-bourgogne.fr
}

Keywords: Echinoidea, Atelostomata, graph theory, plate pattern

Graph theory concerns with the study of mathematical structures used to model pairwise relations between objects from a certain collection, and many situations in various fields can be conveniently described using graphs, from architecture to 
social and biological sciences. The echinoderm skeleton consists of many elements (so-called plates or ossicles), the boundary patterns of which are essential in systematics and related to main evolutionary events. Here we show how graph theory provides with convenient statistics and is a relevant tool for depicting and describing apical plate patterns of atelostomates, a well diversified sub-group of irregular echinoids.

In atelostomates, there are between six and nine apical plates that constitute the so called apical system, a skeletal structure involved in basic biological functions (reproduction and inner pressure control) and growth. The boundary pattern of apical plates has always been a concern of systematicists, and the way this pattern has changed through time a key to understand the evolution of atelostomates.

According to graph theory, $6.8710^{10}$ different boundary patterns can be constructed with nine elements (total number of isomorphic graphs), that is the maximum number of possible patterns. The extensive survey of literature along with our own observations led to only identify 134 different boundary patterns in adult atelostomates, that is to say 134 different ways apical plates connect to each other. This relatively low morphological diversity suggests strong biological and/or phylogenetic constraints.

The numeration and analysis of contacts among plates show that the number and density of contacts within the apical systems are low as compared to the maximum number of possible contacts indicated by graph theory, and that compactedness is unevenly arranged among plates. The comparison with random models show that those results are very unlikely to happen by chance. This latter point is discussed in relation to the evolution of the clade.

\section{The Micraster (Echinoidea; Spatangoida) succession of Northern Cantabria (Northern Spain) - preliminary data [oral presentation]}

\section{Nils Schlüter}

Institut für Geologische Wissenschaften, Fachrichtung Paläontologie, Freie Universität Berlin, Germany; E-mail:nils.schluter@gmx.de

Keywords: Echinoidea, Cretaceous, phylogeny, biostratigraphy, Spain

In the area surrounding the Cantabrian Capital Santander, Upper Cretaceous deposits are very well exposed. These are mainly marl-/limestone alternations, yielding a highly diverse echinoid fauna.

The irregular echinoid Micraster L. Agassiz is quite common in the Turonian to Campanian strata. In some intervals (e. g. Lower Coniacian, Upper Thalassinoides Rhytmites - Santonian) Micraster is superabundant. Last systematic works on Micraster of this area date back to the beginning of the $20^{\text {th }}$ century. Only few references on Micraster can be found afterwards. However, the genus Micraster is treated as a classical example of continous evolutionary lineages. This was 
examplified on populations especially of southern England and NW-Germany at the end of the $19^{\text {th }}$ respectively in the last decades of the $20^{\text {th }}$ century. These evolutionary lineages were elaborated on the stratigraphical succession of distinct morphological attributes (e. g. ornamentation of petals and periplastronal area, plastronal structure, change of the testshape: trapezoidal to cordiform). This chronology of morphological changes within the populations is also partly observed in the North Cantabrian Basin. Like elsewhere it begins in the Upper Turonian by a transition from the 'primitive' Micraster leskei (Desmoulins) to more 'advanced' forms with a rapid increase of different morphotypes. During the Campanian Micraster seems to vanish in this area.

Some stratigraphical events (Micraster leskei (small) -, Micraster leskei (large) - event, FAD of advanced forms of Micraster) found in the North Cantabrian Basin can easily be correlated with other Cretaceous basins (e. g. Anglo-Parisian Basin).

It is not clear yet, whether stratigraphic changes of morphotypes in this area are caused by a local evolutionary lineage or by a strongly facies-controlled distribution of distinct morphotypes. This question is still to be studied.

\section{Unusual fossil echinoderm faunas from the Mississippian (late Viséan) of northwest Ireland [oral presentation]}

\section{George D. Sevastopulo \\ Department of Geology, Trinity College, Dublin 2, Ireland; E-mail: gsvstpul@tcd.ie}

Keywords: Crinoidea, Blastoidea, Asteroidea, Cyclocystoidea, Echinoidea, Holothuroidea, Ophiocistioidea, Ophiuroidea, Carboniferous, Ireland

Two localities in northwest Ireland have yielded rich echinoderm faunas of late Viséan age. The faunas are dominated by micromorph crinoids, but include small blastoids, and the remains, mostly disarticulated, of asteroids, larger crinoids, cyclocystoids, echinoids, holothuroids, ophiocistioids and ophiuroids. The palaeoenvironment of the echinoderm-bearing horizons is interpreted as having been very shallow. The fauna contains taxa such as the micromorph crinoids Cranocrinus, Monobrachiocrinus and a sundacrinid for which these are the oldest stratigraphical records; others such as Hadroblastus for which this is the youngest record; others such as Synbathocrinus and a calceocrinid, which are rare in rocks of this age in western Europe. Some of the crinoids had very short stems by which they were attached to hard substrates. Carboniferous faunas of this character are rare but may contain important information about the evolution of late Palaeozoic echinoderm faunas. 


\section{Sea urchin natural population: a tool to evaluate the health condition of the Algiers bay [oral presentation]}

\section{Dina Lila Soualili-Mezali \\ Département des Ressources Halieutiques, Faculté des Sciences Exactes, et Sciences de la Nature et de la Vie, Université Abelhamid Ibn Badis-Mostaganem, BP 300 rue Hocine Hamadou, 27000, Mostaganem,Algérie; E-mail: soualilid@yahoo.fr}

Keywords: Echinoidea, Paracentrotus, heavy metals, population, reproduction, growth, Algiers bay

The aim of this study was to evaluate the presence and the impact of heavy metal contaminants in Algiers coastal water through the sea urchin bioindicator Paracentrotus lividus, in its larval and post- metamorphic stage.

Three stations were studied in Algiers area (Alger Plage, Tamentfoust and Sidi Fredj). The analysis of the heavy metal contamination in the abiotic and biotic compartments and the evaluation of its effects on the Paracentrotus lividus larval development (while using bioassays and the natural populations), made it possible to target a local pollution in both stations of Algiers bay (Alger plage \& Tamentfoust). However, if the direct effect of the heavy metal contamination seems convincing on the larval development in both stations, it appears less significant for the young and adult sea urchins, in which variability was partly required for other environmental factors. In fact, different results were obtained in the healthy station located outside the Algiers bay (Sidi Fredj), where we obtain healthy adult sea urchin which presents longer and fine spines. The hydrodynamism and the movable substrate involve a flatness of the sea urchin test allowing a better adherence. The abundance of food expressed by a continuous and relatively high trophic activity leads to a good gonadic production with a spreading generally occurring in spring and early winter. As for the sea urchins of Algiers bay, the trophic activity is also continuous, translating food sufficiency. However, the trophic index is weaker than in the station situated far away from the Algiers bay (Sidi Fredj) and confirms a lower availability of food which would lead to a different reproduction strategy: a more extreme gonadic development but also less spreading. In the Algiers bay, the 'alger plage' station appears rich in organic matter (the rate in the sediment relatively higher). The absorption of the organic matter could benefit the somatic growth of the sea urchins inhabiting this area. 


\title{
Crystalline mineral in the earliest stage of camarodont and stirodont sea urchin tooth formation [oral presentation]
}

\author{
Stuart R. Stock ${ }^{1}$, Jonathan D. Almer ${ }^{2}$, Xianghui Xiao ${ }^{2} \&$ Arthur Veis $^{3}$ \\ ${ }^{1}$ Department of Molecular Pharmacology \& Biological Chemistry, Northwestern University, Chicago, IL, \\ USA; E-mail:s-stock@northwestern.edu \\ ${ }^{2}$ The Advanced Photon Source, Argonne National Lab., Argonne, IL, USA; \\ E-mail:almer@aps.anl.gov\&xhxiao@aps.anl.gov \\ ${ }^{3}$ Department of Cell and Molecular Biology, Northwestern University, Chicago, IL, US A; \\ E-mail:aveis@northwestern.edu
}

Keywords: Echinoidea, camarodont, stirodont, tooth, x-ray diffraction, microComputed Tomography

Sea urchin teeth grow continuously and contain all stages of tooth development from the lightly mineralized plumula (aboral) to the increasingly dense shaft to the nearly solid calcite incisal end (adoral). Initially, two stacks of symmetricallyoriented primary plates grow, each in a separate syncytial space. Only at the beginning shaft region (where the keel of camarodonts and stirodonts begins to form) does a second stage of mineralization link adjacent plates (and needleprisms). Since the late 1960s, many investigators have shown that the shaft and incisal end of sea urchin teeth diffract x-rays as if the teeth were single-crystals. It was unclear, however, how the parallel but spatially-separate primary plates attained the same crystallographic orientations. Current fashion holds that amorphous calcium carbonate (ACC) forms first and that transformation to calcite occurs only via orientation transfer from more mature calcite portions of the tooth (specifically through pillar bridges that first arise on the shaft's abaxial surface). Another, out-of-favor possibility is that a single nucleation event occurs in each syncytial space and that the heterogeneous nucleation is governed by some presently unidentified templating site. This paper addresses the question of whether calcite is present in the least mature portions of the plumulae of camarodont and stirodont teeth.

Synchrotron, high-energy x-ray diffraction of living teeth in their natural milieu (enclosed in their membrane and immersed in colemic fluid) showed calcite to be present throughout the plumula. Synchrotron microComputed Tomography of the youngest portions of the teeth showed that about 50 of the most aboral primary plates were within the area interrogated by the $\mathrm{x}$-ray microbeam, and none of the plates extended into the shaft region of the tooth. Thus, ACC cannot be the sole calcium carbonate phase present in the plumula and any oriented-crystallization mechanism must allow for calcite in separate syncytial spaces. 


\title{
Diadema spines: Quantitative role of bridges between septs (wedges) in resisting bending [oral presentation]
}

\author{
Stuart R. Stock ${ }^{1}$, Fang Yuan ${ }^{2}$, L. Catherine Brinson ${ }^{2,3}$ \& Francesco De Carlo ${ }^{4}$ \\ ${ }^{1}$ Department of Molecular Pharmacology \& Biological Chemistry, Northwestern University, Chicago, IL, \\ USA; E-mail:s-stock@northwestern.edu \\ ${ }^{2}$ Department of Materials Science \& Engineering, Northwestern University, Evanston, IL, USA; \\ E-mail:fyuan@northwestern.edu \\ ${ }^{3}$ Department of Mechanical Engineering, Northwestern University, Evanston, IL, USA; \\ E-mail:cbrinson@northwestern.edu \\ ${ }^{4}$ The Advanced Photon Source, Argonne National Lab., Argonne, IL, US A; \\ E-mail: decarlo@aps.anl.gov
}

Keywords: Echinoidea, Diadema, spine, finite element, stress, microComputed Tomography

Spines of sea urchins of Diadematidae are lightweight structures and can reach impressive lengths. The spines consist of radially-oriented wedges surrounding a central lumen which can be open or contain stereom. In Diadema, these wedges can extend unbroken five or more centimeters, and, if unsupported laterally, would be very unstable Euler columns. Bridges link adjacent wedges and are contiguous with the single crystal calcite in the wedges. The literature suggests that the bridges prevent buckling of the structure but offer no quantitative support for this very plausible hypothesis. This paper numerically investigates the role of bridges in Diadema spines' resistance to bending.

Synchrotron microComputed Tomography (microCT) was performed on spines of Diadema setosum. Microstructures representative of the 3D architecture seen in microCT were the input for finite element modeling (FEM) of spine response to bending. The performance of different bridge arrangements and distribution of bridge mass are compared via FEM, and inferences from geometry and mechanical response illuminate mechanisms of crystal morphology control during spine growth.

\section{Role of estradiol in the reproductive biology of echinoids [oral presentation]}

Michela Sugni ${ }^{1}$, Silvia Mercurio ${ }^{1}$, Denise Fernandes $^{2}$, Cinta Porte $^{2} \&$ M. Daniela Candia Carnevali ${ }^{1}$

${ }^{1}$ Department of Biology 'Luigi Gorini', University of Milan, Milan, Italy;

E-mail:michela.sugni@unimi.it

${ }^{2}$ Department of Environmental Chemistry, Consejo Superior de Investigaciones Cientificas, Barcelona, Spain; E-mail:cpvqam@cid.csic.es 
Keywords: Echinoidea, hormonal regulation, estradiol, reproduction

Despite the extensive use of sea urchins in embryology, the hormonal mechanisms regulating echinoid reproductive processes are scarcely known. To overcome this gap of knowledge, in this research we focused on sex steroids and particularly on estradiol $\left(\mathrm{E}_{2}\right)$, whose presence and seasonal variations were actually reported in different echinoderm tissues by past studies. We administered (via peristomial injection) three different concentrations ( $2 \mathrm{ng} / \mathrm{mL}, 20 \mathrm{ng} / \mathrm{mL}$ and $200 \mathrm{ng} / \mathrm{mL}$ ) of 17ß-estradiol to specimens of the sea urchin Paracentrotus lividus for 2 and 12 weeks. The lowest concentration was close to the physiological one, previously measured in field specimens. Despite the actual increase of circulating $\mathrm{E}_{2}$ in the coelomic fluids, both short- and long-term hormonal treatment did not induce marked variations in the considered reproductive parameters. The Gonad Index appeared to be more influenced by the feeding ratio than by the $\mathrm{E}_{2}$. Similarly, the maturative stage of the gonads was not markedly affected by the hormone, although some slight sex-specific differences could be observed: treated females never reached the maximum maturative stage compared to the controls as instead happened in males injected with the lowest $\mathrm{E}_{2}$ concentration. The activities of the enzymes involved in estradiol synthesis and metabolism suggested the presence of homeostatic mechanisms to maintain the endogenous $\mathrm{E}_{2}$ levels within a certain threshold. Overall our present results suggest that $\mathrm{E}_{2}$ does not markedly influence echinoid reproduction and, particularly, it does not promote female maturation, as on the contrary reported for vertebrates and also suggested for asteroid echinoderms.

\section{A new family within the holothuroid order Dactylochirotida [oral presentation]}

\section{Ahmed Thandar \& Preyan Arumugam}

\section{School of Biological \& Conservation Sciences, University of KwaZulu-Natal, Westville, Durban, South Africa; E-mail: thandara@uk.zn.ac.za@2005500752@uk.zn.ac.za}

Keywords: Holothuroidea, Dactylochirotida, South Africa

A new holothuroid species occurring in deep waters $(710-775 \mathrm{~m}$ ) off the South African east coast is characterized by body wall ossicles comprising only tables with a trilocular disc and a solid spire ending in 2-3 diverging processes/teeth. Such ossicles bear a striking resemblance to those of the molpadid Cherbonniera utriculus Sibuet, occurring in deep Atlantic waters. But this is where the similarity ends. In the presence of podia, the simplicity of the tentacles and the calcareous ring, and the presence of retractor muscles, the new species is undoubtedly referable to the order Dactylochirotida. No existing family of this order is characterized by table-like ossicles except the extraordinary Rhopalodinidae. However, this family is characterized by mouth and anus situated at the tip of a long pro- 
boscis-like structure and tables have multilocular discs and are usually accompanied by plates. Hence a new genus and family is here suggested to accommodate the South African form. The new species comes quite close to the South African dendrochirotid, Cucumella triplex Ludwig \& Heding, described from a single specimen from Agulhas Bank $(155 \mathrm{~m})$, differing from it in the simplicity of the tentacles, the sparseness of the podia and the consistency of trilocular table discs. In C. triplex, on the other hand, the tentacles are stated to be branched, the podia well developed and the tables possess trilocular to multilocular discs. A re-examination of the type is awaited to determine whether this species can also be referred to the new family.

\section{Role of life-history strategy in echinoderm sensitivity to near-future ocean acidification [oral presentation]}

Mike S. Thorndyke ${ }^{1} \&$ Sam T. Dupont ${ }^{2}$

${ }^{1}$ The Royal Swedish Academy of Sciences, Sweden; E-mail: mike.thorndyke@marecol.gu.se

${ }^{2}$ Department of Marine Ecology, University of Gothenburg, Sweden; E-mail: sam.dupont@marecol.gu.se

Keywords: Echinodermata, ocean acidification, life-history, evolution, development

Ocean acidification (OA) is believed to be a major threat for near-future ecosystems and that amongst the most sensitive taxa will be calcifying organisms and the free-living larval stages produced by many benthic marine species. In this respect, echinoderms are one of the taxa potentially most at risk. We demonstrate the importance of taking life-history strategy into account when assessing the impact of OA on echinoderms. For example, impact of OA on some, but not all, planktotrophic larvae can be dramatic with $100 \%$ mortality within 8 days in conditions predicted by 2050. However, lecithotrophic larvae appear to benefit from OA (increased growth, with no impact on survival or calcification). Our results suggest that (i) lecithotrophic species may be better competitors than planktotrophic ones in near-future oceans with important consequences at the ecosystem level and (ii) some of the original OA paradigms (e.g. OA will negatively impact calcifiers) should be reconsidered.

\section{A new echinoderm Lagerstätte from the Pliensbachian (Early Jurassic) of the French Ardennes [posterpresentation]}

Ben Thuy ${ }^{1}$, Andy Gale ${ }^{2} \&$ Mike Reich ${ }^{1,3}$

${ }^{1}$ Georg-August-Universität Göttingen, Abt. Geobiologie, Goldschmidtstr. 3, D-37077 Göttingen, Germany; E-mail:nebyubt@yahoo.com 
${ }^{2}$ School of Earth and Environmental Sciences, University of Portsmouth, Burnaby Building, Burnaby Road, Portsmouth, PO1 3QL, UK; E-mail:andy.gale@port.ac.uk

${ }^{3}$ Georg-August-Universität Göttingen, Museum, Sammlungen \& Geopark, Goldschmidtstr. 1-5, D-37077 Göttingen, Germany; E-mail:mreich@gwdg.de

Keywords: Echinodermata, Lagerstätte, Jurassic, Pliensbachian, France

A succession of clays with thin shell beds from the French Ardennes, dated to the late Early Pliensbachian Davoei Zone and yielding abundant well-preserved remains of all five extant classes of echinoderms, is described here as a new Lagerstätte. The echinoderms occur in the form of isolated ossicles, semi-articulated plate aggregates and abundant intact skeletons with even the most delicate appendices preserved in place and the finest skeletal structures hardly blurred by recrystallisation. The outstandingly good preservation of the echinoderm specimens allows for a morphological assessment of the represented taxa in detail only rarely achievable by fossil material. The material described herein thus significantly contributes to a better understanding of the systematic position and phylogenetic background of many Early Jurassic echinoderm taxa.

The echinoderms are considered to have been buried as an autochthonous or at least parautochthonous assemblage among clumps and beds of Modiolus bivalves. The depositional setting most likely represented a relatively shallow, near-shore soft-bottom environment in which conditions repeatedly favoured the settlement and subsequent effective burial of bivalve-echinoderm assemblages, leading to the formation of the thin highly fossiliferous shell beds intercalating the otherwise nearly sterile clays. The Sedan Lagerstätte opens a unique window into the palaeoecology of an extinct shallow-water soft-bottom community closely comparable to recent analogues.

\section{Cretaceous bathyal echinoderms from the subtropical N-Atlantic: insights into the origin and evolution of modern deep-sea communities [oralpresentation]}

Ben Thuy ${ }^{1}$, Andy Gale $^{2}$, Mike Reich ${ }^{1,3}$, Lea D. Numberger ${ }^{1,4}$, Sabine Stöhr ${ }^{5}$ \& Michal Kucera ${ }^{6}$

${ }^{1}$ Georg-August-Universität Göttingen, Abt. Geobiologie, Goldschmidtstr. 3, D-37077 Göttingen, Germany; E-mail:nebyubt@yahoo.com

${ }^{2}$ School of Earth and Environmental Sciences, University of Portsmouth, Burnaby Building, Burnaby Road, Portsmouth, PO1 3QL, UK; E-mail:andy.gale@port.ac.uk. 
${ }^{3}$ Georg-August-Universität Göttingen, Museum, Sammlungen \& Geopark, Goldschmidtstr. 1-5, D-37077 Göttingen, Germany; E-mail:mreich@gwdg.de

${ }^{4}$ E-mail: lnumber@gwdg.de

${ }^{5}$ Swedish Museum of Natural History, Department of Invertebrate Zoology, Box 50007, 10405 Stockholm, Sweden; E-mail: sabine.stohr@nrm.se

${ }^{6}$ Institute of Geosciences, University of Tuebingen, Sigwartstrasse 10, D-72076 Tübingen, Germany; E-mail:michal.kucera@uni-tuebingen.de

Keywords: Echinodermata, deep-sea, Lower Cretaceous, geological history, N-Atlantic

The origin and possible antiquity of the modern deep-sea fauna have been controversially debated since the beginning of deep-sea research in the nineteenth century. Hypotheses have thus far mostly argued on the basis of biogeographic distribution patterns and molecular clock estimates, and have predominantly suggested a latest Mesozoic or Cenozoic origin. Deep-sea anoxic/dysoxic events and the mid-Cenozoic cooling of deep water masses have generally been considered to have eradicated previous deep-sea communities which were then replaced by the modern fauna. However, in the near absence of direct fossil evidence, considerations on the origin of the modern deep-sea fauna are highly speculative. Here, we report on well preserved fossils of a Lower Cretaceous echinoderm assemblage from deep-sea sediments of the NE-Atlantic, consisting of diagnostic disarticulated skeletal parts. The composition of the assemblage on family and, in some cases, genus level is similar to modern deep-sea echinoderm communities. Our findings suggest that at least a significant part of the modern deep-sea fauna is considerably older than previously assumed. They force a thorough reappraisal of the impact on deep-sea biodiversity of major palaeoceanographic events, such as oceanic anoxia/dysoxia, as well as of faunal exchange processes with shallow marine communities.

New insights into mutable collagenous tissue: work in progress and applied perspectives [oral presentation]

Serena Tricarico ${ }^{1}$, Alice Barbaglio ${ }^{1}$, Nedda Burlini ${ }^{2}$, Luca Del Giacco ${ }^{1}$, Anna Ghilardi $^{1}$, Michela Sugni ${ }^{1}$, Cristiano Di Benedetto ${ }^{1}$, Francesco Bonasoro ${ }^{1}$, Iain Wilkie $^{3} \&$ M. Daniela Candia Carnevali ${ }^{1}$

${ }^{1}$ Department of Biology, University of Milan, via Celoria 26, 20133 Milano, Italy;

E-mail: serena.tricarico@unimi.it

${ }^{2}$ Department of Biotechnology and Biomolecular Sciences, University of Milan, via Celoria 26, 20133 Milano, Italy

${ }^{3}$ Department of Biological and Biomedical Sciences, Glasgow Caledonian University, 70 Cowcaddens Road, Glasgow G4 OBA, Scotland, UK 
Keywords: Echinodermata, MCT, collagen, tensilin

The mechanically adaptable connective tissue of echinoderms (Mutable Collagenous Tissue - MCT), which can undergo drastic nervously-mediated changes in its stiffness, tensile strength and viscosity, represents a promising model for biomaterial design and biomedical applications. MCT could be a source of, or an inspiration for, new composite materials whose molecular interactions and structural conformation can be changed in response to external stimuli.

MCT is composed mostly of collagen fibrils comparable to those of mammals plus a variety of other components, including other fibrillar structures (fibrillin microfibrils), proteoglycans and glycoproteins. According to Trotter and coworkers $(1996,2003)$, the extracellular matrix of holothurians includes at least two important glycoproteins, stiparin and tensilin, that can modulate the aggregation of collagen fibrils and their capacity for reciprocal sliding and establishing interfibrillar links.

This contribution presents the latest results of a detailed analysis of MCT components in the sea urchin Paracentrotus lividus: focusing on (1) biochemical characterization of the fibrillar components (extraction, purification and quantifycation of collagen from MCT samples); (2) biomolecular analysis of the presumptive glycoprotein components. Preliminary data have been obtained on the biomolecular characterization of tensilin. The next steps will be the synthetic production of tensilin-like protein and combining it with collagen at different degree of purification. The final aims will be to confirm the presence and the role of these glycoproteins in echinoids and to manipulate simpler components in order to produce a composite with mutable mechanical properties.

In the long term, MCT could provide inspiration for biomimetic materials and offer great potential for economically relevant biotechnological and clinical applications that require, for example, the controlled and reversible plasticization and/or stiffening of connective tissue.

\section{Watch Your Step - Photoreceptors in Sea Urchin Tube Feet [oral presentation]}

Esther Ullrich-Lüter ${ }^{1}$, Sam T. Dupont ${ }^{2}$, Enrique Arboleda $^{3,4}$, Maria Ina Arnone $^{3}$ \& Harald Hausen ${ }^{1,5}$

${ }^{1}$ Universität Bonn, Institut für Evolutionsökologie \& Ökologie, D-53121 Bonn, Germany;

E-mail:eullrich@evolution.uni-bonn.de

${ }^{2}$ Gothenburg University, Department of Marine Ecology, The Sven Lovén Centre for Marine Sciences, 45034 Fiskebackskil, Sweden; E-mail:sam.dupont@marecol.gu.se

${ }^{3}$ Stazione Zoologica Anton Dohrn,80121 Naples, Italy; E-mail:miarnone@szn.it

${ }^{4}$ Max F. Perutz Laboratories, 1030 Wien, Austria; E-mail:enrique.arboleda@mfpl.ac.at 
${ }^{5}$ Sars International Centre for Marine Molecular Biology, 5008 Bergen, Norway; E-mail: harald.hausen@sars.uib.no

Keywords: Echinoidea, photoreceptors, dermal light sense, tube feet

Although sea urchins show many reactions upon light, hitherto not any visual organ could be detected in this phylum. Genome data of the recently sequenced purple sea urchin Strongylocentrotus purpuratus enabled us now to uncover a complex system of dispersed r-opsin positive photoreceptor cells (PRCs) in sea urchin (and starfish) tube feet. S. purpuratus reacts photonegatively upon illumination and our results from electron microscopy, immunogold detection, immunohistochemistry and in situ-hybridization revealed up to 140 distinct PRCs in each tube foot, meaning up to 200.000 PRCs per animal. In the absence of true cerebral eyes these PRCs co-opt the animal's calcite corona to fulfill the requirements for directional vision. Functionally, the whole sea urchin thus represents a giant compound eye integrating data from all around the body. Our findings of distinct PRCs in echinoids also challenges the traditional 'echinoderm dermal-light-sense' hypothesis and provides a new basis for re-evaluating echinoderm photobiology.

\section{Feeding habits of the common sea star Echinaster sepositus and its ecological implications on Mediterranean shallow rocky bottoms} [oral presentation]

\section{Adriana Villamor ${ }^{1} \&$ Mikel A. Becerro ${ }^{2}$}

Centre d'Estudis Avançats de Blanes (CSIC), Accés a la Cala St. Francesc 14, Blanes, Girona, E-17300,Spain; E-mail: villamon@ceab.csic.es

Keywords: Asteroidea, Echinaster, feeding, ecology, Mediterranean

The distribution of marine species is determined by large scale factors which delimit biogeographical regions. On a smaller scale the distribution of species is a function of complex abiotic and biotic interactions, resulting in the actual assemblages and communities we observe.

Echinaster sepositus is a common Mediterranean sea star, found in many of its ecosystems. However its function and main interactions are virtually unknown to date, but recent data on distribution patterns in shallow rocky bottoms indicate that biotic interactions may be responsible for its patchy distribution. Further information on the ecology and function of this common sea star is fragmentary and casual.

Among the interactions established between organisms, trophic relations are the most important and their knowledge is basic to elucidate the structure of the ecosystem and the function on it of the species involved. 
We conducted field observations, aquarium experiments and stable isotope analysis in order to clarify feeding habits of this species in shallow rocky bottoms. Field observations on benthic species where Ecbinaster sepositus preferentially everted its stomach led us to experimentally test these preferences. Subsequent stable isotope analysis clarified the real relation existing between E. sepositus and the preferred species. Both field observations and aquarium experiments indicated that E. sepositus everted its stomach preferentially on several algae and sponges, but stable isotope analysis indicated that what the sea star is mainly assimilating are certain groups of meiofauna found inside these hosts. Isotopic signal also indicated that it might feed on the alga Peyssonnelia squamaria.

We conclude that Echinaster sepositus is a generalist omnivorous feeder, whose feeding activity might not drastically change the community organization, although an impact on meiofaunal community structure cannot be ruled out. The strong correlation with crustose coralline algae is indirect, possibly through facilitation.

The present study sheds light on the feeding habits of this common sea star and gives evidence of the feeding activity of Echinaster sepositus on several groups mediated by algae. Due to the high densities this species reaches, further studies on its impact on meiofaunal assemblages will help to fully understand its role on Mediterranean shallow rocky bottoms.

\section{Functional properties of proteins from wounded sea star Asterias rubens (L.) coelomic liquid - effect on invertebrate cells [poster presentation]}

Irina Voronkina ${ }^{1}$, Kristina Holm $^{2}$, N. S. Sharlaimova ${ }^{1}$, Mike S. Thorndyke ${ }^{2}$ \& Bodil Hernroth ${ }^{2}$

${ }^{1}$ Department of Cell Cultures, Institute of Cytology, Sankt-Petersburg, 194064, Russia;

E-mail:voronirina@list.ru

${ }^{2}$ The Royal Swedish Academy of Sciences, Sven Lovén Centre for Marine Sciences, Kristineberg 566, SE-45034 Fiskebäckskil,Sweden; E-mail:bodil.bernroth@marecol.gu.se

Keywords: Asteroidea, Asterias, wound healing, cell viability, adhesion, anti-microbial activity

The echinoderms have a great capacity of wound healing and can recover after losing big parts of the body. Earlier, a change has been recognized in the protein expression of the coelomic fluid due to wounding of the seastar Asterias rubens. Proliferative and adhesive properties of three protein fractions, separated by size, from the coelomic fluid of wounded A. rubens, were tested here on coelomocytes/haemocytes from three groups of invertebrates, the echinoderm, A. rubens itself, the mollusk Mytilus edulis and the tunicate Ciona intestinalis. In addition the antimicrobial property of the protein fractions was tested on the Gram-negative bacterium Vibrio parahaemolyticus. The three size fractions were identified by 
electrophoresis (Fraction $1>95 \mathrm{kDa}$, Fraction 2: 30-70 kDa, Fraction 3: 15$70 \mathrm{kDa}$ ). All of the fractions promoted proliferation of the autologous coelomocytes and Fraction 1 did so even for haemocytes of M. edulis. Fraction 1 did also facilitate adhesion of all the cell types and Fraction 3 had a negative influence on adhesion of coelomocytes from C. intestinalis. Fraction 2 showed a slight anti-proliferative effect of haemocytes of $M$. edulis and as well antimicrobial properties. However, the strongest antimicrobial effect was caused by Fraction 3. This fraction, with smaller proteins, may contain cytokine-like molecules but also the invertebrate form of lysozyme, previously described in the seastar. Although the proteins within the fractions somewhat overlapped in size the three fractions obviously showed differences in properties. The differences in response between the cells of different phyla suggest receptor mediated response.

This study was financially supported by the scientific foundations of The Royal Swedish Academy of Sciences, FDS06-121 and FOA07B-306, Russian Leading Scientific School program (\#07-04-011-90a) and Adlerbertska forskningsstiftelsen, Sweden.

\title{
Proteins of sea star Asterias rubens (L.) coelomic liquid and their influence on mammal cells and tissue [oralpresentation]
}

\author{
Irina Voronkina ${ }^{1}$, N. S. Sharlaimova ${ }^{1}$, M. Protasov $^{2} \&$ G. Pinaev ${ }^{1}$ \\ ${ }^{1}$ Department of Cell Cultures, Institute of Cytology, Sankt-Petersburg, 194064, Russia; \\ E-mail:voronirina@list.ru \\ ${ }^{2}$ Scientific Research Center, I. P. Pavlov, St. Petersburg State Medical University, Sankt-Petersburg, \\ Russia
}

Keywords: Asteroidea, Asterias, wound healing, regeneration

Many marine organisms have a high ability for regeneration of tissues, even in adult state. The ability to quickly and fully restore various organs and body parts after damage is one of the main features of echinoderms. Many processes associated with regeneration have been studied on echinoderms because they, along with chordates, belong to the Deuterostomia. Coelomic cavities of the starfish Asterias rubens have a large number of circulating cells - coelomocytes, which play a major role in the processes associated with the closure of wounds and regeneration. After disruption of tissue integrity coelomocytes form a clot that closes the wound and at the same time they secrete various proteins, cytokines and growth factors, which change coelomic fluid protein composition. It is known that such factors such as BMP2, TNF, IL-1 can be found in the coelomic fluid and they can enchance processes associated with tissue repair. In the present study the dynamics of coelomic fluid protein composition during the first 3 days after wounding was studied by 2D phoresis. It was shown that at the initial stage of wound healing a large amount of peptides appeared in coelomic fluid. These proteins were obtained by gel-chromatography and antibodies were raised against 
these proteins. The action of the starfish proteins on adhesion, survival, proliferation and migration of various vertebrate cell lines in culture was studied as well on wound healing process on the model of deep wounds in rats. It was shown that these coelomic fluid proteins can be divided for at least three groups by type of biological activity - stimulating the proliferation and migration of mammalian cells, adhesive proteins and cytotoxic ones. The same effect these proteins have on rat tissues at wound model. The rate of wound closure varied depending on type of protein added to wound. The process of wound healing in rats was evaluated by histological slides, as well as some biochemical parameters. The results showed that the effect of protein factors that appear in the coelomic fluid of Asterias rubens after wounding on the mammal cells and tissues is similar to the action of these factors on the cells of marine invertebrates. This suggests that obtained protein factors can be used in the study of regeneration in vertebrates.

This work obtained financial support by Russian Fund of Basic Research grants 08-0410090-k and 05-04-08017-ofi_a.

\section{Another wolf in sheep's clothing: the black sea urchin Arbacia lixula (L.) is carnivorous in the Mediterranean [oralpresentation]}

Owen S. Wangensteen ${ }^{1}$, Alex García-Cisneros ${ }^{1}$, Mireia Recasens ${ }^{1}$, Xavier Turón $^{2} \&$ Creu Palacín ${ }^{1}$

${ }^{1}$ Department of Animal Biology, Facultat de Biologia, Universitat de Barcelona, Spain; E-mail: owenwangensteen@ub.edu

${ }^{2}$ Centro de Estudios Avanzados de Blanes, CSIC, Spain

Keywords: Echinoidea, Arbacia, Paracentrotus, trophic relationships, stable isotope analysis

Regular echinoids are considered structuring species that play a central role in benthic ecosystems. The most common sea urchins in Mediterranean coastal communities, Paracentrotus lividus (Lamarck, 1816) and Arbacia lixula (Linnaeus, 1758), have been traditionally regarded as herbivores. Several studies analysing gut contents led to infer that $P$. lividus is a grazer of diverse erect algae, whereas A. lixula feeds mainly on incrusting coralline algae.

However, a variety of experimental evidences (behavioural observations, gut content analysis, multiple-choice feeding-preference experiments, analysis of digestibility) show that American species of genus Arbacia (A.punctulata, A. dufresnei, A. spatuligera) have omnivorous or definitely carnivorous diets.

In this work, we used Stable Isotope Analysis (SIA) for characterising trophic interactions between both sea urchins and other representative species of invertebrates and algae. The study was carried out at three Mediterranean localities: Tossa de Mar and Torredembarra (Catalonia) and Carboneras (Andalusia), and one Atlantic (Tenerife, Canary Islands). At Tossa de Mar a 15-month follow-up was also carried out. 
The results of SIA consistently show that, contrary to common belief, the black sea urchin $A$. lixula has a mainly carnivorous diet at all sampled localities, while $P$. lividus is herbivorous, in agreement to current belief. This is in contrast with the results of gut contents analyses of the same samples, which show a predominantly algal diet for both sea urchin species. This pattern is apparent in all the sampled localities and throughout the whole year.

This study evidences that gut content analyses may yield contradictory or hardly interpretable results when applied to marine invertebrates. Stable Isotope Analysis is a more reliable technique to study trophic interactions in low mobility benthic species, which may feed on different food sources with very dissimilar digestibility.

Ecological implications of $A$. lixula carnivory for the dynamics of Mediterranean ecosystems are still to be evaluated. Having an accurate picture of trophic relations is essential for successful management of marine reserves or local fisheries, since conservation measures or procedures that are based on false premises may yield the opposite effects than those originally intended.

\section{An Early Permian crinoid fauna from Crete [oral presentation]}

\section{Gary D. Webster}

School of Earth and Environmental Sciences, Washington State University, Pullman, WA, USA 99164-2812; E-mail:webster@wsu.edu

Keywords: Crinoidea, Early Permian, taxonomy, Crete, Greece

Early Permian crinoids, discovered by Heinz König, are reported from a small cape at Bali, north central Crete, Greece. The specimens have undergone lowgrade metamorphism, but are moderately well preserved. This is the first Paleozoic crinoid fauna reported from Greece.

At the generic level the cladid dominated fauna shows greatest affinity with North American faunas and secondarily with Timor faunas. It includes new species of the disparid Synbathocrinus, the flexible Artichthyocrinus, in addition to the cladids Apographiocrinus, Pyndaxocrinus, Protencrinus, and Moapacrinus?

\section{Large-scale non-invasive imaging of sea urchins (Echinodermata:} Echinoidea): a preliminary list of available datasets [poster presentation]

\section{Alexander Ziegler}

Institut für Immungenetik, Charité-Universitätsmediæin Berlin, Thielallee 73, D-14195 Berlin, Germany; E-mail: alexander.ziegler@charite.de

Keywords: Echinoidea, anatomy, MRI, soft tissue, $\mu \mathrm{CT}$, morphology, hard-part anatomy 
A number of novel imaging techniques such as magnetic resonance imaging (MRI), micro-computed tomography $(\mu \mathrm{CT})$, confocal laser scanning microscopy (CLSM), and synchrotron radiation micro-computed tomography (SR $\mu \mathrm{CT})$ permit gathering anatomical data of whole biological specimens non-invasively. Although SR $\mu$ CT and CLSM yield excellent image data at high resolutions, the focus of my work is on MRI and $\mu \mathrm{CT}$, primarily because of the suitability of these techniques for highthroughput analyses of sea urchin specimens (Echinodermata: Echinoidea). MRI and $\mu \mathrm{CT}$ generate entirely digital raw image data that can be used either for direct observation or for manual as well as automated 3D visualization. Since freshly fixed specimens as well as century-old museum material can be successfully scanned using both methodologies, a large taxon sampling became possible, resulting in datasets of representative species from almost 50 of the currently recognized 58 extant sea urchin families. In total, 48 2D MRI datasets with a resolution of $50 \times 50 \times 200 \mu \mathrm{m}, 563 \mathrm{D}$ MRI datasets ranging in isotropic resolution from 20 to $96 \mu \mathrm{m}$ (most of them at $81 \mu \mathrm{m}$ ), and $79 \mu \mathrm{CT}$ datasets ranging in isotropic resolution from 9 to $24 \mu \mathrm{m}$ (most of them at ca. $14 \mu \mathrm{m}$ ) were gathered.

I here present a compilation of these datasets, listing them by family and species, including information on the representative scanning techniques and dataset resolution. Using a number of examples, the potential of these datasets for comparative soft tissue as well as hard-part anatomy is described. The general availability of these datasets is highly desirable, but cannot yet be offered due to serious limitations in depositing such extensive amounts of raw data in the currently available morphological databases.

\title{
Is there independent anatomical support for the Odontophora (Echinoidea: Echinoida)? [posterpresentation]
}

\author{
Alexander Ziegler ${ }^{1} \&$ Andreas Kroh $^{2}$ \\ ${ }^{1}$ Institut für Immungenetik, Charité-Universitätsmediżin Berlin, Thielallee 73, D-14195 Berlin, \\ Germany; E-mail: alexander.zieglen@charite.de \\ ${ }^{2}$ Naturbistorisches Museum Wien, Geologie \& Paläontologie, Burgring 7, 1010 Wien, Austria; E-mail: \\ andreas.krob@nbm-wien.ac.at
}

Keywords: Echinoidea, Camarodonta, Aristotle's lantern, morphology, classification

The taxon Odontophora has recently been established and comprises camarodont sea urchins with a distinct skeletal protrusion on the epiphysis. This process, termed tooth support, lies on the adaxial edge of the wing of the epiphysis and flanks the proximal part of the sea urchin tooth at the point where the plumula merges with the solid tooth shaft. Although the function of the tooth support is still unknown, it constitutes a skeletal feature that can be easily observed both in fossil as well as extant material and could therefore be useful for classification 
purposes. Originally, three taxa are included in the Odontophora: the Echinometridae, the Strongylocentrotidae, and the Toxopneustidae. Although closely related to the former taxa, the Parasaleniidae, the Parechinidae, and the Echinidae were excluded based on the absence of a tooth support as well as other characters. Here, we try to show whether the hypothetical grouping based on a cladistic analysis on the family level also holds true on the genus level. We combined classical dissection and SEM imaging of skeletal structures with $\mu \mathrm{CT}$ imaging of whole specimens, thereby improving our understanding of the position and potential function of the tooth support. Representatives of almost all extant genera of the Odontophora were examined. Further results, acquired using magnetic resonance imaging (MRI), strongly indicate that there is indeed independent anatomical support for the taxon Odontophora, as exemplified by the presence of highly specialized protractor muscles present in the Echinometridae, the Strongylocentrotidae, and the Toxopneustidae.

\title{
Origin of the gastric caecum in sea urchins (Echinodermata: Echinoidea) [oral presentation]
}

\author{
Alexander Ziegler ${ }^{1}$, Rich Mooi $^{2}$, Gauthier Rolet $^{3} \&$ Chantal De Ridder ${ }^{3}$ \\ ${ }^{1}$ Institut für Immungenetik, Charité-Universitätsmediz̨in Berlin, Thielallee 73, D-14195 Berlin, \\ Germany; E-mail: alexander.ziegler@charite.de \\ ${ }^{2}$ California Academy of Sciences, Golden Gate Park, 55 Music Concourse Drive, San Francisco, \\ California, 94118, USA; E-mail: rmooi@calacademy.org \\ ${ }^{3}$ Laboratoire de Biologie Marine, Université Libre de Bruxelles, 50 avenue F.D. Roosevelt, 1050 \\ Bruxelles, Belgium; E-mail:grolet@ulb.ac.be $\approx$ cridder@ulb.ac.be
}

Keywords: Echinoidea, anterior stomach, MRI, caeca, digestive tract, evolution

In sea urchins (Echinodermata: Echinoidea), a highly specialized gastric caecum can be found in members of a derived subgroup, the Irregularia (cake urchins, sand dollars, heart urchins, and related forms). As such a caecum has not been reported from 'regular' sea urchin taxa, the aim of this study was to elucidate its evolutionnary origin. Using morphological data derived from dissection and magnetic resonance imaging (MRI) as well as extensive literature studies, we compared the digestive tract of 168 echinoid species belonging to 51 extant families. Based on a number of characters such as topography, general morphology, mesenterial suspension, and integration into the haemal system, we homologize the gastric caecum with the more or less pronounced dilation of the anterior stomach that is observed in most 'regular' sea urchin taxa. In the Irregularia, a gastric caecum can be found in all taxa except in the Laganina and Scutellina. It is also undeveloped in certain spatangoid species (Aceste, Aeropsis). According to our findings, the sea urchin gastric caecum constitutes a synapomorphy of the Euechinoidea. Its occur- 
rence in 'regular' euechinoids is linked to the presence of an additional festoon of the anterior stomach in ambulacrum III. Both structures, the additional festoon and the gastric caecum, are absent in the Cidaroida. Since the degree of specialization of the gastric caecum is most pronounced in the predominantly sedimentburrowing irregular taxa, we hypothesize that its evolution is closely linked to the development of more elaborate infaunal lifestyles.

\title{
Licence to frill: specialized protractor muscles in derived camarodont sea urchins (Echinoidea: Echinoida) [oral presentation]
}

\author{
Alexander Ziegler ${ }^{1}$, Leif Schröder ${ }^{2}$, Susanne Mueller $^{3} \&$ Thomas Stach $^{4}$ \\ ${ }^{1}$ Institut für Immungenetik, Charité-Universitätsmediz̨in Berlin, Thielallee 73, D-14195 Berlin, \\ Germany; E-mail: alexander.zieglen@charite.de \\ ${ }^{2}$ Leibniz-Institut für Molekulare Pharmakologie, Molecular Imaging, Campus Berlin-Buch, Robert- \\ Rössle-Straße 10,D-13125 Berlin, Germany; E-mail: Ischroeder@fmp-berlin.de \\ ${ }^{3}$ Center for Cardiovascular Research, Charité-Universitätsmediz̨in Berlin, Charitéplatz. 1, D-10117 \\ Berlin, Germany; E-mail: susanne.mueller1@charite.de \\ ${ }^{4}$ Institut für Biologie, Systematik. und Evolution der Tiere, Freie Universität Berlin, Königin-Luise-Straße
1-3, D-14195 Berlin, Germany; E-mail: tstach@_zoosyst-berlin.de
}

Keywords: Echinoidea, Camarodonta, magnetic resonance imaging, retractor muscle, smooth muscle

The sea urchin feeding apparatus, commonly known as Aristotle's lantern, is present in all 'regular' as well as selected irregular taxa. This complex organ is composed of various skeletal and soft tissue elements that are located within the so-called peripharyngeal (or lantern) coelom. The Aristotle's lantern is manipulated by a set of muscles that are derived from coelomic epithelia and that histologically constitute smooth muscles. The two muscles primarily acting in protrusion and withdrawal of the feeding apparatus are termed protractor and retractor muscles, respectively. Sea urchin protractor muscles have been described in detail in selected sea urchin taxa, in particular in Stylocidaris (Cidaroida) and Paracentrotus (Echinoida). These analyses reveal that the shape of both the adaxial as well as the abaxial surface of these muscles can be described as flat. Using magnetic resonance imaging (MRI), a non-invasive imaging technique, we discovered conspicuously shaped protractor muscles in whole specimens of derived camarodont sea urchin taxa such as Echinometra, Sphaerechinus, and Strongylocentrotus. Our analyses reveal that the adaxial surface of these specialized protractor muscles consists of muscle bundles packed into several large parallel protrusions that are directed perpendicular to the main orientation of the muscle. Due to their peculiar shape we denominate this novel muscle type as 'frilled protractor muscle'. Using large-scale comparative analyses by MRI, we have found that frilled protractor muscles are present only in 
the Strongylocentrotidae, the Echinometridae, as well as the Toxopneustidae. Based on the available evidence, we hypothesize that the function of frilled protractor muscles is to increase the uptake of oxygen through an extension of the muscle's surface. 


\title{
Excursion Guides
}

\section{The echinoderm collections of the Berlin Natural History Museum}

\author{
Carsten Lüter \& Christian Neumann \\ Museum für Naturkunde, Leibniz-Institut für Evolutions- und Biodiversitätsforschung an der Humboldt- \\ Universität zu Berlin, Invalidenstr.43,D-10115 Berlin, Germany; E-mail: carsten.lueter@mfn-berlin.de \\ \&christian.neumann@mfn-berlin.de
}

Keywords: Echinodermata, palaeontology, zoology, collections, Berlin, Natural History Museum

The Museum für Naturkunde Berlin is one of the world's principal institutions in the field of evolution and biodiversity research, including aspects of planetology. The Museum für Naturkunde carries out basic and applied research focussing on: (1) biodiversity, (2) evolution, (3) (palaeo-)ecology and geobiology of the earth, and (4) geology and mineralogy of meteorite impacts.

With more than 30 million objects in its zoological, palaeontological, geological and mineralogical collections, the Museum für Naturkunde is one of the largest scientific collections in the world. Its collections are of international importance and comprise specimens from all over the world. They include such extraordinary objects as the Berlin specimen of the early bird Archaeopteryx and fossils from the Tendaguru locality (among them Brachiosaurus brancai).

From 1810 to 2008, the Museum für Naturkunde was part of the Humboldt University, Berlin. On January 1, 2009, it became a separate foundation of the Leibniz Association.

\section{Palaeozoology}

The collections of Invertebrate Palaeontology comprise microfossils and macroinvertebrates with an estimated $>14,000$ type and figured macroinvertebrate specimens. The geographical range is worldwide with German and European material predominant and well represented. These include excellent collections from famous Konservat-Lagerstätten like the Hunsrück Slate, Holzmaden, Solnhofen, Crato Formation (Cretaceous, Brasil) and Baltic amber. Foreign material stems from 
northern and eastern Africa, the Middle East and many other regions. The collection is mostly arranged systematically but includes important stratigraphical and regional suites. Some of the collections are historical, for example those from Ernst Friedrich von Schlotheim (1764-1832), Christian Leopold von Buch (1774 1853), Georg Carl Berendt (1790-1850), Christian Gottfried Ehrenberg (17951876), and Georg August Schweinfurth (1836-1925).

A stronghold of the collection of fossil Echinodermata is the crinoid collection, which contains many type specimens from Otto Jaekel (1863-1929), Hertha SievertsDoreck (1899-1991), Georges Ubaghs (1916-2005), and many others. The echinoid collection includes the large collection of G. Schweinfurth (Late Cretaceous and Palaeogene of Egypt and the Middle East).

\section{Zoology}

The recent invertebrate collections (excl. entomology) are huge and looked after by 5 curators responsible for collections of molluscs, crustaceans, 'worm-like animals', non-insect arthropods, and Marine Invertebrates, the latter containing the echinoderms. The original hand-written main catalogue contains 7345 lots of echinoderms of all five major groups. Amongst them we have recently identified primary types of 472 species. The main part of the collection stems from several large expeditions of the late $19^{\text {th }}$ and early $20^{\text {th }}$ century, such as the 'Gazelle'-Expedition (1874-76), the German Deep-Sea Expedition (1898-99), and the German SouthPolar Expedition (1901-03). The recent echinoderm collection is especially rich in type material described by Ludwig Döderlein (1855-1936), Carl Eduard v. Martens (1831-1904), Johannes Peter Müller (1801-1858) \& Franz Hermann Troschel (1810-1882), and Theophil Studer (1845-1922). In August 2010, all alcoholpreserved echinoderm specimens were moved into the refurbished east wing of the Museum. This part of the building was destroyed in February 1945 and could be officially re-opened in September 2010 to house all wet collections of the Museum according to the latest standards of specimen preservation and safety. With some 80.000 ltrs of highly concentrated ethanol distributed over thousands of specimen jars it is Berlin's largest alcohol store! 


\title{
A Triassic echinoderm lagerstätte - Herberhausen quarry, near Göttingen
}

\author{
Gernot Arp \\ Georg-August-Universität Göttingen, Abt. Geobiologie, Goldschmidtstr. 3, D-37077 Göttingen, \\ Germany; E-mail:garp@gwdg.de
}

Keywords: Echinodermata, Triassic, Herberhausen, Lower Saxony, Germany

Location: Topographic Map 1 : 25000 Sheet 4426 Ebergötzen. R 3569 775, H 57 11 950. Quarry ca. $1 \mathrm{~km}$ E of Herberhausen (Göttingen).

Stratigraphic position: Jena Formation, Lower Muschelkalk (Anisian), Middle Triassic (Figs. 1-2).

Sedimentology and Palaeontology: In this small quarry of the Göttingen Forest, an almost $13 \mathrm{~m}$ thick section of the Lower Muschelkalk, which is in total approximately 100 to $110 \mathrm{~m}$ thick in the region, is accessible. Stratigraphically, the profile encompasses the Terebratula beds and the overlying Wellenkalk 2 (Wellenkalk is a wavy bedded marly limestone). The layers dip at an angle of $19^{\circ}$ towards $260^{\circ}(\mathrm{W})$, towards the Leinetalgraben. The importance of the outcrop lies in the exceptionnally well preserved echinoderm fauna and an exposed bedding plane nicely showing current ripple marks (Fig. 3).

The bottom of the section begins with the middle part of the Terebratula beds, i.e. a Wellenkalk intercalation. In addition to bioturbated mudstones, thin crossbedded ooid-bioclast grainstones with intraclasts occur.

The Upper Terebratula bed consists of an approximately $50 \mathrm{~cm}$ thick oolithic limestone bed with shell debris (ooid-bioclast grainstone with intraclasts), which displays prominent ripple marks at its top. The asymmetric current ripple marks have a wavelength of ca. $75 \mathrm{~cm}$, an amplitude of ca. $2.5 \mathrm{~cm}$ and strike at ca. $115^{\circ}$; these characteristics document a seafloor water current from NNE for this stratigraphic horizon.

On top of the Upper Terebratula bed lie relatively solid, partially laminated Wellenkalke with several thin beds of shell debris, some of them showing graded bedding, which are ascribed to tempestites (storm deposits). From these deposits, 11 genera of bivalves with 14 species were listed by Hagdorn and Simon (1983). Most common are the epibyssate Hornesia socialis and the shallow endobenthic myophorids (Neoschizodus laevigatus, Neoschizodus orbicularis, Myophoria vulgaris, Myophoria incurvata, Lyriomyophoria elegans). Less common are 'Mytilus eduliformis', the nuculoid Palaeonucula goldfussi and pholadomyoid Pleuromya sp. (Hagdorn \& Simon 1983). The oyster-like Placunopsis sp. is characteristic for hardground surfaces. In addition, several gastropod genera have been found (Loxonema, Undularia, Omphaloptycha, Worthenia), as well as the scaphopod Dentalium torquatum (Hagdorn \& Simon 1983). Among the brachiopods, Coenothyris vulgaris is most frequent. 


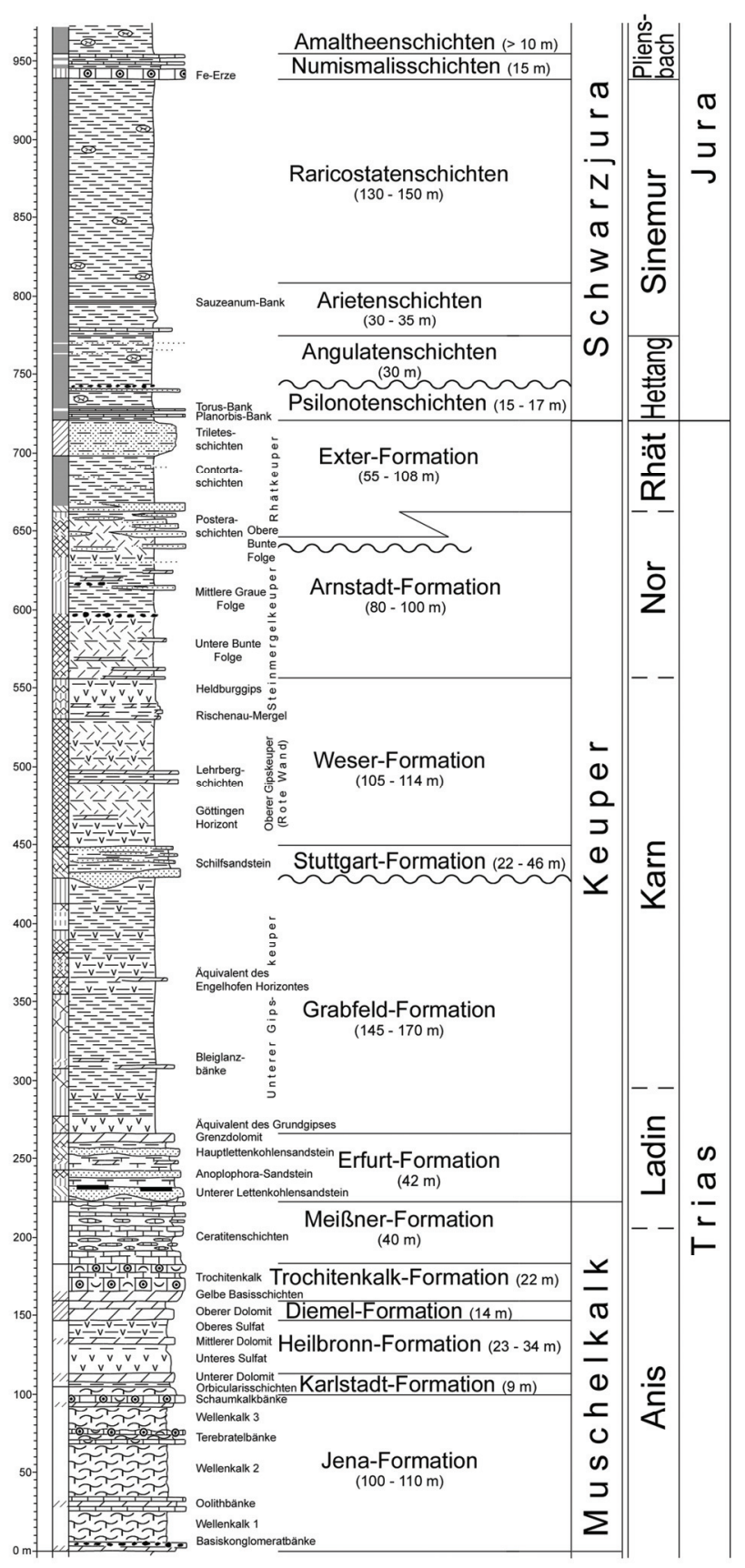

Fig. 1 Lithostratigraphical chart: 'Muschelkalk', 'Keuper' and Early Jurassic (Anisian to Pliensbachian) (from Arp et al. 2004). 


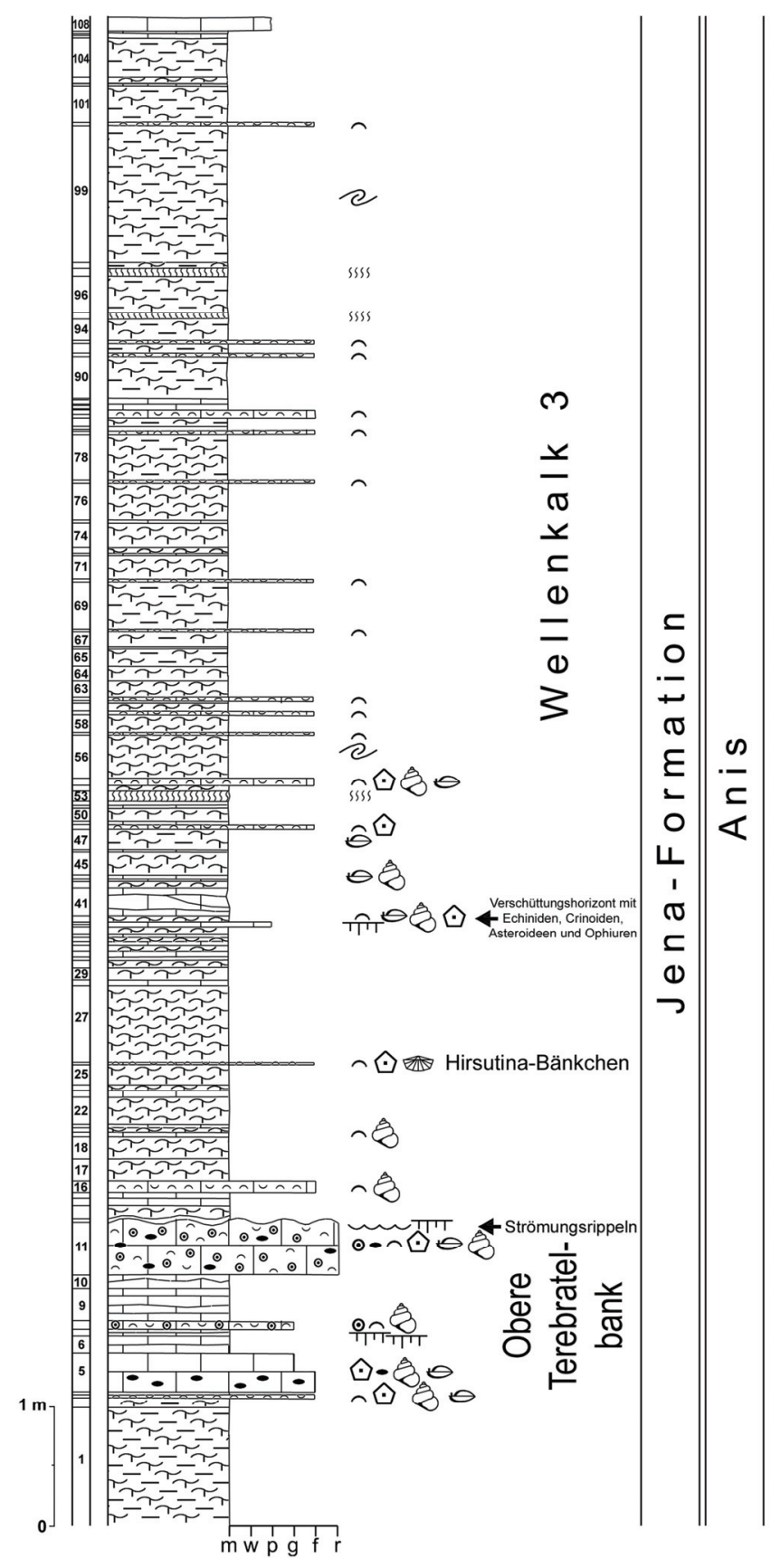

Fig. 2 Section of the Jena Formation (Anisian), Herberhausen Quarry, Göttingen Forest (from Arp et al. 2004). 
One of these beds of shell debris (bed 26, Hirsutina bed) contains the spiriferid brachiopod Hirsutina birsutinella, which indicates the stratigraphic position stated above (Hagdorn \& Simon 1983). Echinoderms are represented by isolated skeletal elements of Chelocrinus, Holocrinus and Serpianotiaris, whereas vertebrates are only represented by unidentifiable bone fragments.

A hardground with overlying obrution deposits occurs approximately $2.5 \mathrm{~m}$ above the Upper Terebratula bed (bed 39). This bed has yielded complete sea urchins, sea lilies, brittle stars and starfishes: Chelocrinus carnalli, Holocrinus dubius, Serpianotiaris coaeva, ?Aplocoma sp., Trichasteropsis bilertorum, Migmaster angularis etc. (Blake \& Hagdorn 2003, Seppelt 2004, Bielert \& Bielert 2004, Blake et al. 2006, Thuy \& Reich pers. comm.).

These beds of shell debris, which are generally relatively rich in species, display a gradual depletion of stenohaline faunal elements toward the top, until only myophorid bivalves occur. The Wellenkalke, on the other hand, exhibit a fauna largely restricted to trace fossils (predominantly Cruziana association with Rbizocorallium jenense, Pholeus abomasoformis and Planulites sp.; cf. Knaust 1998). Individual beds of Wellenkalk also display slump folds or sinusoidally deformed veins (Sigmoidalklüftung), which are interpreted as reflecting earthquake-induced shear movements in gel-like carbonate sediment (Szulc 1993, Rüffer 1996, Neuweiler et al. 1999).

Generally, a subtidal depositional setting with moderate water depth and limited circulation is assumed for the Wellenkalk. The distinct key horizons (such as the Terebratula beds) were interpreted differently, though. While Franke et al. (1977) assign the ooid-rich Schaumkalkbänke (beds of porous cellular limestone) to shallow $(<2 \mathrm{~m})$, agitated water and assume short-term regressions of the ocean, Lukas (1991) suggests that the formation of the key horizons rich in ooids and shell debris reflects a partial destruction of barrier-like calcareous sand dunes in the area of Berlin-Brandenburg causing a temporarily enhanced water circulation. Sea level fluctuations may have played a role, though their significance is limited to the destruction of the sand barriers. On the other hand, Götz (1996) interprets the recurring sequences of Wellenkalk, Gelbkalk (yellow coloured dedolomite) and various calcareous sands (ooids, shell debris, rubble) to be small cycles controlled by sea level fluctuations.

$\rightarrow$-..Fig. 3 Jena Formation (Anisian) of the Herberhausen Quarry, Göttingen Forest. (1) Top of Upper Terebratula bed with distinct ripple marks on the surface, bed 11; (2) These asymmetric current ripple marks of bed 11 document a water current from NNE reaching the floor of the water body; (3) Spiriferid brachiopod Hirsutina birsutinella from the Hirsutina bed, bed 26; (4) Hardground surface of bed 38 with two specimens of Serpianotiaris coaeva and crinoid columnals of Holocrinus dubius [leg. S. Seppelt, Hildesheim]; (5) Close-up view of one of the specimens of Serpianotiaris in (4); (6) Brittle star ?Aplocoma sp., bed 39; (7) Holotype of the asteroid Trichasteropsis bilertorum, bed 39 [Muschelkalkmuseum Ingelfingen MHI 1755, Photo: F. Bielert, Braunschweig]; (8) Sinusoidally deformed veins (Sigmoidalklüftung) in bed 53. 

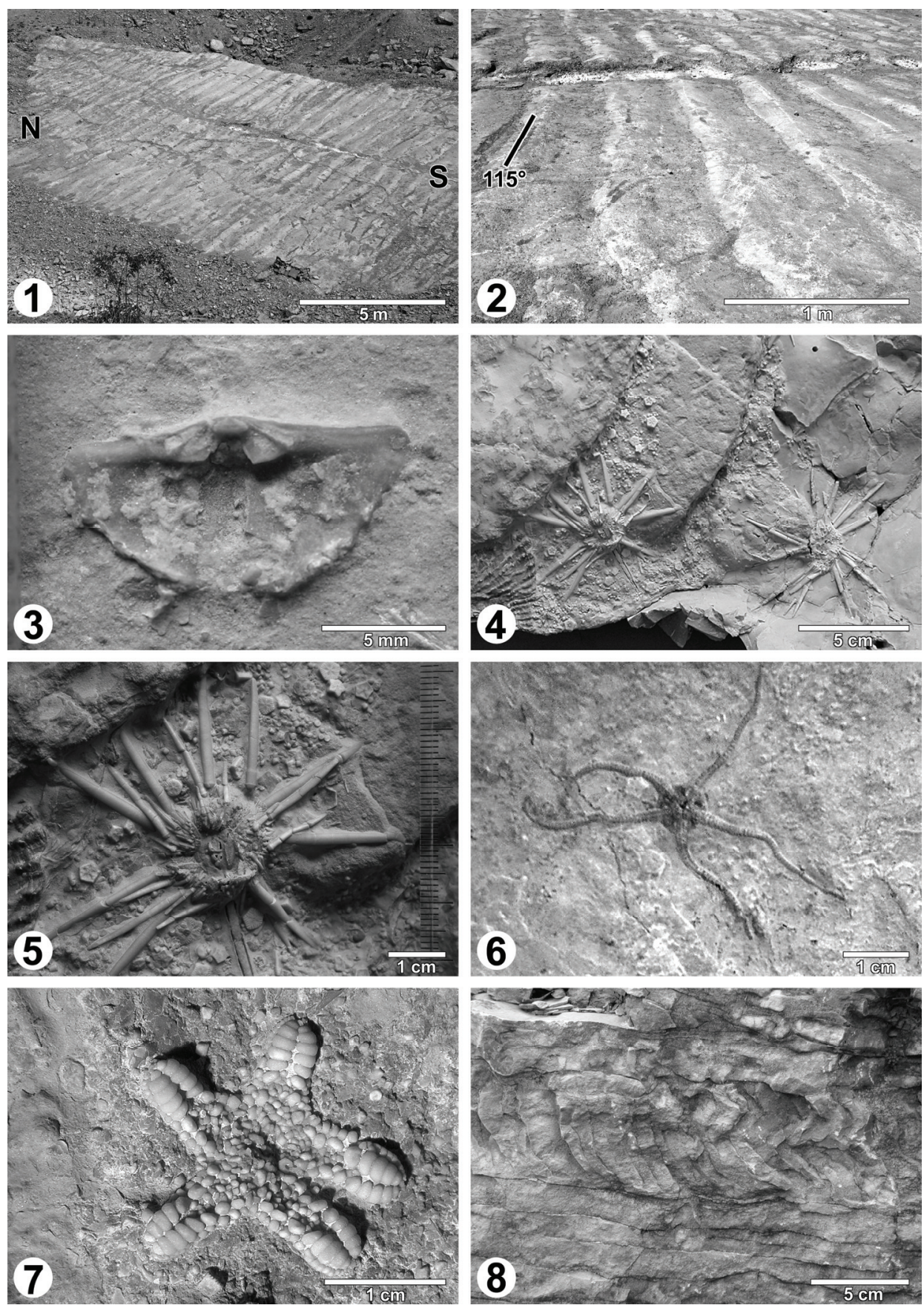


\section{References}

Arp, G., Hoffmann, G., Seppelt, S. \& Riegel, W. (2004): Exkursion 6. Trias und Jura von Göttingen und Umgebung. In: Reitner, J., Reich, M. \& Schmidt, G. (eds.): Geobiologie 2. 74. Jahrestagung der Paläontologischen Gesellschaft in Göttingen 02. bis 08. Oktober 2004, Exkursionen und Workshops. Universitätsdrucke Göttingen: 157-192.

Bielert, F. \& Bielert, U. (2004): Echinodermen-Lagerstätten der Oberen Terebratelbank des Unteren Muschelkalks von Südniedersachsen. In: Reich, M.; Hagdorn, H. \& Reitner, J. (eds.): Stachelhäuter 2004. 3. Arbeitstreffen deutschsprachiger Echinodermenforscher in Ingelfingen, 29. bis 31. Oktober 2004. Arbeiten und Kurzfassungen. Universitätsdrucke Göttingen: 7-12; Göttingen (Universitäts-Verlag).

Blake, D. B. \& Hagdorn, H. (2003): The Asteroidea (Echinodermata) of the Muschelkalk (Triassic of Germany). Paläontologische Zeitschrift 77 (1): 23-58.

Blake, D. B., Bielert, F. \& Bielert, U. (2006): New early crown-group asteroids (Echinodermata: Triassic of Germany). Paläontologische Zeitschrift 80 (3): 284-295.

Franke, W., Paul, J. \& Schröder, H. G. (1977): Stratigraphie, Fazies und Tektonik im Gebiet des Leinetal-Grabens (Trias, Tertiär). Exkursionsführer Geotagung 1977 II: 41-62 [Exkursion 1]; Göttingen.

Götz, A. (1996): Fazies und Sequenzanalyse der Oolithbänke (Unterer Muschelkalk, Trias) Mitteldeutschlands und angrenzender Gebiete. Geologisches Jahrbuch Hessen 124: 67-86.

Hagdorn, H. \& Simon, T. (1983): Ein Hartgrund im Unteren Muschelkalk von Göttingen. $\operatorname{Der} A$ ufschluß 34: 255-263.

Knaust, D. (1998): Trace fossils and ichnofabrics on the Lower Muschelkalk carbonate ramp (Triassic) of Germany: tool for high-resolution sequence stratigraphy. Geologische Rundschau 87: 21-31.

Lukas, V. (1991): Die Terebratel-Bänke (Unterer Muschelkalk, Trias) in Hessen - ein Abbild kurzzeitiger Faziesänderungen im westlichen Germanischen Becken. Geologisches Jabrbuch Hessen 119: 119-175.

Neuweiler, F., Peckmann, J. \& Ziems, A. (1999): Sinusoidally deformed veins („Sigmoidalklüftung ${ }^{6}$ ) in the Lower Muschelkalk (Triassic, Anisian) of Central Germany: sheet injection structures deformed within the shallow subsurface. Nenes Jabrbuch für Geologie und Paläontologie, Abhandlungen 214: 129-148.

Rüffer, T. (1996): Seismite im Unteren Muschelkalk westlich von Halle (Saale). Hallesches Jabrbuch für Geowissenschaften (B: Geologie, Paläontologie, Mineralogie) 18: 119-130.

Seppelt, S. (2004): Sedimentologie und Paläontologie des Unteren Muschelkalks im Profil Forststeinbruch Herberhausen (Göttinger Wald). [unveröffentlichte] Bachelorarbeit, Geowissenschaftliches Zentrum, Georg-August-Universität Göttingen: 27+20 pp.

Szulc, J. (1993): Early Alpine tectonics and lithofacies succession in the Silesian part of the Muschelkalk basin. A synopsis. In: Hagdorn, H. \& Seilacher, A. (eds.): Muschelkalk. Schöntaler Symposium 1991. Sonderbände der Gesellschaft für Naturkunde in Württemberg 2: 19-28; Stuttgart. 


\title{
The late Cretaceous (Campanian) echinoderm faunas from the Hannover area
}

\author{
Nils Schlüter ${ }^{1} \&$ Frank Wiese ${ }^{2}$ \\ ${ }^{1}$ FR Paläontologie, Freie Universität Berlin, Malteserstr. 74-100, D-12249 Berlin, Germany; \\ E-mail:nils.schluter@gmx.de \\ ${ }^{2}$ Georg-August Universität Göttingen, Abt. Geobiologie, Goldschmidtstr. 3, D-37077 Göttingen, \\ Germany; E-mail:frwiese@snafu.de
}

Keywords: Echinodermata, Cretaceous, Campanian, Hannover, Lower Saxony, Germany

Location: In the Hannover area, Campanian (Upper Cretaceous) echinodermbearing strata are excellently exposed in three large quarries (map sheet TK 25 3625 Lehrte: Teutonia Nord, Teutonia AG, SE of Hannover; Alemannia, Holcim AG, $1 \mathrm{~km}$ SE of Hannover and Germania IV, Teutonia AG, in the SE of Hannover; Fig. 1). Structurally, they are located in the Lehrte West syncline.

Stratigraphic position: Lithostratigraphically, the visited succession belongs to the Misburg Formation. Biostratigraphic subdivision in the area is based mainly on irregular echinoids and belemnites. The quarries cover an interval from the Lower Campanian lingua/quadrata Zone to the Upper Campanian minor/polyplocum/vulgaris Assemblage Zone (Fig. 2), and the total composite thickness of the succession is ca. $380 \mathrm{~m}$ (100 m Alemannia, $280 \mathrm{~m}$ Teutonia).

Sedimentology and Palaeontology: The Campanian sediments in the excursion area were deposited on a wide epicontinental shelf-sea. Compared to the concomitant distal pure white chalk facies of Lägerdorf (Schleswig-Holstein, northern Germany or the White Chalk of England), the sediments of the Hannover area were deposited in a more proximal setting, exhibiting monotonous marls at the base of the succession (Emscher Formation), followed by orbitally driven marl/limestone alternations with varying $\mathrm{CaCO}_{3}$ contents between 65 and $90 \%$ (Misburg Formation). The microfacies consists of mud- to wackestones, which are dominated by calcareous dinoflagellate cysts and planktonic foraminifera (for details see Abu-Maaruf 1975; Niebuhr 1995, 1999; Niebuhr \& Reich 2004). Due to the abundance of macrofossils, 13 biozones could be distinguished (Ernst 1975; Niebuhr 1995). These are based mainly on irregular echinoids, belemnites and ammonites and are mostly concurrent range and assemblage zones of 2 to 3 distinct taxa (Fig. 2). It is interesting to note that irregular echinoids are the most important group for biozonation. 


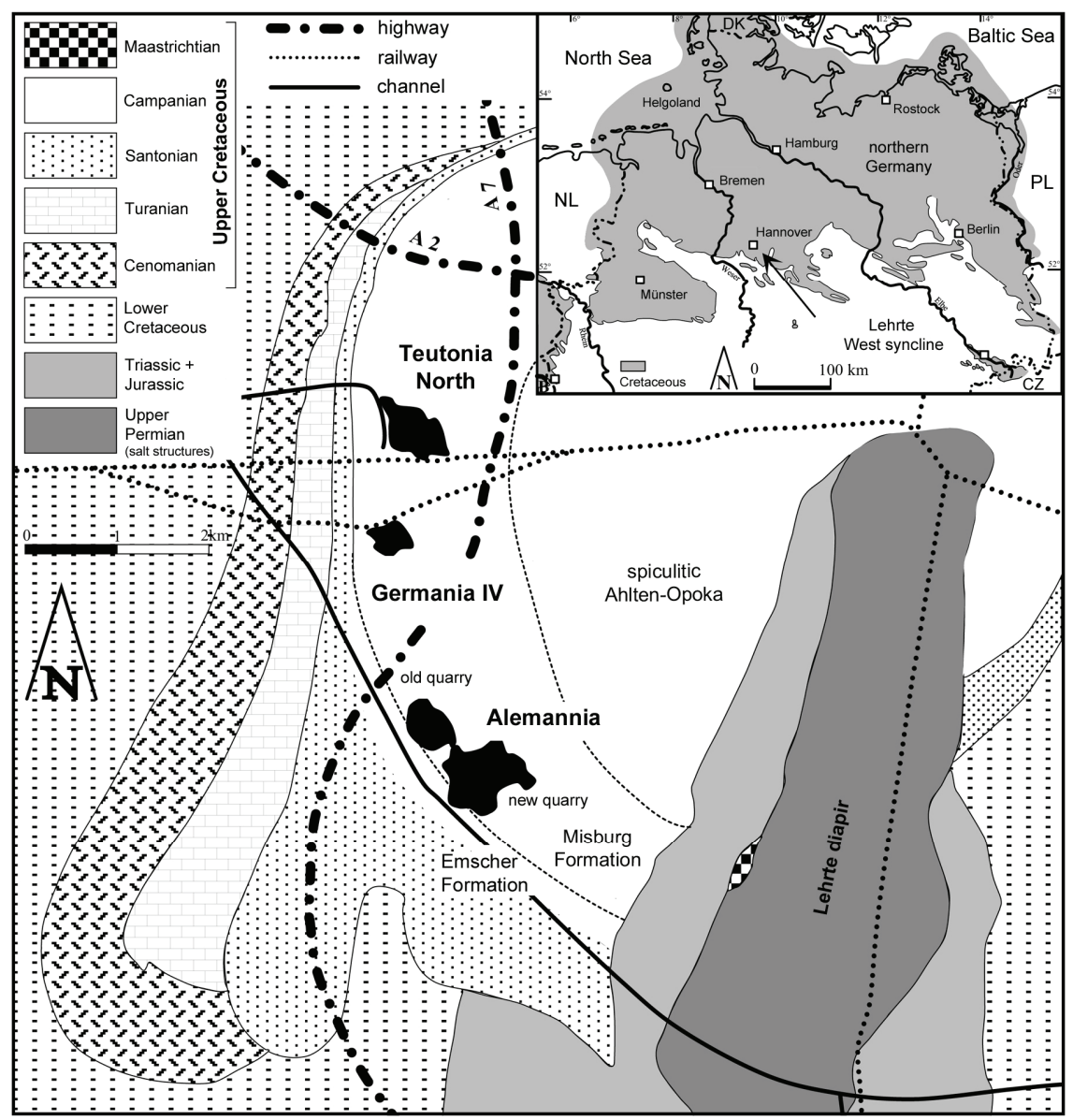

Fig. 1 Simplified geological map of the Hannover area with the location of the quarries (from Niebuhr \& Reich 2004, modified).

Apart from ammonites, belemnites and sponges (see Ernst 1968, Jagt \& Neumann 2006; Niebuhr 1995, 2004), irregular echinoids are the most dominating macrofaunistic elements, of which the genera Offaster, Galeola, Galerites, Micraster and Echinocorys are the most abundant taxa. In the past, these occurrences were, therefore, used for phylogenetic studies of the most typical Cretaceous irregular echinoids (e. g. Ernst 1970, 1971, 1972; Schulz 1985). Other irregular taxa are very rare (e. g. Conulus, Diplodetus, Hemiaster, Echinogalerus; Neumann, 2002). A number of regular echinoid species is recorded (see below), but they are not frequent. Crinoids (e. g. Bourgeticrinus) and asteroids (e. g. Metopaster, Nymphaster, Recurvaster) are abundant. The Goniasteridae are the most frequent representatives in the area (Neumann 2007). 


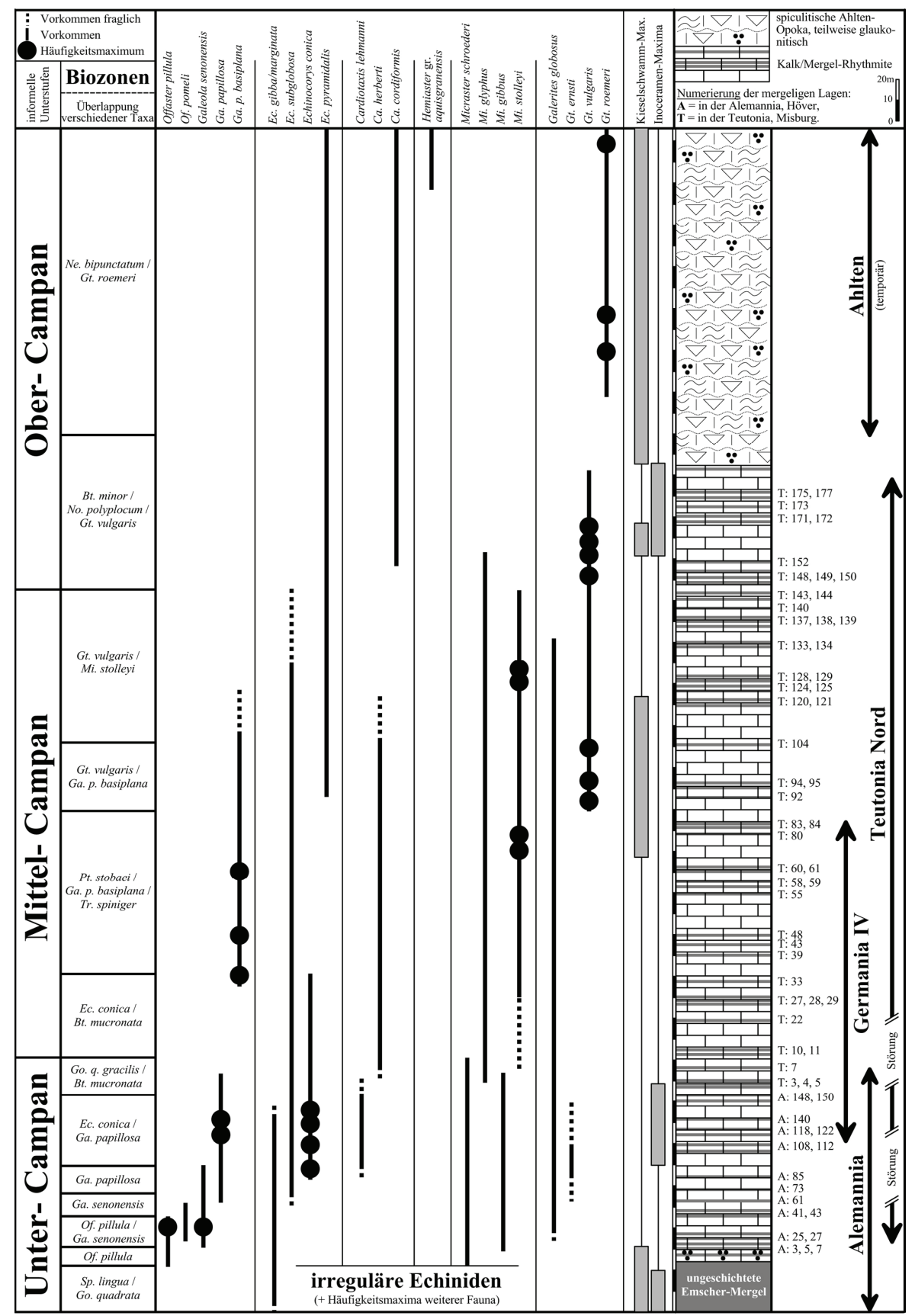

Fig. 2 Vertical range of biostratigraphically significant irregular echinoids from the Campanian of the Lehrter West syncline and abundance peaks of hexactinellid sponges and inoceramid bivalves (from Niebuhr \& Reich 2004). 
These taxa are usually found disarticulated in the form of isolated ossicles; however, articulated specimens can also - rarely - be found (Amme 2005; Helm \& Frerichs 2005; Neumann \& Jagt 2007; Fig. 3). Only from arm fragments, few species of ophiuroids are recorded so far (Helm et al. 2005). Holothurians occur also, but have not yet been investigated in detail (M. Reich, 2010, pers. comm.).

Table 1 Fauna list of Echinoidea (after Ernst 1970, 1971, 1972; Frerichs 2005; Krupp 2006; Neumann 2002; Schulz 1985 and own observations*), Crinoidea (after Amme 2005); Asteroidea (after Helm \& Frerichs 2005); Ophiuroidea (Helm et al. 2005); and Holothuroidea (Reich pers. comm. 2010).

\section{Echinoidea:}

irregular echinoids:

Micraster ex. gr. schroderi/glyphus

Micraster gibbus

Micraster fastigatus

Micraster stolleyi

Micraster senonensis

Echinocorys scutata

Echinocorys conica

Cardiotaxis heberti

Galerites vulgaris

Galerites globosus

Galerites ernsti

Galerites roemeri

Galerites sulcatoradiatus

Offaster pilula

Galeola senonensis

Galeola pappilosa

Echinogalerus peltiformis

Conulus matesovi

Hagenowia blackmorei

Diplodetus sp.

Hemiaster ex. gr. aquisgranensis

Perionaster cotteaui

regular echinoids:

Phymosoma koenigii

Phymosoma granulosum

Cosmocyphus princeps*

Gauthieria psendoradiata

Gautbieria alterna*

Diplotagma altum

Bathysalenia granulosa

Pleurosalenia heberti

Boletecbinus rowei

Stereocidaris cf. hagenowi

Stereocidaris screptrifera
Hirudocidaris hirudo*

Phalacrocidaris merceyi

\section{Crinoidea:}

Bourgueticrinus brydonei

Bourgueticrinus cylindricus

Bourgueticrinus ellipticus

Austinocrinus rothpletzi

Gammarocrinites sp.

\section{Asteroidea:}

Metopaster uncatus

Metopaster polyplacus

Metopaster praetumidus

Metopaster parkinsoni

? Parametopaster sp.

Recurvaster ex. gr. radiatus

"Recurvaster" stainsforthi

Nymphaster sp.

Chomaster rectus

Crateraster quinquelobata

Pycinaster cf. crassus

Ophyraster oligoplax

Stauranderaster senonensis

Valettaster cf. ocellatus

\section{Ophiuroidea:}

Ophiomusium subcylindricum

Ophiotitanos serrata

Ophioderma? substriatum

Stegophiura? hagenowi

\section{Holothuroidea:}

Calclamna parasp. [Dendrochirotida] Hemisphaeranthos parasp. [Myriotrochidae] Jumaraina parasp. [Chiridotidae] 


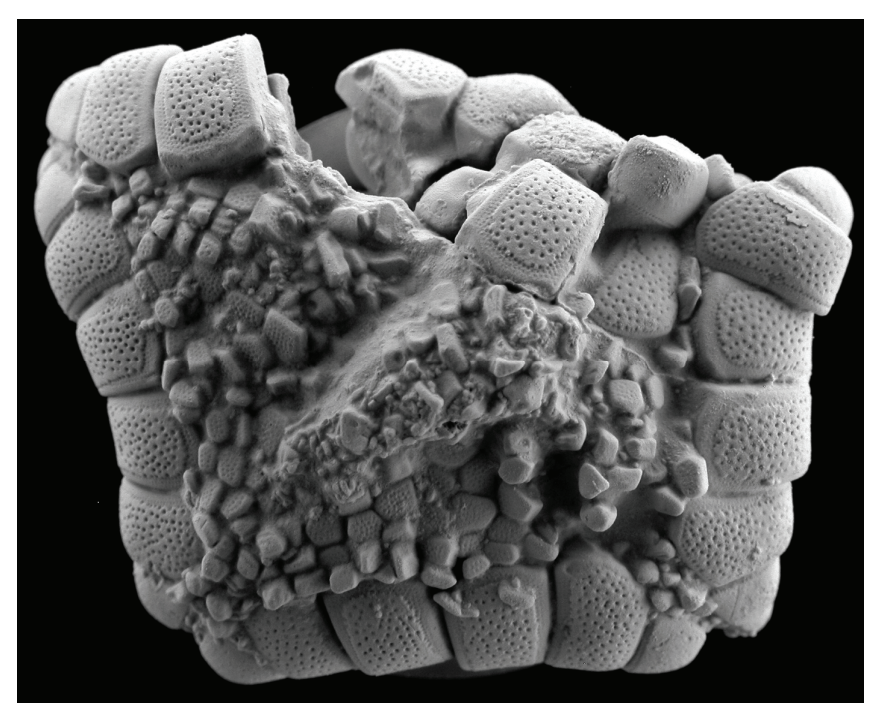

Fig. 3 Juvenile specimen of the asteroid Metopaster parkinsoni [max. width $=29 \mathrm{~mm}$ ]; from the Lower Campanian (pilula / senonensis Zone) of Misburg (quarry Teutonia Nord), Lower Saxony [coll. M. Holschemacher, Michendorf] (from Neumann \& Jagt 2007; photograph kindly provided by the author).

\section{References}

Abu-Maaruf, M. (1975): Feingliederung und Korrelation der Mergelkalk-Fazies des UnterCampan von Misburg, Höver und Woltorf im ostniedersächsischen Becken. Berichte der Naturbistorischen Gesellschaft Hannover 119: 127-204.

Amme, R. (2005): Seelilien. In: Arbeitskreis Paläontologie Hannover (ed.): Fossilien aus dem Campan von Hannover: 42-43; Hannover (APH).

Ernst, G. (1968): Die Oberkreide-Aufschlüsse im Raume Braunschweig-Hannover und ihre stratigraphische Gliederung mit Echinodermen und Belemniten, 1. Teil: Die jüngere Oberkreide (Santon - Maastricht). Berichte der Naturwissenschaftlichen Gesellschaft, Beihefte 5: 235-284.

Ernst, G. (1970): Zur Stammesgeschichte und stratigraphischen Bedeutung der EchinidenGattung Micraster in der nordwestdeutschen Oberkreide. Mitteilungen aus dem GeologischPaläontologischen Institut der Universität Hamburg 39: 117-135.

Ernst, G. (1971): Biostatistische Untersuchungen über die Ontogenie und Phylogenie der Offaster/Galeola-Stammesreihe aus der borealen Oberkreide. Neues Jahrbuch für Geologie und Paläontologie, Abhandlungen 139: 169-225.

Ernst, G. (1972): Grundfragen der Stammesgeschichte bei irregulären Echiniden der nordwesteuropäischen Oberkreide. Geologisches Jahrbuch (A: Allgemeine und regionale Geologie BR Deutschland und Nachbargebiete, Tektonik, Stratigraphie, Paläontologie) 4: 63-175.

Ernst, G. (1975): Stratigraphie, Fauna und Sedimentologie der Oberkreide von Misburg und Höver bei Hannover (Exkusrionsführer). Mitteilungen aus dem Geologisch-Paläontologischen Institut der Universität Hamburg 44: 69-97. 
Frerichs, U. (2005): Seeigel. In: Arbeitskreis Paläontologie Hannover (ed.): Fossilien aus dem Campan von Hannover: 30-41; Hannover (APH).

Helm, C. \& Frerichs, U. (2005): Seesterne. In: Arbeitskreis Paläontologie Hannover (ed.): Fossilien aus dem Campan von Hannover: 84-88; Hannover (APH).

Helm, C., Jagt, J. W. M. \& Kutscher, M. (2005). Schlangensterne. In: Arbeitskreis Paläontologie Hannover (ed.): Fossilien aus dem Campan von Hannover: 89-90; Hannover (APH).

Jagt, J. W. M. \& Neumann, C. (2006): Late Campanian polyptychoceratine ammonites from the Lehrte West Syncline, Hannover area, northwest Germany. Cretaceous Research 27: 565-576.

Krupp, R. (2006). Patagiosites stobaei und Phymosoma koenigii aus dem Campan von Misburg. Arbeitskreis Paläontologie Hannover 34: 113-118.

Neumann, C., Jagt, J. W. M. \& Ham, R. W. J. van der (2002): Rare Campanian echinoids from Höver and Misburg (Hannover area, Lower Saxony, Germany). Mitteilungen des Museums für Naturkunde Berlin (Geowissenschaftliche Reibe) 5: 119-137.

Neumann, C. \& Jagt, J. W. M. (2007): Ein juveniler Seestern aus dem Untercampan von Misburg: Metopaster parkinsoni. Arbeitskreis Paläontologie Hannover 35: 83-88.

Niebuhr, B. (1995): Fazies-Differenzierungen und ihre Steuerungsfaktoren in der höheren Oberkreide von S-Niedersachsen/Sachsen-Anhalt (N-Deutschland). Berliner geowissenschaftliche Abhandlungen (A: Geologie und Paläontologie) 174: 1-131.

Niebuhr, B. (1999): Cyclostratigraphic correlation of outcrops and electronic borehole measurements in the Middle Campanian marl/limestone rhythmites of northern Germany. Beringeria 23: 47-54.

Niebuhr, B. (2004): Late Campanian nostoceratid ammonites from the Lehrte West Syncline near Hannover, northern Germany. Acta Geologica Polonica 54 (4): 473-487.

Nieburg, B. \& Reich, M. (2004): Exkursion 7. Das Campan (höhere Ober-Kreide) der Lehrter Westmulde bei Hannover. In: Reitner, J., Reich, M. \& Schmidt, G. (eds.): Geobiologie 2. 74. Jahrestagung der Paläontologischen Gesellschaft in Göttingen 02. bis 08. Oktober 2004, Exkursionen und Workshops. Universitätsdrucke Göttingen: 193-210.

Schulz, M.-G. (1985): Die Evolution der Echiniden-Gattung Galerites im Campan und Maastricht Norddeutschlands. Geologisches Jabrbuch (A: Allgemeine und regionale Geologie BR Deutschland und Nachbargebiete, Tektonik, Stratigraphie, Paläontologie) 80: 1-96. 


\title{
Echinoderms in the southern German Bight (southern North Sea) - a species overview
}

\author{
Karin Boos $^{1} \&$ Mike Reich ${ }^{2,3}$ \\ ${ }^{1}$ Biologische Anstalt Helgoland, Marine Station, Alfred Wegener Institute for Polar and Marine \\ Research, P.O.Box 180,D-27483 Helgoland, Germany; E-mail: Karin.Boos@awi.de \\ ${ }^{2}$ Georg-August University Göttingen, Museum, Collections \& Geopark, Goldschmidtstr. 1-5, \\ D-37077 Göttingen, Germany; E-mail: mreich@gwdg.de \\ ${ }^{3}$ Georg-August University Göttingen, Department of Geobiology, Goldschmidtstr. 3, D-37077 Göttingen, \\ Germany
}

Keywords: Asteroidea, Ophiuroidea, Echinoidea, Holothuroidea, biodiversity, North Sea, German Bight, Helgoland

The following summary gives an overview on the echinoderm species found in the German Bight (southern North Sea). While numerous species have been recorded throughout various studies dating back to the 1870 s, several species have only been recorded on rare occasions, which might be on account of misidentifications or occasional distributions due to unusual environmental conditions (Table 1, after Gerdes 1977, and references therein). According to their occurrences over the last century, species have been rated 'common' or 'rare'. Other overviews on the echinoderm fauna of German marine areas are rare or rather published decades ago, like older faunal handbooks (Mortensen \& Lieberkind 1928, Lieberkind 1928). Focussing on the most common species, the following presentation concentrates on those likely to be found nowadays. These include representatives of the Asteroidea, Ophiuroidea, Echinoidea and Holothuroidea.

\section{Asteroidea:}

\section{Common starfish - Asterias rubens [Fig. 1A]}

Asterias rubens is the most common and familiar starfish in the north-eastern Atlantic areas. It is found amongst a variety of substrata, including coarse and shelly gravel and rock as well as biotic hard bottoms, such as beds of mussels and barnacles. Abundances may vary between some ten to hundred ind. $\mathrm{m}^{-2}$ on soft bottoms. Reaching body sizes between $10-50 \mathrm{~cm}$ in diameter and a life span of 58 years, A. rubens is variable in colour, usually occurring in shades of orange, pale brown or violet. Its tapering arms are often slightly turned up at the tip when active. With a well developed olfactory sense, this species is able to detect and predate upon a wide variety of living organisms (including infaunal molluscs, polychaetes and other echinoderms) and scavenges on carrion. Through suction 
with its tube feet, the animal will adhere to the shell of its preferred prey species, the blue mussel Mytilus edulis, and is able to evert its stomach lobes into the bivalve through an opened slit of less than $0.1 \mathrm{~mm}$, and subsequently, through the secretion of gastric fluids, digests it. As a voracious consumer of the commercially important bivalve, $A$. rubens has gained considerable negative importance within the aquaculture and fishing industries. Depending on the prevailing food conditions, $A$. rubens may show great plasticity in growth as well as in shrinkage of body size (Budd 2008, and references therein).

\section{Spiny comb star / Sand star - Astropecten irregularis}

Typically buried in soft sediments, Astropecten irregularis is not as conspicuous as the common star fish $A$. rubens. $A$. irregularis has a stiff flattened body and can grow up to $20 \mathrm{~cm}$ in diameter. The dorsal surface seems roughened and granulated and may appear in shades of sandy brown, yellow, orange or pink. Often it shows purple colouration at the tip of each arm. The edges of the arms are bordered with double rows of large marginal plates, the upper marginal plates each equipped with a long conical spine, giving the animal a comb-like appearance. Generally, specimens can be found partially buried in clean sand or sandy mud from the sublittoral down to depths of about $1000 \mathrm{~m}$, from where they maintain contact with the surface with the tips of their arms protruding through the sediment (Sabatini 2008, and references therein).

\section{Common sun star - Crossaster papposus}

Bearing 10-12 (rarely 8-16) arms and giving it its eponymic sun-like appearance, Crossaster papposus is a very distinct starfish species. It can grow up to $34 \mathrm{~cm}$ in diameter, carry small spines all over its dorsal body surface and is usually coloured in various shades of red and may occur with beautiful patterns of brown and white markings dorsally and yellow-white markings ventrally. C. papposus is typically found on sand, rocky substratum, mussel and oyster beds ranging from the lower intertidal zone to depths of several $100 \mathrm{~m}$. Living an epibenthic and predatory lifestyle, C. papposus appears to be highly mobile. Large individuals were found to cover distances of more than $5 \mathrm{~m}$ in approx. 12 hours. In fact, C. papposus has been found to migrate large distances when hunting its prey organisms using its olfactory abilities to sense live prey, such as other echinoderms, bivalves, cnidarians or tunicates, as well as conspecific mates or predators (Grush 1999, Wilson 2008, and references therein).

$\rightarrow$....Table 1 Echinoderm species found in the southern German Bight and around Helgoland between 1871 and 2010 with an overall rating of their commonness. 


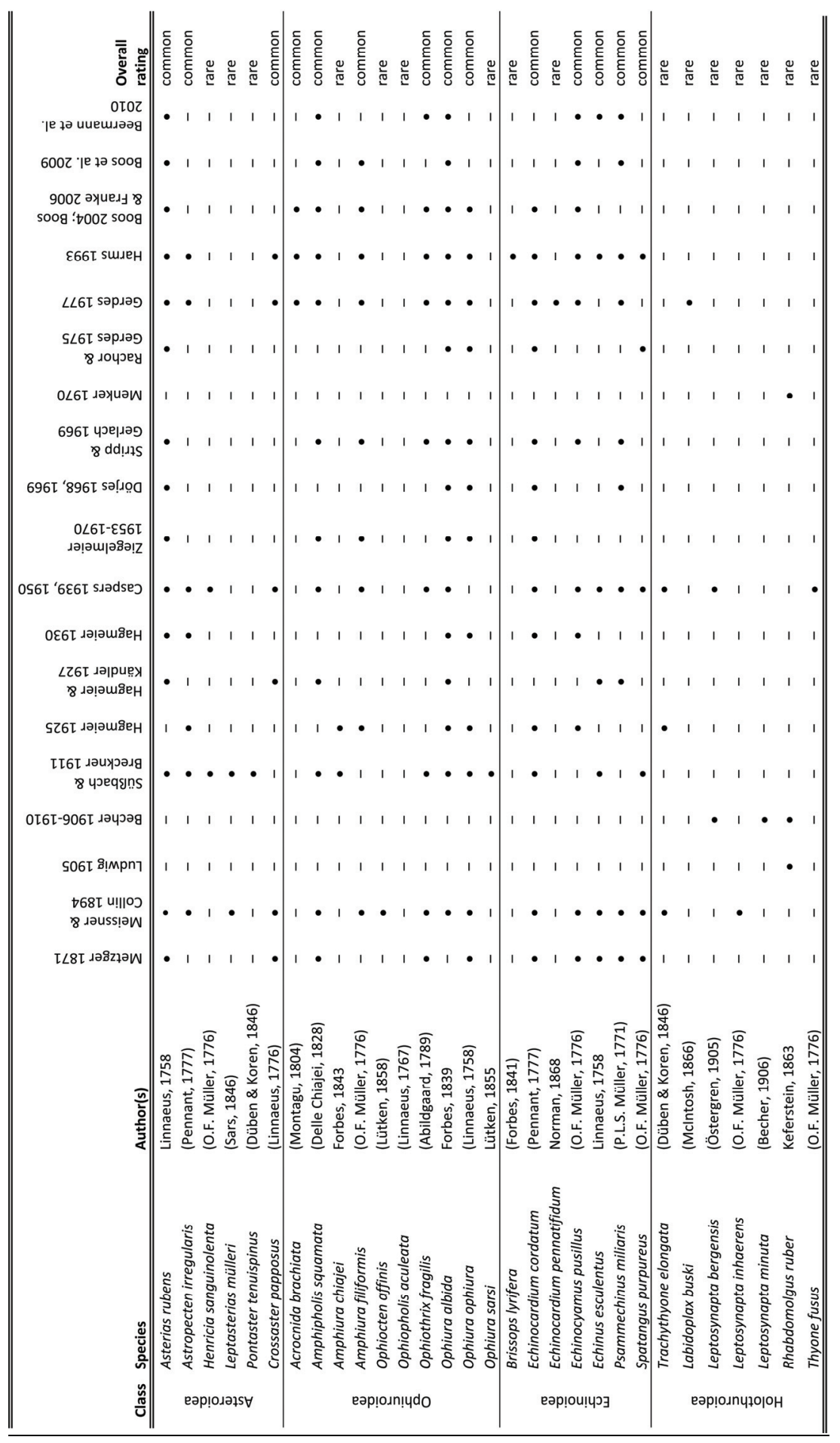




\section{Ophiuroidea:}

\section{Small brittle star - Amphipholis squamata [Fig. 1C]}

Amphipholis squamata is a hermaphrodite and brooding species reaching a body disc diameter of about $5 \mathrm{~mm}$ when fully grown, appearing in greyish, white, brown and orange colourations (Rowley 2006). Because this species does not release masses of planktonic larvae but only few crawl-away juveniles per brood, abundance may vary from several to nearly 200 ind. $\mathrm{m}^{-2}$ (Berberich 1989). This cosmopolitan species has a vertical distribution ranging from the upper tidal zones down to depths of several $100 \mathrm{~m}$. Leading a cryptic lifestyle, A. squamata can be found around the rocky intertidal areas of Helgoland in habitats such as crevices in rockpools or holdfasts of different macroalgae (Boos \& Franke 2006).

\section{Sand burrowing brittlestars - Acrocnida brachiata and Amphiura filiformis [Fig. 1D]}

Both Acrocnida bracbiata and Ampbiura filiformis are infaunal species burrowing approximately $10 \mathrm{~cm}$ into soft sediments while three of their long and slender arms protrude through the sediment surface in order to dab across the sediment or to sway through the water column for food particles (Barnes 2008, Hill \& Wilson 2008). Disc diameters may reach about $2 \mathrm{~cm}$, while the entire animal may measure about 10 to $15 \mathrm{~cm}$. Both species appear in orange and/or brown colouration with numerous spines along their slender arms and are often found sympatrically around the close vicinity of Helgoland. While A. filiformis is the most common infaunal brittlestar in the southern North Sea, with abundances of several 100 ind. $\mathrm{m}^{-2}$, A. bracbiata was first identified in the German Bight in the 1970s (Gerdes 1977), most likely originating from populations found along the British and French coasts. Both species are known for their enormous capability to autotomize arms and even parts of their body disc

\section{Common brittlestar - Ophiothrix fragilis}

Ophiothrix fragilis is a large brittlestar with a disc diameter of approximately $2 \mathrm{~cm}$ and arm length about five times the disc diameter. It appears in various colourations ranging from brown to purple, blue and yellow. The arms are covered with numerous long spines with which this rheophilic suspension feeder is able to spread mucus threads and capture particles from the water column. Found amongst lower shore habitats between bedrock, boulders and coarse and soft sediments, this cryptic species is often found in low abundances around the German Bight, while populations around the British and French coasts may completely cover areas of soft sediment surfaces like carpets, summing up to several 100 or 1000 ind. $\mathrm{m}^{-2}$ (Jackson 2008, and references therein). 


\section{Two epibenthic brittlestars - Ophiura albida and Ophiura ophiura [Fig. 1E]}

Both Ophiura albida and O. ophiura are among the most common brittlestars in the southern North Sea. Opposed to their amphiurid relatives, these two species appear more stout and robust and with less flexible arms. While O. ophiura may reach about $30 \mathrm{~mm}$ in disc diameter with arm lengths of 4 times that size, O. albida is about half the size (Wilson 1999, Ruiz 2008). Typically they appear in brownish, purple and/or orange colouration. In addition, O. albida shows distinct white marks on its radial shields on the dorsal disc side. O. ophiura is easily distinguished from its congener by rows of little pits along the ventral side of its arms. The two species occur sympatrically on different sediment types in abundances reaching up to several 100 ind. $\mathrm{m}^{-2}$ (Goldschmidt 1996). While both species are predominantly carnivorous, O. ophiura has been designated a true predator and hunter for small epibenthic invertebrates (Feder 1981), whereas O. albida may exhibit surface and subsurface deposit feeding as an important secondary feeding mechanism (Jangoux \& Lawrence 1982).

\section{Echinoidea:}

\section{Small heart urchin / Sea potato - Echinocardium cordatum}

The infaunal living Echinocardium cordatum is a common species typically found in burrowing about $8-15 \mathrm{~cm}$ deep in sheltered sandy areas. Its vertical distribution ranges from subtidal habitats down to about $200 \mathrm{~m}$ (Hill 2008). The heart shaped irregular urchin, with a size of about $6-9 \mathrm{~cm}$ in length and a maximum life span of 10-20 years, is covered in a dense felt of yellow or brown spines, generally directed backwards. Generally this species appears in high abundances and can be found washed upon the shore. Because of its infaunal lifestyle, it typically feeds as a subsurface deposit feeder.

\section{Edible sea urchin - Echinus esculentus [Fig. 1B]}

Ecbinus esculentus is a rather large globular shaped regular sea urchin, which can grow up to $16 \mathrm{~cm}$ in diameter. This urchin can reach a life span of 7-8 years and occasionally even up to 16 years. Its test typically appears in pinkish-red colours, but can occasionally appear in yellow, green or purple as well. Numerous spines covering the test are generally reddish with violet and white colourations. Although found on rocky substratum off the sublittoral fringes, it may be found at depths below $100 \mathrm{~m}$. Echinus esculentus is an omnivorous grazer feeding on seaweeds and small encrusting invertebrates, such as barnacles or bryozoans. This species plays an important role as a grazer in kelp communities, controlling the lower limit of Laminaria hyperborean beds (Tyler-Walters 2008, and references therein). 


\section{Green sea urchin - Psammechinus miliaris}

Psammechinus miliaris is a regular sea urchin, almost round and slightly flattened, which can grow up to nearly $60 \mathrm{~mm}$ in diameter and reach an age of up to 12 years. It has a green colour with very distinctive violet tips on the spines, which are short, robust and closely packed. This species is typically found on rocky shores under stones, boulders and bedrock as well as amongst seaweeds or seagrass beds and sometimes on muddy, sandy or gravelly sediments. P. miliaris is an omnivorous grazer typically feeding on macroalgae, hydroids, bryozoans, boring sponges, barnacles, mussels and polychaetes. Along the European coasts, abundances may range from single individuals up to some 10 or 100 ind. $\mathrm{m}^{-2}$ in shallow seagrass beds (Jackson 2008, and references therein).

\section{Pea urchin - Echinocyamus pusillus}

Echinocyamus pusillus is the smallest sea urchin to be found around the southern North Sea. This irregular urchin reaches $1 \mathrm{~cm}$ in diameter, is covered with spines and is typically whitish-brown or yellow in colour when alive and healthy, but will turn green when damaged or preserved. E. pusillus is found in intertidal areas down to depths exceeding $1000 \mathrm{~m}$. It lives buried in coarse sand or gravel and feeds on detritus, foraminiferans and different microalgae. As opposed to other sea urchins, this species has its mouth and anus located on the underside and the ambulacral areas and tube feet, arranged in petal-shaped patterns, are confined to the upper side of the body (Hosie 2009, and references therein).

$\rightarrow \cdots \cdot$ Fig. 1 Members of the Asteroidea (A), Echinoidea (B), Ophiuroidea (C-E) and Holothuroidea $(\mathrm{F}-\mathrm{H})$ from the southern German Bight, southern North Sea.

(A) Asterias rubens Linnaeus, 1758, a living specimen in the Helgoland aquarium, diameter approx. $13 \mathrm{~cm}$; (B) Echinus esculentus Linnaeus, 1758, a living specimen in the Helgoland aquarium, diameter approx. $10 \mathrm{~cm}$; (C) Amphipholis squamata (Delle Chiajei, 1828), preserved specimen (scale bar: $2 \mathrm{~mm}$ ), south of Helgoland, 'Tiefe Rinne' $\left(54^{\circ} 08^{\prime} \mathrm{N}\right.$ 0755'E) [KBB]; (D) Acrocnida bracbiata (Montagu, 1804), preserved specimen (scale bar: $10 \mathrm{~mm})$, southeast of Helgoland $\left(54^{\circ} 05^{\prime} \mathrm{N} 08^{\circ} 02^{\prime} \mathrm{E}\right)$ [KBB]; (E) Ophiura albida Forbes, 1839, preserved specimen (scale bar: $2 \mathrm{~mm}$ ), south of Helgoland, 'Tiefe Rinne' $\left(54^{\circ} 08^{\prime} \mathrm{N}\right.$ 0756'E) [KBB]; (F) Trachythyone elongata (Düben \& Koren, 1846), preserved specimen

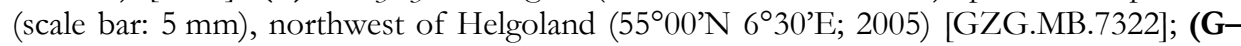
H) Leptosynapta inhaerens (O. F. Müller, 1776), preserved specimen (G; scale bar: $1 \mathrm{~mm}$ ), and enlargement of anchor and anchor plate ossicles from the body wall $(\mathrm{H}$; scale bar: $0.25 \mathrm{~mm}$ ), south of Helgoland, 'Tiefe Rinne', $43 \mathrm{~m}$ water depth $\left(54^{\circ} 09^{\prime} 00^{\prime \prime} \mathrm{N} 07^{\circ} 53^{\prime} 00^{\prime \prime E}\right.$; 2008) [GZG.MB.7323]. Photographs: A-B: U. Nettelmann; C-E: K. Boos; F-H: GZG Museum. Abbreviations: KBB - coll. K. Boos, Bremen; GZG.MB - Geoscience Centre Göttingen, Marine biological coll. 

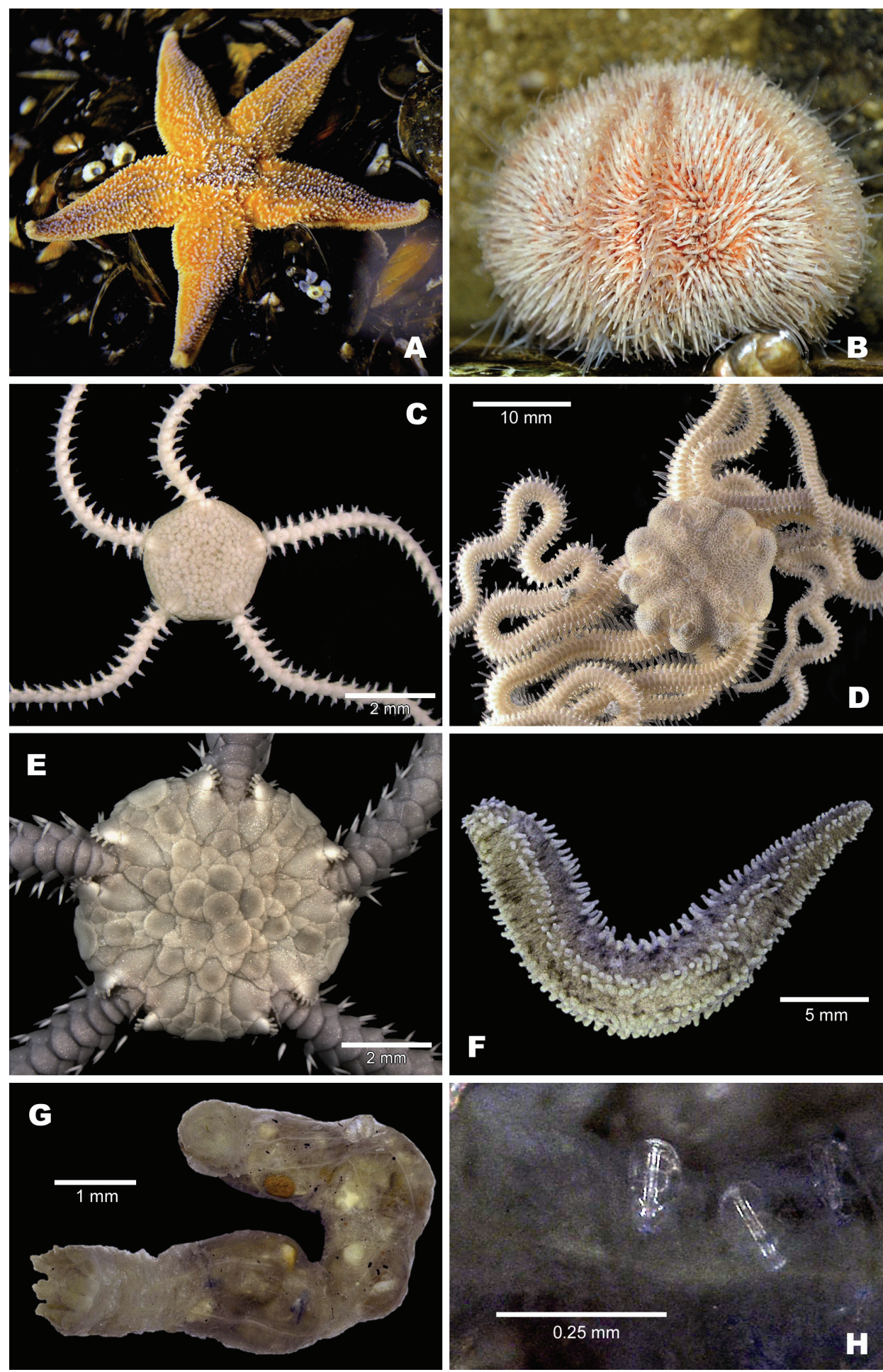


\section{Holothuroidea:}

\section{Trachythyone elongata [Fig. 1F]}

Trachythyone elongata is a greyish to light or dark brownish infaunal (anterior and posterior ends out of the seabed) sea cucumber (Dendrochirotida: Cucumariidae) with a slender, U-shaped (or sometimes S-shaped) body, up to $10 \mathrm{~cm}$ in length. All tube feet are distinct and arranged in five double rows in large specimens, whereas in small specimens in five single rows only. This species has 8 richly branched tentacles as well as two short bifurcate ones in midventral position. The whole body wall of T. elongata is stiff due to the package of body wall ossicles in form of smooth and smaller plates of irregular outline with numerous perforations. There are also small rod-shaped ossicles (tentacles) and minute basket-shaped ossicles with a central primary cross (mostly in the tube feet) (Madsen \& Hansen 1994).

First described from the west coast of Sweden (Düben \& Koren 1846), this species can usually be found in mud or muddy sand, in 5 to $80 \mathrm{~m}$ water depth (Madsen \& Hansen 1994). On the French Atlantic coast T. elongata is also found in intertidal sandy bottom sediments as well as recorded from depths down to $150 \mathrm{~m}$ (off the coast of Portugal). T. elongata is able to hibernate during winter time.

\section{Leptosynapta inhaerens [Fig. 1G-H]}

Leptosynapta inhaerens is a transparent or pale red to reddish-brown medium-sized $(10-30 \mathrm{~cm})$ sea cucumber (Apodida: Synaptidae), which lives in sand, gravel or sandy mud as well as under stones or among seagrass between 0 and $50 \mathrm{~m}$ water depth. The body wall is thin and translucent, with anchor and anchor plate ossicles. Additional minute ossicles occur within the distal part of the tentacles (rods with branched ends) as well as in the base of the tentacles and in the longitudinal muscles (granular or C-shaped ossicles). It usually has 12 tentacles with 5-6 pairs of digits and a long terminal digit, all with sensory buds. The calcareous ring has 5 perforated radial elements and 7 interradial elements, including two additional interradial pieces in the dorsal interradius. Ciliated funnels are present and essentially fan-shaped (Madsen \& Hansen 1994).

Originally described from southern Norway (Müller 1776), L. inhaerens is widely distributed and also known from the west coast of Europe and the Mediterranean.

\section{Rhabdomolgus ruber}

This uncommon interstitial reddish sea cucumber (Apodida: Synaptidae) is recorded from depths of 4-21 $\mathrm{m}$ and coarse sand only. The body is up to $10 \mathrm{~mm}$ long with 10 comparatively large and weakly lobed tentacles without digits but with basal sensory buds. These sticky tentacles serve both movement and feeding. R. ruber is dioecious, whereas most other synaptids are hermaphroditic. The calcareous ring has 5 interradial and 5 radial pieces, the latter ones not perforated. Body wall ossicles are completely absent, as also ciliated funnels are not present (Madsen \& Hansen 1994). 
For a long time, there were no other records of R. ruber than from the type locality of the northern coast of France (Keferstein 1863) as well as from Helgoland (e. g. Ludwig 1905, Menker 1970), but the species was very recently recorded off Irish waters (Broszeit et al. 2010).

\section{References}

Barnes, M. (2008): Acrocnida bracbiata. Sand burrowing brittlestar. Marine Life Information Network: Biology and Sensitivity Key Information Sub-programme [on-line]. Plymouth: Marine Biological Association of the United Kingdom. [cited 09/08/2010].

Available from: <http://www.marlin.ac.uk/speciesinformation.php?speciesID=2501>

Beermann, J.; Boos, K.; Reichert, K.; Haldin, J.; Franke, H.-D. (2010): Zeigereigenschaften Makrozoobenthos (MZB)-Helgoland 2009. MZB Monitoring und Bewertung nach EUWRRL, Landesamt für Landwirtschaft, Umwelt und ländliche Räume (LLUR) des Landes Schleswig-Holstein, Endbericht: 81 pp.

Berberich, D. (1989): Vergleichende Untersuchungen zur Artenzusammensetzung, Abundanz und Biomasse des Makrozoobenthos der Helgoländer Tiefen Rinne von 1936/37 und 1988/89. Diplomarbeit, Technische Hochschule Darmstadt: 142 pp.

Boos, K. (2004): Ökologische Untersuchungen an Ophiuren der Deutschen Bucht. Diplomarbeit, Freie Universität Berlin: 85 pp.

Boos, K. \& Franke, H.-D. (2006): Brittle stars (Echinodermata: Ophiuroidea) in the German Bight (North Sea) - species diversity during the past 130 years. Journal of the marine Biological Association of the United Kingdom 86: 1187-1197.

Boos, K.; Beermann, J.; Reichert, K. \& Franke, H. -D. (2009): Zeigereigenschaften Makrozoobenthos (MZB)-Helgoland - Entwicklung eines Bewertungsverfahrens nach EUWRRL. Helgoland MarBIT Modul, Landesamt für Landwirtschaft, Umwelt und ländliche Räume (LLUR) des Landes Schleswig-Holstein: 196 pp.

Broszeit, S.; Davenport, J. \& McAllen, R. (2010): First documented record of Rhabdomolgus ruber (Echinodermata: Holothuridea) in Irish waters. Marine Biodiversity Records 3: e64. doi:10.1017/S1755267210000485

Budd, G. (2008): Asterias rubens. Common starfish. Marine Life Information Network: Biology and Sensitivity Key Information Sub-programme [on-line]. Plymouth: Marine Biological Association of the United Kingdom. [cited 09/08/2010].

Available from: http://www.marlin.ac.uk/speciesimportance.php?speciesID=2657

Düben, M. W. \& Koren, J. (1846): Öfversigt af Skandinaviens Echinodermer. Kungliga Svenska Vetenskapsakademiens handlingar [1844]: 229-328.

Feder, H. M. (1981): Aspects of the feeding biology of the brittlestar Ophiura texturata. Ophelia 20: 215-235.

Gerdes, D. (1977): Zur Verbreitung der Echinodermen in der Deutschen Bucht. Diplomarbeit, Christian-Albrechts Universität Kiel: 56 pp.

Goldschmidt, A. (1996): Echinodermata, Stachelhäuter. In: Westheide, W. \& Rieger, R. (eds.): Speqielle Zoologie, Teil 1: Einzeller und Wirbellose Tiere: pp. 778-834, Jena (Gustav Fischer).

Grush, H. (1999): Crossaster papposus (On-line), Animal Div. Web. Access. Aug. 09, 2010 at http://animaldiversity.ummz.umich.edu/site/accounts/information/Crossaster_papposus.html. 
Harms, J. (1993): Check list of species (algae, invertebrates and vertebrates) found in the vicinity of the island of Helgoland (North Sea, German Bight) - a review of recent records. Helgoländer Meeresuntersuchungen 47: 1-34.

Hill, J. (2008): Echinocardium cordatum. Sea potato. Marine Life Information Network: Biology and Sensitivity Key Information Sub-programme [on-line]. Plymouth: Marine Biological Association of the United Kingdom. [cited 09/08/2010]. Available from:

http://www.marlin.ac.uk/speciesimportance.php?speciesID $=3228$

Hill, J. \& Wilson, E. (2008): Amphiura filiformis. A brittlestar. Marine Life Information Network: Biology and Sensitivity Key Information Sub-programme [on-line]. Plymouth: Marine Biological Association of the United Kingdom. [cited 09/08/2010]. Available from:

http://www.marlin.ac.uk/speciesfullreview.php?speciesID=2503

Hosie, A. (2009): Echinocyamus pusillus. A pea urchin. Marine Life Information Network: Biology and Sensitivity Key Information Sub-programme [on-line]. Plymouth: Marine Biological Association of the United Kingdom. [cited 09/08/2010]. Available from: http://www.marlin.ac.uk/speciesinformation.php?speciesID=3233

Jackson, A. (2008): Ophiothrix fragilis. Common brittlestar. Marine Life Information Network: Biology and Sensitivity Key Information Sub-programme [on-line]. Plymouth: Marine Biological Association of the United Kingdom. [cited 09/08/2010]. Available from: http://www.marlin.ac.uk/speciesimportance.php?speciesID=3976

Jackson, A. (2008): Psammechinus miliaris. Green sea urchin. Marine Life Information Network: Biology and Sensitivity Key Information Sub-programme [on-line]. Plymouth: Marine Biological Association of the United Kingdom. [cited 09/08/2010]. Available from:

http://www.marlin.ac.uk/speciesimportance.php?speciesID=4216

Keferstein, W. (1863): Unters. Niedere Seetiere. Über Rhabdomolgus ruber g. et sp. n., eine neue Holothurie. Zeitschrift für wissenschaftliche Zoologie 12: 34-35.

Lieberkind, I. (1928): Echinodermata (Stachelhäuter, Echinodermen). In: Dahl, F. (ed.): Die Tierwelt Deutschlands und der angrenzenden Meeresteile nach ibren Merkmalen und nach ibrer Lebensweise. 4. Teil. Porifera-Hydrozoa-Coelenterata-Echinodermata: pp. 263-332, Jena (Gustav Fischer).

Ludwig, H. (1905): Ein wiedergefundenes Tier: Rhabdomolgus ruber Keferstein. Zoologischer Anzeiger 28: 458-459.

Madsen, F. J. \& Hansen, B. (1994): Echinodermata: Holothurioidea. Marine Invertebrates of Scandinavia 9: $143 \mathrm{pp}$.

Menker, D. (1970): Lebenszyklus, Jugendentwicklung und Geschlechtsorgane von Rhabdomolgus ruber (Holothuroidea: Apoda). Marine Biology 6: 167-186.

Mortensen, T. \& Lieberkind, I. (1928): Echinodermata. In: Grimpe, G. \& Wagler, E. (ed.): Tierwelt der Nord- und Ostsee 8: 128 pp., Leipzig (Geest \& Portig).

Müller, O. F. (1776): Zoologiae Danicae prodromus: 274 pp., Havniae (Impensis auctoris).

Rowley, S. (2006): Amphipholis squamata. Small brittle star. Marine Life Information Network: Biology and Sensitivity Key Information Sub-programme [on-line]. Plymouth: Marine Biological Association of the United Kingdom. [cited 09/08/2010]. Available from:

http://www.marlin.ac.uk/speciesinformation.php?speciesID=2499

Ruiz, A. (2008): Ophiura ophiura. A brittlestar. Marine Life Information Network: Biology and Sensitivity Key Information Sub-programme [on-line]. Plymouth: Marine Biological Association of the United Kingdom. [cited 09/08/2010]. Available from: http://www.marlin.ac.uk/speciesinformation.php?speciesID=3981 
Sabatini, M. (2008): Astropecten irregularis. A sand star. Marine Life Information Network: Biology and Sensitivity Key Information Sub-programme [on-line]. Plymouth: Marine Biological Association of the United Kingdom. [cited 09/08/2010]. Available from: http://www.marlin.ac.uk/speciesinformation.php?speciesID =2669

Tyler-Walters, H. (2008): Echinus esculentus. Edible sea urchin. Marine Life Information Network: Biology and Sensitivity Key Information Sub-programme [on-line]. Plymouth: Marine Biological Association of the United Kingdom. [cited 09/08/2010]. Available from: http://www.marlin.ac.uk/speciesimportance.php?speciesID=3237

Wilson, E. (1999): Ophiura albida. A brittlestar. Marine Life Information Network: Biology and Sensitivity Key Information Sub-programme [on-line]. Plymouth: Marine Biological Association of the United Kingdom. [cited 09/08/2010]. Available from: http://www.marlin.ac.uk/speciesinformation.php?speciesID $=3980$

Wilson, E. (2008): Crossaster papposus. Common sun star. Marine Life Information Network: Biology and Sensitivity Key Information Sub-programme [on-line]. Plymouth: Marine Biological Association of the United Kingdom. [cited 09/08/2010]. Available from:

$<$ http://www.marlin.ac.uk/speciesinformation.php?speciesID=3093> 


\section{Index of Authors}

Abdallah, Hassen 40,41

Agatsuma, Yukio ..22, 70

Almer, Jonathan D. 101

Alt, Claudia 92

Alvarado, Juan José .23

Angulo-Preckler, Carlos ......................... 44

Arboleda, Enrique 107

Arnone, Maria Ina. 107

Arp, Gernot 119

Arumugam, Preyan 103

Ávila, Sérgio P. ... 66

Barbaglio, Alice........................................ 106

Barber, Don ............................................... 51

Barker, Michael F. ....................................... 9

Barreto, Ângela ........................................... 96

Barrio, Juan M............................................ 74

Becerro, Mikel A. ..................................... 108

Bohatý, Jan .......................................24, 73

Bonasoro, Francesco ............................ 106

Boos, Karin $25,93,131$

Brinson, L. Catherine 102

Briz, Oreto .74

Brocke, Rainer .49

Burlini, Nedda 106

\section{Caballero-Ochoa,}

Andrea Alejandra 26

Cachão, Mário. 81

Candia Carnevali, M. Daniela ...102, 106

Cao, Xuebin .63

Caulier, Guillaume $.27,28$

Chalmin, Emilie .44

Chang, Yaqing 63
Chenuil, Anne. 36

Clemente, Sabrina 29,51

Coelho, Ana Varela $37,38,96$

Coppard, Simon E. 30

Cortés, Jorge .23

Cruz, Teresa 56

David, Bruno $14,30,31,83,97$

De Carlo, Francesco 102

De Ridder, Chantal $31,83,114$

Deckers, Mart J. M. .58

Del Giacco, Luca. 106

Delroisse, Jérôme 32

Derstler, Kraig 65

DeVictor, Susan T. 80

Di Benedetto, Cristiano ......................... 106

Dorey, Narimane 33

Dupont, Sam T. 9, 33, 79, 104, 107

Dynowski, Janina $.34,35$

Ebert, Thomas A 29, 51

Eble, Gunther 97

Eeckhaut, Igor 27,28

Egea, Emilie 36

Eléaume, Marc 69

Féral, Jean Pierre........................................ 36

Fernandes, Denise ................................ 102

Festeau, Alain 83

Flammang, Patrick ................... 27, 32, 50

Franco, Catarina Ferraz ............ 37, 38, 96

François, Eric .. 97

Fujikura, Katsunori. 39

Fujita, Toshihiko . $39,55,78$ 
Gale, Andy (Andrew S.)..11, 40, 104, 105

Gallemí, Jaume .40, 41, 43

García-Cisneros, Alex. 111

García-Sanz, Sara . .44

Gaymer, Carlos F. .. 64

Gebruk, Andrey .. 92

Gerbaux, Pascal .27

Ghilardi, Anna 106

Girod, Peter 59

Glass, Alexander 52

Gomes da Silva, Serge.

González, Nieves 31

Gorzelak, Przemysław..... .. 74

Guensburg, Thomas E

Gutow, Lars ... 44

Guzmán, Hector..

Haroun, Ricardo 44

Haude, Reimund $.45,46,47,48,49$

Hausen, Harald 107

Hein, Uwe 24,73

Heinrichs, Till .. 49

Hennebert, Elise..... 50

Hernández, José Carlos 29,51

Hernroth, Bodil 109

Holm, Kristina 109

Hotchkiss, Frederick H. C. 52

Hunter, Aaron W. $53,54,67,77$

Ikeda, Minoru . .. 70

Inomata, Eri. .22

Irimura, Seiichi 39

Irvine, Tennille R. .. 64

Ishida, Yoshiaki .55

Jacinto, David. 56

Jagt, John W. M. $57,58,59$

Jerjen, Iwan 72

Jones, Alice. 60
Kanazawa, Ken'ichi 60,96

Keesing, John K. .. 64

Kinoshita, Junji 22

Kiyomoto, Masato................................... 55

Klein, Adrian .35

Kroh, Andreas ....... 11, 30, 61, 66, 87, 113

Kucera, Michal. .105

Laffont, Rémi $.83,97$

Laguarda-Figueras, Alfredo .. 26

Lane, David J. W. 62

Lawrence, Addison L. 63

Lawrence, John M. $13,63,64$

Lazăr, Iuliana. 43

Lefebvre, Bertrand $14,65,67,77$

Lepoint, Gilles 28

Lessios, Harilaos A. .66

Lüter, Carsten. .117

Madeira, Patrícia ......................................... 66

Makhlouf, Yamouna................................. 67

Mallefet, Jérôme ...................16, 32, 60, 69

Mandic, Oleg 61

Marrocchi, Yves 44

Matsui, Toshiyuki.............................22, 70

Mazur, Maciej ............................................... 44

Meibom, Anders....................................... 44

Mercurio, Silvia........................................ 102

Mezali, Karim ......................................... 71

Mihaljević, Morana................................... 72

Mirantsev, George V.............................. 72

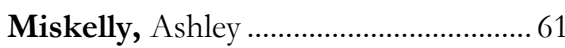

Montaño-Moctezuma, Gabriela......... 29

Mooi, Rich $11,14,30,114$

Mueller, Susanne 115 
Nakajima, Masamichi. .70

Nardin, Elise $24,73,77$

Navarro, Pablo G $. .74,75$

Nebelsick, James H. 35,75

Neumann, Christian .59, 76, 117

Noailles, Fleur .77

Numberger, Lea D. 105

O'Hara, Timothy D. 69

O'Loughlin, P. Mark 88

Ogasawara, Makoto $.22,70$

Okanishi, Masanori .78

Ortega-Martinez, Olga .... .79

Palacín, Creu 111

Palazón-Fernández, José Luis 80

Paulay, Gustav 71

Pawson, David L 16,80

Pawson, Doris J .16, 80

Pereira, Bruno. 81

Pereira, Pedro 81

Pérez-Portela, Rocío .............................. 82

Pierrat, Benjamin 83

Pinaev, G. 110

Pineda-Enríquez, Tania.... ... 84

Porte, Cinta. 102

Protasov, M. 110

Rakotoarisoa, Pricilla .27

Recasens, Mireia 111

Régnault, Serge 67

Reich, Mike $48,85,86,87,88,89$ $90,92,104,105,131$

Reyes-Bonilla, Hector ... 23

Riegel, Walter 49

Rogacheva, Antonina. 92

Rolet, Gauthier. 114

Roth-Nebelsick, Anita 35

Rozhnov, Sergey V $72,93,94$

Russell, Michael P. .29, 51
Saborowski, Reinhard ............................ 95

Saitoh, Masaya.......................................... 96

Sakae, Toshiro .......................................... 55

Sakurai, Kazuhiko ...................................... 54

Santos, Romana ......................... 37, 38, 96

Saucède, Thomas ..............................83, 97

Schlüter, Nils .................................. 98, 125

Scholz, Joachim ....................................... 17

Schröder, Leif .......................................... 115

Sedberry, George R.................................. 80

Seilacher, Adolf (Dolf) ............................ 19

Sevastopulo, George D.......................... 99

Sharlaimova, N. S. ........................109, 110

Smith, Andrew B...................... 30, 72, 89

Solís-Marín, Francisco Alonso............... 84

Soualili-Mezali, Dina Lila .................... 100

Stach, Thomas........................................ 115

Stegemann, Tanja …………………….... 90

Stock, Stuart R...............................101, 102

Stöhr, Sabine.............................. 20, 92, 105

Stolarski, Jarosław ...................................... 44

Sugni, Michela................................102, 106

Sumrall, Colin D...................................... 77

Suzuki, Hideshi.......................................... 55

Tanaka, Gengo ......................................... 55

Thandar, Ahmed .................................... 103

Thorndyke, Mike (Michael) S........... 9, 33 79, 104, 109

Thuy, Ben ........................................104, 105

Toda, Nanako ........................................... 22

Tricarico, Serena ..................................... 106

Turón, Xavier............................................ 111

Tuya, Fernando.................................44, 75

Ullrich-Lüter, Esther.............................. 107 
Van Nedervelde, Fleur ......................... 28

Veis, Arthur. 101

Villamor, Adriana $. .82,108$

Voronkina, Irina $.109,110$

Wangensteen, Owen S 111

Watanabe, Masayuki 22

Watts, Stephen A. 63

Webster, Gary D. 112

Wiese, Frank. 125
Wilkie, Iain ..........................................106

Wolkenstein, Klaus............................... 21

Xiao, Xianghui............................................ 101

Yuan, Fang.............................................. 102

Zamora, Samuel......................................... 77

Ziegler, Alexander................ 61, 112, 113

114,115 
Echinoderms are a vast group of spiny-skinned animals including starfish, brittle-stars, sea urchins, sand dollars, feather stars, sea lilies and sea cucumbers. These relatives of chordates and hemichordates have inhabited the world's oceans for more than 500 million years. Modern members of the Echinodermata are, with over 7000 species, an integral part of marine communities from the intertidal to the deep sea. Echinoderms play a major ecological role in marine habitats and are of economic importance in fisheries, aquaculture and biomedicine.

The present volume contains the abstracts of lectures and posters presented during the 7 th European Conference on Echinoderms (ECE) as well as excursion guides.

This year's conference was held at the northern campus of the Georg-August University in Göttingen, Germany, from October 2-9, 2010. More than 100 biologists, palaeontologists and other scientists from 25 countries participated.

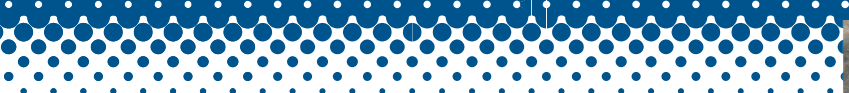

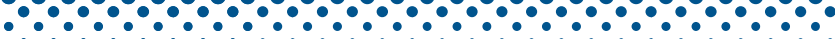
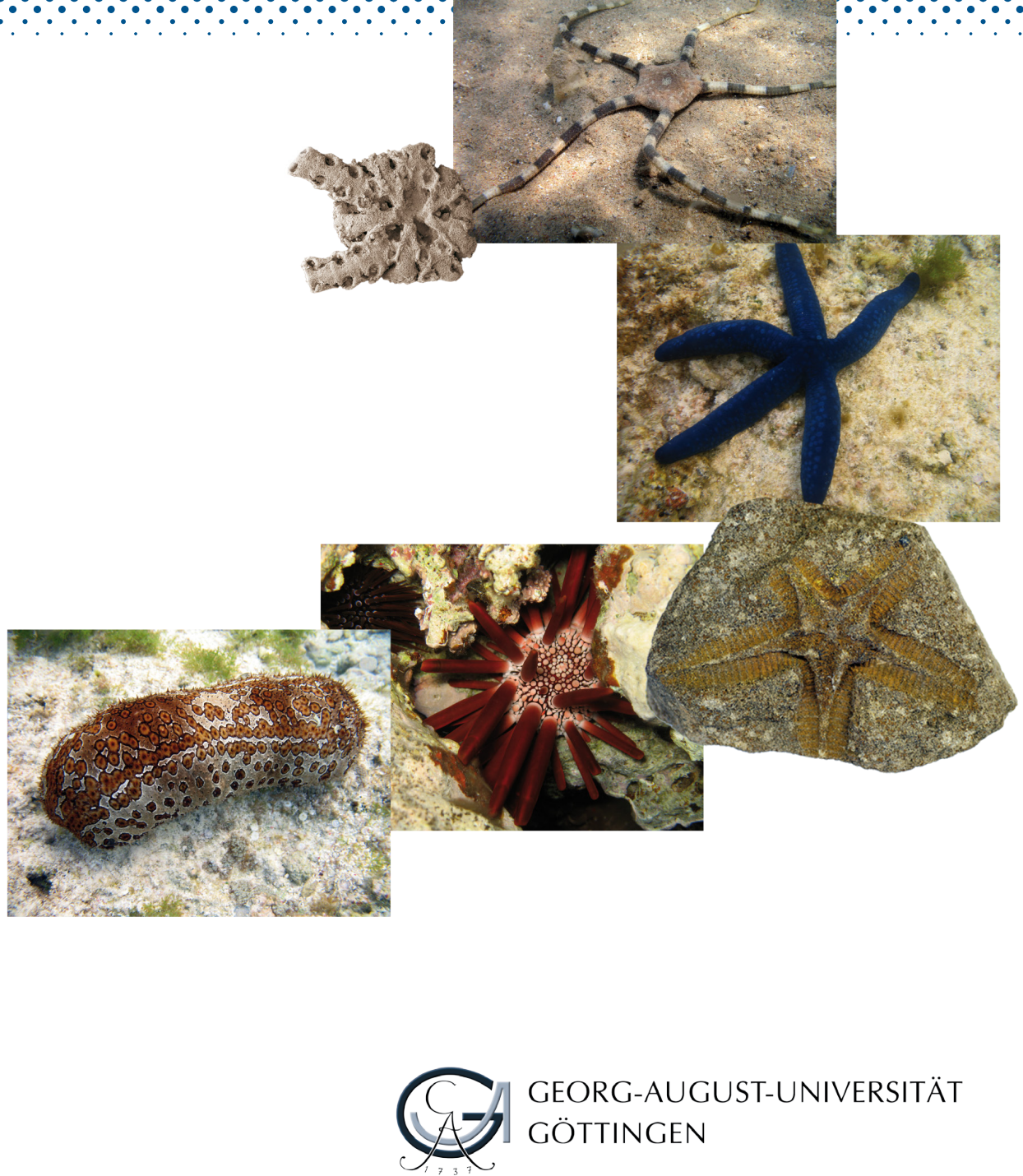